\title{
Enhanced Durability for High-Temperature Desulfurization Sorbents for Moving-Bed Applications
}

\section{Option 3 Program: Development and Testing of Additional Zinc Titanate Sorbents}

\author{
Final Report \\ September 1992 - May 1996 \\ By: \\ R.E. Ayala \\ T.L. Chuck
}

Work Performed Under Contract No.: DE-AC21-88MC25003

For

U.S. Department of Energy

Office of Fossil Energy

Federal Energy Technology Center

Morgantown Site

P.O. Box 880

Morgantown, West Virginia 26507-0880

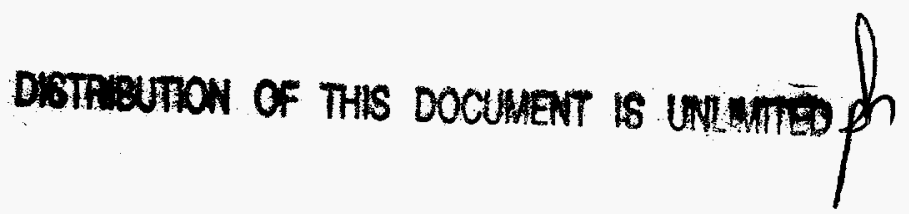

GE Corporate Research and Development

P.O. Box 8

Schenectady, New York 12301 


\section{Disclaimer}

This report was prepared as an account of work sponsored by an agency of the United States Government. Neither the United States Government nor any agency thereof, nor any of their employees, makes any warranty, express or implied, or assumes any legal liability or responsibility for the accuracy, completeness, or usefulness of any information, apparatus, product, or process disclosed, or represents that its use would not infringe privately owned rights. Reference herein to any specific commercial product, process, or service by trade name, trademark, manufacturer, or otherwise does not necessarily constitute or imply its endorsement, recommendation, or favoring by the United States Government or any agency thereof. The views and opinions of authors expressed herein do not necessarily state or reflect those of the United States Government or any agency thereof. 


\section{DISCLAIMER}

Portions of this document may be illegible electronic image products. Images are produced from the best available original document. 


\begin{abstract}
The integrated gasification combined cycle (IGCC) power system using high-temperature coal gas cleanup is one of the most promising advanced technologies for the production of electric power based on coal in an environmentally acceptable manner. Unlike conventional low-temperature cleanup systems that require costly heat exchangers, hightemperature coal gas cleanup systems can be operated near $900-1000^{\circ} \mathrm{F}$ or higher, conditions that are a closer match with the gasifier and turbine components in the IGCC system, thus resulting is a more efficient overall system
\end{abstract}

GE is developing a moving-bed, high-temperature desulfurization system for the integrated gasification combined-cycle (IGCC) power cycle in which zinc-based regenerable sorbents are currently being used as desulfurization sorbents. Zinc titanate and other zinc-based oxides are being considered as sorbents for use in the Clean Coal Technology Demonstration Program at Tampa Electric Co.'s Polk Power Station. A key to success in the development of high-temperature desulfurization systems is the matching of sorbent properties for the selected process operating conditions, namely, sustainable desulfurization kinetics, high sulfur capacity, and mechanical durability over multiple cycles. Additionally, the sulfur species produced during regeneration of the sorbent must be in a form compatible with sulfur recovery systems, such as sulfuric acid or elemental sulfur processes.

The objective of this contract is to identify and test sorbent fabrication methods and chemical compositions that enhance the long-term chemical reactivity and mechanical strength of zinc titanate and other novel sorbents for moving-bed, high-temperature desulfurization of coal-derived gases.

A parametric study on the use of calcium sulfate additives to zinc titanate was conducted for zinc titanates having a 2:1 and 1.5:1 zinc-to-titanium molar ratio, and they showed a beneficial effect on crush strength of fresh 2:1 zinc titanate sorbents. Additional work is required to determine the feasibility of calcium sulfate use in view of the observed slower rate of sulfidation and zinc sulfate decomposition during regeneration. Sorbent formulations were prepared using commercial-scale fabrication equipment, and provided proof on the feasibility of easily scaling the fabrication techniques from laboratory procedures and equipment.

In addition, a test procedure was developed to screen sorbent formulations based on resistance to spalling and pellet breakage induced by zinc sulfate formation in the presence of sulfur dioxide and excess oxygen conditions. 


\section{ACKNOWLEDGMENTS}

Special thanks to E. Gal and M. Arnold at GE Environmental Services, Inc., who contributed with the mechanical characterization measurements, and to R. Gupta and S.K. Gangwal at Research Triangle Institute, who contributed with TGA and porosimetry measurements. The author also acknowledges the helpful discussions with Mr. S. Jain, former DOE's Program Contracting Office Representative and Mr. D. Cicero, current DOE's Program Contracting Office Representative. This work was sponsored by the U.S. Dept. of Energy under Contract DE-AC21-88MC25003. 


\section{TABLE OF CONTENTS}

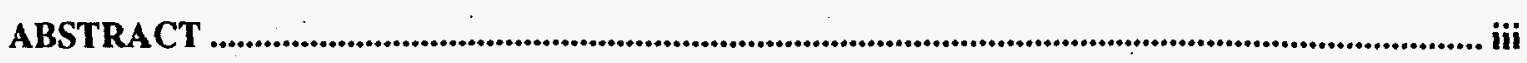

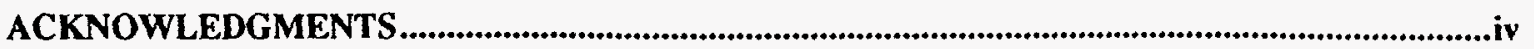

TABLE OF CONTENTS ......................................................................Error! Bookmark not defined.

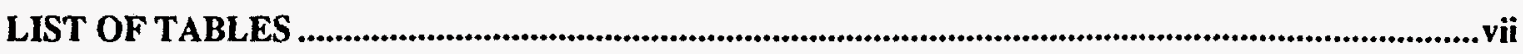

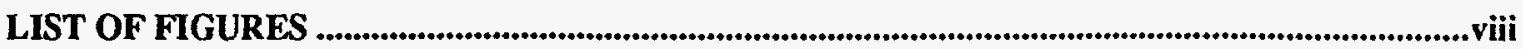

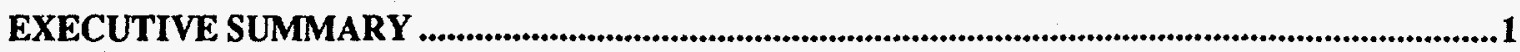

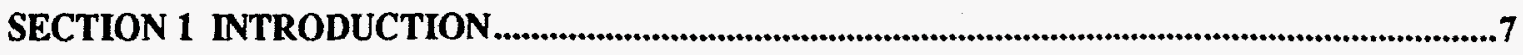

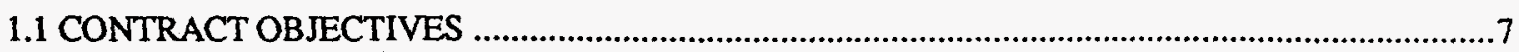

1.2 BACKGROUND

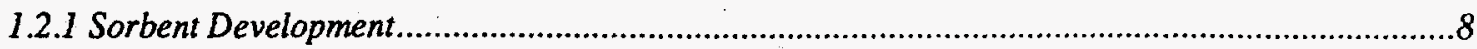

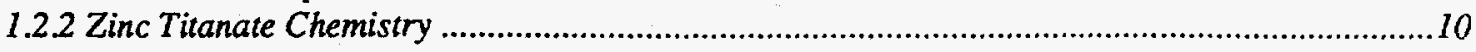

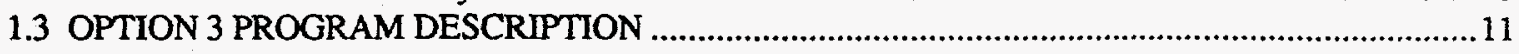

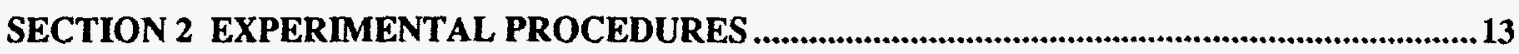

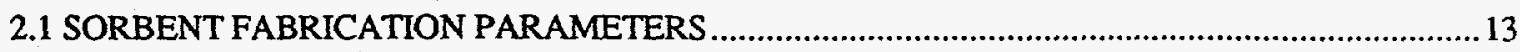

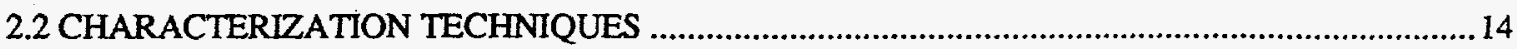

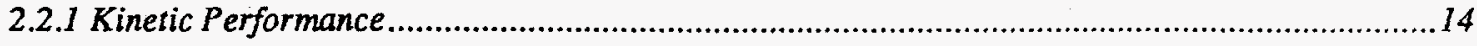

2.2.1.1 TGA Chemical Reactivity .............................................................................................................14

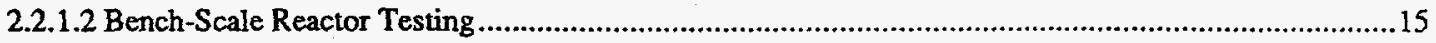

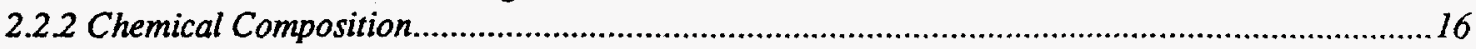

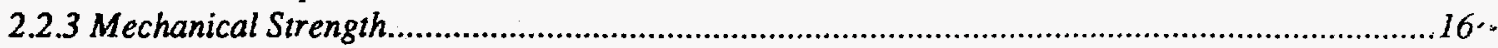

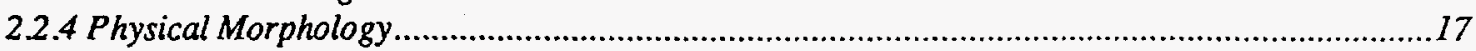

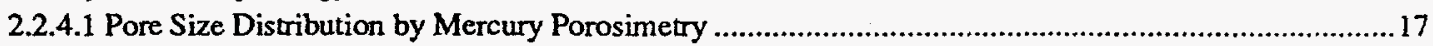

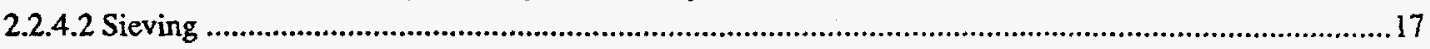

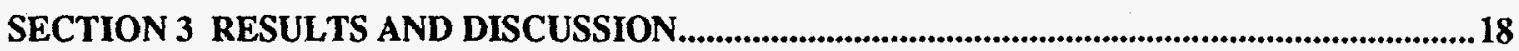

3.1 CHARACTERIZATION AND SCREENING OF FRESH FORMULATIONS ................................18

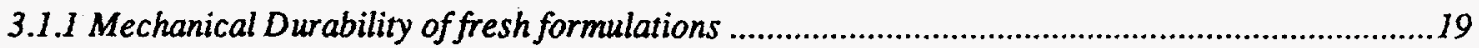

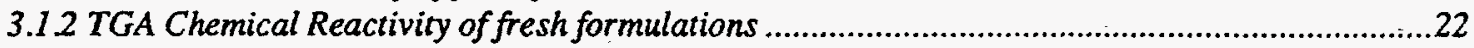

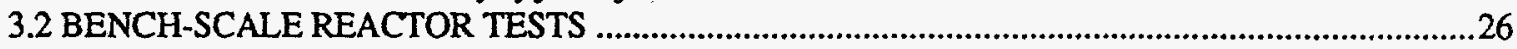

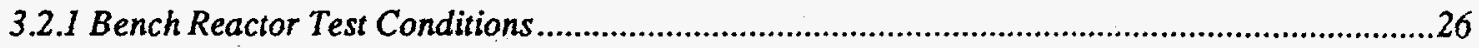

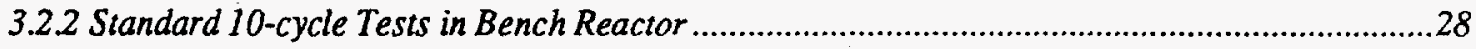

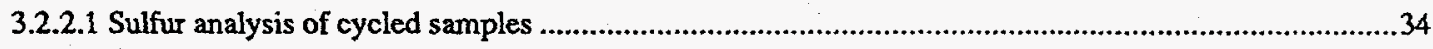

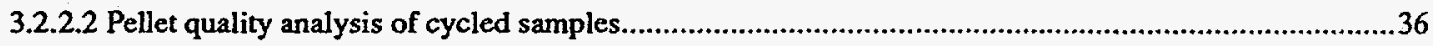

3.2.2.3 Pore size distribution analysis of cycled samples ..................................................................................

3.2.3 Accelerated Sulfidation/Regeneration Tests in Bench Reactor .................................................40

3.2.3.1 Mechanical and Chemical Characterization .................................................................................

3.2.3.2 Correlation of sulfate analyses by TGA reactivity and gravimetric methods.....................................46

3.2.4 Modifications of the bench reactor for pressurized operation ...............................................48

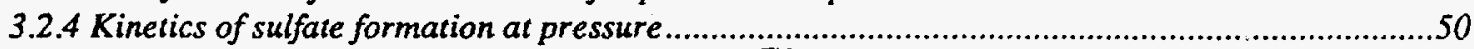

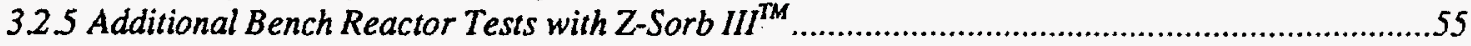

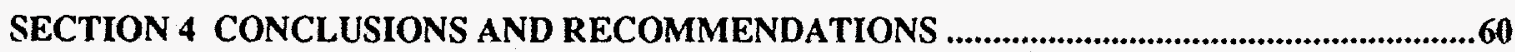


4.1 CONCLUSIONS

.60

4.2 RECOMMENDATIONS..

.62

REFERENCES... 


\section{LIST OF TABLES}

TABLE 1.- CHEMICAL COMPOSITION OF INITIAL ZINC TITANATE FORMULATIONS ..........................................13

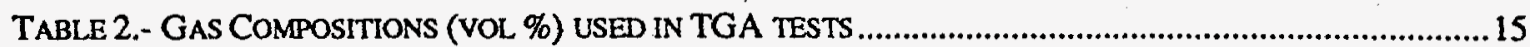

TABLE 3.- SIMULATED COAL GAS COMPOSITION FOR BENCH-SCALE TESTTNG ........................................... 15

TABLE 4.- CALCINATION TEMPERATURES FOR VARIOUS ZINC TITANATE FORMULATIONS .............................18

TABLE 5.- PROPERTIES OF OPTION 3 ZINC TITANATE FORMULATIONS ..................................................

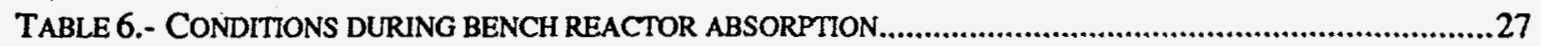

TABLE 7.- CONDITONS DURING STANDARD BENCH REACTOR REGENERATION ...........................................28

TABLE 8.- CONDITIONS DURING ACCELERATED BENCH REACTOR REGENERATION ........................................28

TABLE 9.- SULFUR LOADING ON SAMPLES REMOVED FROM THE BENCH REACTOR SYSTEM .............................34

TABLE 10. - PORE SIZE ANALYSIS OF SORBENTS CYCLED IN THE BENCH REACTOR ........................................39

TABLE 11.- REGENERATION CONDITONS FOR ACCELERATED BENCH TESTS ................................................41

TABLE 12.- CHEMICAL AND MECHANICAL PROPERTIES OF 5-CYCLE ZINC TITANATE...................................43

TABLE 13.- COMPARISON OF DEGREES OF SPALLING AFTER 6 CYCLES OF ACCELERATED BENCH TESTS ...........44

TABLE 14.- SULFATE LEVELS AND OTHER CHARACTERISTTCS OF THE CYCLED LA 103-B2 ZINC TTTANATE .......45

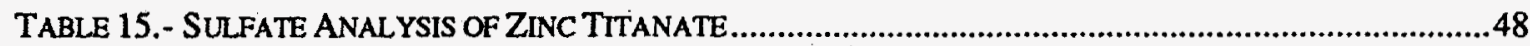

TABLE 16.- PHYSICAL PROPERTIES OF T-2535M2 ZINC TITANATE SORBENT …........................................51

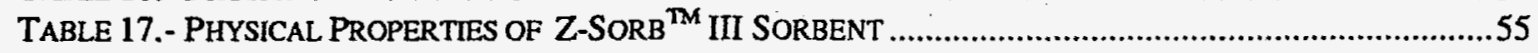




\section{LIST OF FIGURES}

FIGURE 1.- CRUSH STRENGTH (TOP) AND ATTRITION RESISTANCE (BOTTOM) OF FRESH SORBENTS .21

FIGURE 2.- TGA CHEMICAL REACTIVITY OF OPTION 2 SORBENT L-3787M (TOP, LABELED 2A1.7M2) AND

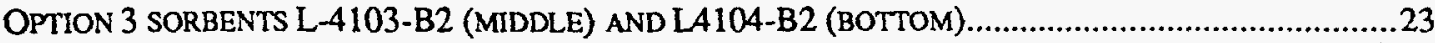

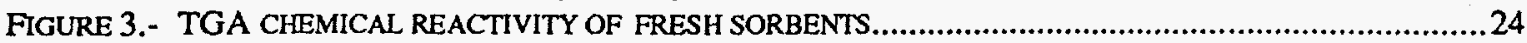

FIGURE 4.- TGA CURVE OF FRESH L4 103-B2 (2.0 ZINC TITANATE) SORBENT. ......................................25

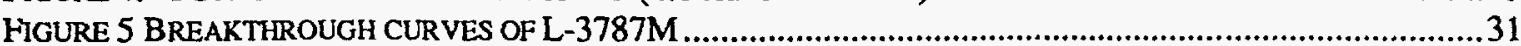

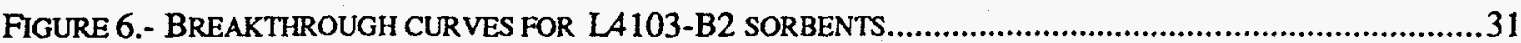

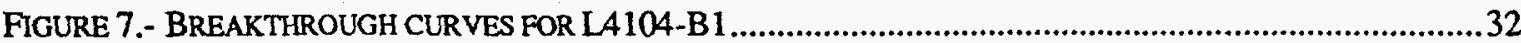

FIGURE 8.- BREAKTHROUGH CURVE OF LA104-B2 (10\% CA SULFATE) SORBENT.......................................32

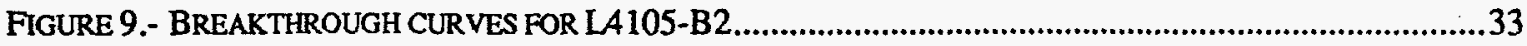

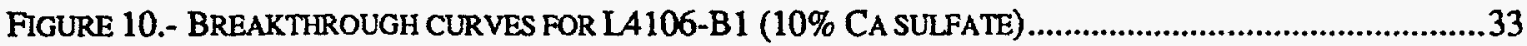

FIGURE 11.- SO2 EVOLUTION DURING REDUCTIVE REGENERATION OF BENCH SORBENTS...............................36

FIGURE 12.-PELLET SIZE DISTRIBUTION OF 10-CYCLE SORBENTS ................................................................37

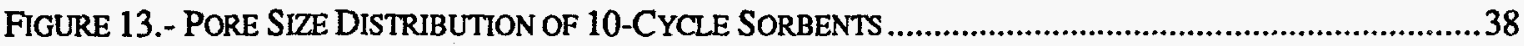

FIGURE 14.- PORE SIZE DISTRIBUTION OF L4 103-B2 SORBENT …............................................................40

FIGURE 15.- PORE SIZE DISTRIBUTION OF L4104-B2 SORBENT …..........................................................40

FIGURE 16.- RESULTS OF THE ACCELERATED SULFIDATION TESTS AFTER 3 CYCLES ...................................42

FIGURE 17.- TGA CHEMICAL REACTIVTTY OF SORBENTS ...........................................................................4

FIGURE 18. - SCHEMATIC DIAGRAM OF BENCH-SCALE REACTOR SYSTEM WTTH RECYCLE ...........................49

FIGURE 19.- TGA REACTIVTTY OF T-2535M2 ZINC TITANATE AS A FUNCTTON OF SULFIDATTON PRESSURE ....52

FIGURE 20.- BENCH REACTOR TESTING OF T-2535M ZINC TITANATE ....................................................52

FIGURE 21.- TGA REGENERATION OF T-2535M2 IN THE PRESENCE (LEFT) OR ABSENCE (RIGHT)OF $\mathrm{O}_{2} \ldots \ldots . . .53$

FIGURE 22 .- ABSORPTION BREAKTHROUGH CUR VES FOR Z-SORB ${ }^{\text {TM }}$ III SORBENT ....................................56

FIGURE 23.- TGA CHEMICAL REACTIVITY OF Z-SORB ${ }^{\text {TM }}$ III SORBENT SAMPLES AFTER 5 AND 10 CYCLES.......57

FIGURE 24.- $\mathrm{SO}_{2}$ EVOLUTION DURING REGENERATION AT 5 ATM AND 1 ATM......................................58

FIGURE 25.- PHASE STABILITY DIAGRAM FOR THE SYSTEM ZN-S-O AT $550^{\circ} \mathrm{C}$ AND $732^{\circ} \mathrm{C} \ldots \ldots . . . . . . . . . . . . . . . .59$ 


\section{BACKGROUND}

\section{EXECUTIVE SUMMARY}

The integrated gasification combined cycle (IGCC) power system using high-temperature coal gas cleanup is one of the most promising advanced technologies for the production of electric power based on coal in an environmentally acceptable manner. In conventional low-temperature cleanup systems, costly heat exchangers are necessary to cool down the coal gas from the gasifier from $1000-2000^{\circ} \mathrm{F}$ to below $300^{\circ} \mathrm{F}$. Unlike these conventional low-temperature cleanup systems, high-temperature coal gas cleanup systems can be operated near $900-1000^{\circ} \mathrm{F}$ or higher. These conditions are compatible with the gasifier and turbine components in the IGCC system, and the result is a more efficient overall system (Rath et al., 1994; Droog, 1993; Corman, 1986). A review of high-temperature desulfurization technology has been given by Thambimuthu (Thambimuthu, 1993) and economic analyses and optimization in various gas stream cleanup systems have been published by Buchanan (Buchanan et al., 1994).

GE is developing a moving-bed, high-temperature desulfurization system for integrated gasification combined-cycle (IGCC) power systems (Bevan et al., 1995; Bevan et al., 1994; Cook et al., 1991) in which zinc-based regenerable sorbents are currently being used as desulfurization sorbents (Ayala et al., 1995). Zinc titanate and other zinc-based oxides are being considered as sorbents for use in the Clean Coal Technology Demonstration Program at Tampa Electric Co.'s Polk Power Station. A key to success in the development of high-temperature desulfurization systems is the matching of sorbent properties for the selected process operating conditions, namely, sustainable desulfurization kinetics, sulfur capacity, and mechanical durability over multiple cycles. Additionally, the sulfur species produced during regeneration of the sorbent have to be in a form compatible with sulfur recovery systems, such as sulfuric acid or elemental sulfur processes.

\section{OBJECTIVES}

The objective of this contract is to identify and test sorbent fabrication methods and chemical compositions that enhance the long-term chemical reactivity and mechanical strength of zinc titanate and other novel sorbents for moving-bed, high-temperature desulfurization of coal-derived gases. A further objective of this program is to test Phillips Petroleum Co's proprietary Z-Sorb ${ }^{\mathrm{TM}}$ III sorbent. Zinc ferrite was studied under the base program of this contract [Ayala, 1991] while novel sorbents, particularly zinc titanatebased sorbents, were studied under the Option 2 program [Ayala, 1993]. This topical report summarizes only the work performed under the Option 3 program which addresses 
the current development of zinc titanate sorbents and evaluation of Phillips Petroleum's ZSorb $^{\text {TM }}$ III sorbent in the pressurized bench-scale reactor.

\section{ACCOMPLISHMENTS}

- Twelve new zinc titanate formulations were prepared using commercial-scale fabrication equipment at UCI. All previous sorbent development work under the Option 2 program had relied on use of laboratory-scale equipment at UCI. This is a major step in proving proof the feasibility of scaling sorbent fabrication technology from laboratory to commercial scale while maintaining the product quality.

- A parametric study on the use of calcium sulfate additives to zinc titanate was conducted for 2:1 and 1.5:1 zinc-to-titanium molar ratios in the fresh sorbent, and showed a beneficial effect on attrition of fresh $2: 1$ zinc titanate sorbents.

- The bench-scale reactor system at GE-CRD was modified for pressurized operation (up to $10 \mathrm{~atm}$ of pressure) in both absorption and regeneration modes. The modifications also added the capability to inject gaseous contaminants found in simulated coal gas (hydrogen chloride, ammonia), and be able to perform regeneration under with gases containing sulfur dioxide (5-10\%), simulating the concentration of sulfur dioxide gases desired for commercial sulfur recovery systems (sulfuric acid plants) and novel processes (elemental sulfur production). This critical to uncover undesired interactions between sorbents and real coal gas components.

- Developed a procedure for testing in an accelerated mode the effect of zinc sulfate formation on sorbent mechanical durability (pellet degradation, including breakage and spalling). This procedure can be used to minimize screening times of sorbent formulations and assess relative performance.

- $\quad$ Performed multicycle tests of Z-Sorb ${ }^{\mathrm{TM}}$ III in the bench reactor and assessed its potential use in high-temperature desulfurization of coal gas.

\section{RESULTS AND CONCLUSIONS}

The following conclusions can be drawn from the characterization and screening of fresh formulations: 
- Addition of $10 \%$ calcium sulfate to the 2.0 zinc titanate formulations increases the crush strength of the fresh sorbents by about $40-50 \%$ to $30 \mathrm{lb} /$ pellet. For the case of $1.5 \mathrm{Zn}:$ Ti zinc titanates, no difference was observed.

- There is no trend seen in the level of attrition resistance of fresh formulations with respect to the zinc-to-titanium ratio or the addition of $10 \%$ calcium sulfate

- The rate of sulfur capture, or reactivity, of fresh formulations does not correlate with chemical composition, but, rather, with the specific pore volume (SPV) of the fresh sorbent. No signs of pore plugging are observed for the formulations having higher SPV's while the lower cases appear to lack the porosity necessary for higher total sulfur loading.

- Higher calcination temperatures resulted in lower SPV's for most of the formulations tested. The lower SPV's resulted in lower reactivity, in general.

The following conclusions can be drawn from standard 10-cycle bench reactor tests

- During standard 10-cycles tests (where no $\mathrm{SO}_{2}$ was present in the inlet regeneration gas), formulations that had the same chemical composition but different rounding method and equipment (laboratory versus commercial-scale equipment) had differences in the performance over 10 cycles. Laboratory formulations (prepared under Option 2 of the program) exhibited less attrition and less variability from pellet to pellet.

- The level of sulfidation influences the measured durability of the formulations. The $\mathrm{H}_{2} \mathrm{~S}$ breakthrough time during bench absorption tests is seen to be related to the calcination temperature of the sorbent and the resulting pellet porosity. Higher calcination times had earlier breakthrough times and lower pellet porosities (i.e., specific pore volumes, SPV). Overall, it appears that the porosity is the major driver for the differences in reactivity in relatively fresh sorbents, rather than the addition of sulfate.

- Calcium sulfate-containing sorbents appear to evolve higher levels of $\mathrm{SO}_{2}$ and to take longer for the $\mathrm{SO}_{2}$ to decrease to low base levels during reductive regeneration. Since calcium sulfate-containing sorbents had initially smaller median pore diameters (MPD), the effect of pore size on $\mathrm{SO}_{2}$ evolution cannot be separated from the presence of calcium sulfate at this point.

- Formulations with a 2:1 $\mathrm{Zn}: \mathrm{Ti}$ molar ratio and $10 \%$ calcium sulfate (i.e., formulations L4104-B1 and L4104-B2) had the lowest amounts of aggregates (less than $0.1 \%$ and virtually no fines (less than $0.01 \%$ after 10 standard cycles, suggesting that this combination of $\mathrm{Zn}: \mathrm{Ti}$, molybdenum, and calcium sulfate produced formulations that had higher durability than the other chemical compositions tested. Formulation 
L4106-B1 had also $10 \%$ calcium sulfate but only a $1.5 \mathrm{Zn}$ :Ti ratio and showed one order of magnitude $(\sim 1 \%)$ more aggregates than the LA104 series. Formulation L4103-B2 did not have any calcium sulfate and exhibited higher percentages of aggregates and fines of all five formulation tested. Optimization of mechanical durability with calcium sulfate is still necessary.

- The beneficial effect of adding calcium sulfate for improved mechanical durability has to be weighed against the lower reactivity (as measured by breakthrough curves) and $\mathrm{SO}_{2}$ evolution during reductive regeneration. Sulfate decomposition appears to be slower in calcium sulfate-containing sorbents.

- Comparison of the pore size distributions for fresh and 10th-regeneration sorbents shows that, probably as a result of the production of aggregates (i.e., broken and cracked pellets), the pore size distribution for the regenerated sorbent was higher in terms of both higher median pore diameter (MPD) and higher SPV. Changes in MPD and SPV are good indicators of the degree of pellet deterioration or sulfate accumulation.

The following conclusions can be drawn from accelerated absorption/regeneration bench reactor tests

- During the first five cycles, in the absence of added $\mathrm{SO}_{2}$ to the inlet regeneration gas, there is very littler mechanical degradation on the sorbents, very likely as a result of formation of very small amounts of sulfates.

- During cycles 6 to 8 , (regeneration under $5 \% \mathrm{SO}_{2}$ in the inlet gas, but keeping temperatures below $1300^{\circ} \mathrm{F}$ ), the results on mechanical degradation were very similar to the first cycles, perhaps with some incipient measurable accumulation of zinc sulfate.

- In contrast, when the 8th cycle was followed by a two-hour period of exposure to $20 \% \mathrm{O}_{2}, 5 \% \mathrm{SO}_{2}$ at $1400^{\circ} \mathrm{F}$, the level of spalling, cracking and pellet deterioration became significant. The results suggest that the level of spalling was exacerbated by the combination of temperature and air in the regeneration gas, rather than by the presence of $\mathrm{SO}_{2}$ alone.

The following conclusions can be drawn from studies of sulfate formation at pressure:

- When large amounts of sulfate are formed in the internal pores of the pellets, the thermal decomposition of sulfate does not occur readily, either because the sulfate I no longer zinc sulfate alone, or there is a capillary vapor pressure equilibrium in the internal pores that slows down the sulfate decomposition (i.e., equivalent to the Kelvin effect in porous media). 
- The improvement in strength by the presence of added calcium sulfate to the sorbents also has the penalty of more difficulty in the decomposition of zinc sulfate. Any selected regeneration scheme has to consider the mechanisms of sulfate formation and decomposition to avoid loss of reactivity or pellet physical degradation.

- Pressurized TGA regeneration demonstrated that conditions that control the level of sulfate formation and decomposition during regeneration can be adjusted to prevent pellet mechanical deterioration. These conditions are primarily temperature and oxygen concentration, rather than the presence of $\mathrm{SO}_{2}$ alone.

- The refurbishment of the bench reactor for pressurized operation allowed the performance of pressurized testing of zinc titanate and Z-Sorb $\mathrm{m}^{\mathrm{TM}}$ sorbent at pressure. However, the reliability of the bellows pump operation was less than desired, forcing operation at times on a single-pass flow of gases rather than the desired operation of a true recycle-loop regeneration mode.

The following conclusions can be drawn from the testing of Z-Sorb $\mathrm{III}^{\mathrm{TM}}$ in the pressurized bench scale reactor:

- Tests performed on Z-Sorb ${ }^{\mathrm{TM}} \mathrm{III}$ showed that the sorbent is capable of reducing $\mathrm{H}_{2} \mathrm{~S}$ levels below a target of $20 \mathrm{ppm}$ during desulfurization of simulated coal gases. During regeneration, sulfate can be decomposed by adjusting the process conditions that lead to thermodynamic instability and thermal decomposition of zinc sulfates

\section{RECOMMENDATIONS}

The presence of calcium sulfate as an additive to zinc titanates certainly looks promising to bring improvements to the mechanical properties of zinc titanate sorbent. The fresh formulations exhibited higher attrition resistance (i.e., lower attrition losses) than the formulations lacking the additive. The development of stronger formulations has certainly moved in the right direction of increasing the mechanical durability of zinc titanate sorbents. However, further tests are required to determine the feasibility of its use in view of the differences in the rate of sulfidation, sulfate decomposition, and the amount of $\mathrm{SO}_{2}$ released during reductive regeneration.

In view of the current improvements in the GE pilot-plant development and operation, it is feasible to think that higher sorbent bed reactivity and higher mechanical durability may be achieved by changing the current $5-\mathrm{mm}$ pellet size, as tested in this Option 3 program, to smaller sizes. We consider by no means that we have arrived at the optimum pellet size is as it was tested in this program, nor that commercial sorbent vendors cannot produce stronger pellets at a different pellet size, say 3-4 mm instead of $5 \mathrm{~mm}$. Further work 
should be done to test the effect of pelletization size on mechanical durability once a chemical formulation has been chosen.

At this point, we cannot assess the intrinsic rate of sulfate decomposition in comparison with other zinc titanates without calcium sulfate, since formulations with added calcium sulfate also exhibited lower pore sizes that also affect the zinc sulfate decomposition. Different concentrations of zinc sulfate should be explored for optimum properties.

Further work is also needed to understand the stability of calcium sulfate in reducing and oxidizing atmospheres. Within the scope of the current program, it was not feasible to determine whether some of the calcium sulfate underwent transition to calcium sulfide during exposure to simulated coal gases and back to calcium sulfate during exposure to oxidizing regeneration gases. Oxygen consumption or release during those steps will certainly affect the controllability of the process in large scale where the oxygen fed to the system will have to be metered more closely to avoid incomplete regeneration or excessive sulfate formation from excess oxygen.

With respect to the regeneration characteristics of zinc titanate sorbents, it is our view that further work is needed to develop a true understanding of the allowable conditions for regeneration in terms of maximum permissible temperatures at various $\mathrm{SO}_{2}$ and $\mathrm{O}_{2}$ concentrations to minimize zinc sulfate formation. Furthermore, the presence of steam in the regeneration gases may further exacerbate the formation of zinc sulfate when calcium sulfate is present, thus increasing pellet deterioration. A better understanding of the above concerns will allow to develop a process more suitable to the operating regime of zinc titanate sorbents containing calcium sulfate additives. 


\section{SECTION 1 \\ INTRODUCTION}

\subsection{CONTRACT OBJECTIVES}

The objective of this contract is to identify and test sorbent fabrication methods and chemical compositions that enhance the long-term chemical reactivity and mechanical strength of zinc titanate and other novel sorbents for moving-bed, high-temperature desulfurization of coal-derived gases. A further objective of this program is to test Phillips Petroleum Co.'s proprietary Z-Sorb ${ }^{\mathrm{TM}} \mathrm{II}$ sorbent. Zinc ferrite was studied under the base program of this contract (Ayala, 1990) while novel sorbents, particularly zinc titanatebased sorbents, were studied under the Option 2 program (Ayala, 1993). This topical report summarizes only the work performed under the Option 3 program (starting in October 1992) which addresses the development of zinc titanate sorbents and evaluation of Phillips Petroleum's Z-Sorb ${ }^{\text {TM }}$ III sorbent in the pressurized bench-scale reactor.

Desired properties to be enhanced for moving-bed sorbent materials are: (1) high chemical reactivity (sulfur absorption rate and total sulfur capacity), (2) high mechanical strength (pellet crush strength and attrition resistance), and (3) suitable pellet morphology (e.g., pellet size, shape, surface area, and pore size distribution). In addition, it is desired to maintain the sorbent properties over extended cyclic use in moving-bed systems.

\subsection{BACKGROUND}

\subsubsection{High-Temperature Desulfurization Systems}

The integrated gasification combined cycle (IGCC) power system using high-temperature coal gas cleanup is one of the most promising advanced technologies for the production of electric power from coal in an environmentally acceptable manner. In conventional cleanup systems, costly heat exchangers are necessary to cool down the gases for cleaning. Unlike these conventional low-temperature cleanup systems, where the coal gas from the gasifier has to be cooled down from $1000-2000^{\circ} \mathrm{F}$ to below $300^{\circ} \mathrm{F}$, hightemperature coal gas cleanup systems can be operated at near $900-1000^{\circ} \mathrm{F}$ or higher, i.e., at conditions compatible with the gasifier and turbine components in the IGCC system. The result is a more efficient overall system (Rath et al., 1994; Droog, 1993; Corman, 1986). A review of of high-temperature desulfurization technology has been given by Thambimuthu (Thambimuthu, 1993) and economic analyses and optimization in various gas stream cleanup systems has been published by Buchanan (Buchanan et al., 1994). 
Over the last decade, the U.S. Department of Energy/Morgantown Energy Technology Center (DOE/METC) has sponsored development of various configurations of hightemperature desulfurization systems (Bossart et al., 1990). Fixed-bed systems, fluidizedbed systems, moving-bed systems, and transport reactor systems for hot gas desulfurization are being pursued under DOE/METC contracts and are described in the literature (McDaniel et al., 1995).

Fluidized-bed systems (Gangwal and Gupta, 1993) are also under development with DOE/METC sponsorship. They have the advantage over fixed-bed systems in that better temperature control can be achieved during regeneration because of better gas-solid mixing. However, sorbents are subject to higher levels of attrition in a fluidized bed, and stronger sorbent materials are necessary. A variation of the fluidized bed concept is being pursued by the transport reactor design of M.W. Kellogg (Gangwal et al., 1995).

$\mathrm{GE}$ is developing a moving-bed, high-temperature desulfurization system for integrated gasification combined-cycle (IGCC) power systems in which zinc-based regenerable sorbents are currently being used as desulfurization sorbents (Bevan et al., 1995; Bevan et al., 1994; Cook et al., 1991). Zinc titanate and other zinc-based oxides are being considered as sorbents for use in the Clean Coal Technology Demonstration Program at Tampa Electric Co.'s Polk Power Station. A key to success in the development of hightemperature desulfurization systems is the matching of sorbent properties for the selected process operating conditions, namely, sustainable desulfurization kinetics, sulfur capacity, and mechanical durability over multiple cycles.

\subsubsection{Sorbent Development}

Earlier experimental studies that pioneered the use of mixed-metal oxides were performed at the Massachusetts Institute of Technology, MIT, (Flytzani-Stephanopoulos et al., 1984; Flytzani-Stephanopoulos et al., 1987; Lew et al., 1989), Research Triangle Institute, RTI, (Gangwal and Harkins 1987, 1988), Electrochem (Jalan, 1989) , U.S. Dept. of Energy/Morgantown Energy Technology Center, DOE/METC (Grindley, 1991), and the Institute of Gas Technology, IGT, (Anderson and Berry, 1987). Mixed-metal oxide sorbents have been studied in the past both as straight zinc titanates, (e.g., $\mathrm{Zn}_{2} \mathrm{TiO}_{4}$ and $\mathrm{Zn}_{2} \mathrm{Ti}_{3} \mathrm{O}_{8}$ ) (Woods et al., 1989) or as combinations of oxides of vanadium, copper, manganese, cobalt, and others; see for instance (Flytzani-Stephanopoulos et al., 1987).

Mixed-metal oxide sorbents have been studied quite extensively in the past, including various types of zinc titanates (e.g., $\mathrm{Zn}_{2} \mathrm{TiO}_{4}$ and $\mathrm{Zn}_{2} \mathrm{Ti}_{3} \mathrm{O}_{8}$ ) (Ayala et al., 1995, 1994, 1993; Gangwal and Gupta, 1993) or as combinations of other metal oxides such as nickel, copper, manganese, cobalt, tin, and others; see for instance (Gasper-Galvin et al., 1994; Gasper-Galvin and Atimtay, 1989, 1991; Hepworth, 1994; Karpuk, 1994). Proprietary zinc-based sorbents, such as Phillips Petroleum Company's Z-Sorb ${ }^{\mathrm{TM}}$ III sorbent and 
METC sorbents, have also been tested (Everitt, 1994; Gangwal et al., 1994; Siriwardane et al., 1994). The reactions occurring during desulfurization of coal gases and regeneration of the sulfided sorbents have been described before in many sources; see for instance, (Gangwal and Gupta, 1993; Westmoreland and Harrison, 1976). More recent studies of sorbent development can be found in the literature (McDaniel et al., 1995)

In order for a metal oxide to be considered suitable for high-temperature desulfurization, the material must exhibit desirable properties in the following areas:

1. Rate of $\mathrm{H}_{2} \mathrm{~S}$ absorption and low equilibrium $\mathrm{H}_{2} \mathrm{~S}$ achievable in the gas phase

2. Ease of regeneration of the sulfide species formed during absorption

3. Likelihood of sulfate formation and ease of sulfate decomposition

4. Metal/sorbent evaporation and temperature of incipient evaporation

5. Formation of low-melting eutectic phases

6. Reduction to metal during absorption due to highly reducing coal gases

7. Interactions between active metal oxide, stabilizers, and support with other components and contaminants in coal gas (e.g., $\mathrm{H}_{2}$, alkali metals, halogens)

8. Sulfur loading of metal oxide and sulfur loading capacity limitations

9. Disposal of spent sorbent metals and deleterious effects of volatilized sorbent metals to other IGCC components (e.g., turbine)

10. Cost of support and/or cost of active metal oxide

The feasibility of operating a moving-bed high-temperature desulfurization system in an economically competitive and technically feasible manner currently restricts its use to a temperature window between $800-1400^{\circ} \mathrm{F}$ and pressures above 10 atmospheres during absorption. Operation below $800^{\circ} \mathrm{F}$ does not take full advantage of higher system efficiency compared to low-temperature cleanup systems, while operation above $1400^{\circ} \mathrm{F}$ requires a tradeoff between more sophisticated material properties/higher capital costs and reliability of process operation. Although this window of operation may expand in the future, these current boundaries of operation are considered realistic.

Preliminary to the preparation of mixed-metal oxide sorbents under the Option 2 program, a review of the literature was done to identify pure metal oxides and combinations of metal oxides that had been evaluated in the past for high-temperature desulfurization of coal gases (Ayala, 1993). Given the degree of advanced development of zinc-based sorbents and the need to minimize secondary undesired reactions (as described 
in items 1-10 above), it was decided to focus first on the optimization of zinc titanate sorbents.

\subsubsection{Zinc Titanate Chemistry}

When calcining mixtures of $\mathrm{ZnO}$ and $\mathrm{TiO}_{2}$ powders at high temperature, three crystalline structures of zinc titanate may form depending on the ratio of zinc to titanium: $\mathrm{ZnTiO}_{3}$, $\mathrm{Zn}_{2} \mathrm{Ti}_{3} \mathrm{O}_{8}$, or $\mathrm{Zn}_{2} \mathrm{TiO}_{4}$. The highest zinc-to-titanium molar ratio zinc titanate, $\mathrm{Zn}_{2} \mathrm{TiO}_{4}$, would be the most desired crystalline phase from the point of view of its higher sulfur capacity. For this case, the overall reaction occurring during $\mathrm{H}_{2} \mathrm{~S}$ absorption from coal gases is as follows:

$$
\mathrm{Zn}_{2} \mathrm{TiO}_{4}+2 \mathrm{H}_{2} \mathrm{~S} \Rightarrow 2 \mathrm{ZnS}+\mathrm{TiO}_{2}+2 \mathrm{H}_{2} \mathrm{O}
$$

A secondary reaction that may take place during desulfurization is the reduction of zinc titanate by hydrogen and carbon monoxide to zinc metal, with the subsequent loss of $\mathrm{Zn}$ caused by evaporation. Zinc metal evaporation becomes significant if desulfurization above $1350^{\circ} \mathrm{F}$ is desired (Gangwal et al., 1988). Since the GE moving-bed system carries out $\mathrm{H}_{2} \mathrm{~S}$ absorption around $900-1000^{\circ} \mathrm{F}$, zinc metal evaporation is not a concern. When regeneration is carried out under dry conditions in the presence of diluted air, the following reaction takes place:

$$
2 \mathrm{ZnS}+\mathrm{TiO}_{2}+3 \mathrm{O}_{2} \Rightarrow \mathrm{Zn}_{2} \mathrm{TiO}_{4}+2 \mathrm{SO}_{2}
$$

In addition to the regeneration reaction, zinc sulfate formation may occur during regeneration, favored below $1200^{\circ} \mathrm{F}\left(648^{\circ} \mathrm{C}\right)$, and at high $\mathrm{O}_{2}$ and $\mathrm{SO}_{2}$ concentrations.

$$
\mathrm{ZnO}+\mathrm{SO}_{2}+\frac{1}{2} \mathrm{O}_{2} \Rightarrow \mathrm{ZnSO}_{4}
$$

Zinc sulfate formation is undesirable because the sulfate occupies more volume than the sulfides in the pores (producing internal pellet stresses) and decomposes during subsequent absorption releasing $\mathrm{SO}_{2}$. Zinc sulfate thermally decomposes in the range of $1112^{\circ} \mathrm{F}\left(600^{\circ} \mathrm{C}\right.$ ) (Wheast and Astle, 1978$)$ to $1364^{\circ} \mathrm{F}\left(740^{\circ} \mathrm{C}\right)$ (Perry and Chilton, 1973). These decomposition temperatures increase at higher concentrations of $\mathrm{SO}_{2}$ and $\mathrm{O}_{2}$. Hence, a regeneration scheme where the temperature is appropriate to minimize zinc sulfate formation or maximize decomposition is desired. 


\subsection{OPTION 3 PROGRAM DESCRIPTION}

Program participants are: GE Corporate Research and Development (GE-CRD, prime contractor), GE Environmental Systems, Inc., (GEESI, subcontractor), and Research Triangle Institute (RTI, subcontractor). United Catalysts, Inc. (UCI) and Phillips Petroleum Company (PPC), acting as vendors, provided the sorbent samples for testing.

The goal of the Option 3 program was to identify and to test sorbent fabrication methods and sorbent chemical compositions that enhance the long-term chemical reactivity and mechanical strength of novel zinc titanate sorbent formulations for moving-bed, hightemperature desulfurization of coal-derived gases. The work was originally divided into several tasks with the following objectives:

- $\quad$ Task 17-Revision to Test Plan for Additional Novel High-Temperature Desulfurization Sorbents

To prepare the revisions to the experimental plan in order to test additional formulations of novel sorbents in the bench-scale reactor unit.

- Task 18 - Sorbent preparation

To prepare and characterize various formulations of desulfurization sorbents in forms suitable for moving-bed desulfurization of hot coal gases. The novel sorbent formulations shall be characterized in terms of their mechanical strength and chemical properties.

- Task 19 - Bench-Scale Modifications and Testing

To test the required number of additional sorbent formulations through at least 10 cycles of operation per the approved test plan (Task 17).

- $\quad$ Task 20 - Bench-Scale Test Analysis

To analyze the cycled sorbent formulations from the bench-scale unit and determine the amount of deterioration in mechanical and chemical properties that occurred during cyclic testing.

- Task 21-Revision of the Topical Report

To provide an updated report containing detailed analysis of sorbent characteristics before and after cyclic testing.

In the course of performing the work on zinc titanate under the Option 3 program, a set of program modifications were issued by the COR from DOE. The purpose of the modifications to Option 3 were to allow for testing of Z-Sorb ${ }^{\mathrm{TM}}$ III sorbent as supplied by Phillips Petroleum Company. The remaining work was divided into six tasks with the following objectives: 
- $\quad$ Task 17a-Revision to Test Plan for Z-Sorb Sorbent testing

To prepare the revisions to the experimental plan prior to Z-Sorb ${ }^{\mathrm{TM}} \mathrm{III}$ testing in the bench-scale reactor unit.

- $\quad$ Task 18 - Sorbent preparation

To obtain Z-Sorb ${ }^{\mathrm{TM}}$ III samples prepared by the Phillips Petroleum Co. and characterize them in terms of their mechanical properties as fresh materials.

- $\quad$ Task 19 - Bench-Scale Modifications and Testing

To modify the bench-scale reactor system and test the Z-Sorb ${ }^{\mathrm{TM}}$ III sorbent through 50 cycles of operation per the approved test plan (Task 17a).

- $\quad$ Task 20 - Bench-Scale Test Analysis

To analyze the cycled sorbent from the bench-scale unit and determine the amount of deterioration in mechanical and other properties that occurred during cyclic testing.

- $\quad$ Task 21 -Revision of the Topical Report

To provide an updated report containing detailed analysis of sorbent characteristics before and after cyclic testing. 


\section{SECTION 2 \\ EXPERIMENTAL PROCEDURES}

\subsection{SORBENT FABRICATION PARAMETERS}

Zinc titanate sorbents were prepared by United Catalysts, Inc., (UCI) as rounded 5-mm pellets. The rounded pellets were prepared to screen a number of chemical formulations for chemical performance in desulfurization to achieve a desired balance of mechanical properties (crush strength and attrition resistance) and chemical properties. The details of the preparation procedure are proprietary to $\mathrm{UCI}$, but in general, the procedure involves mixing of the metal oxide powders followed by forming into shape and calcining at high temperature so that the mixed-metal oxide structure is created by solid-state reactions. The rounding procedure, when used in addition to extrusion, produces stronger pellets and has been shown to aid in the preparation of sorbents more suitable for moving-bed applications (Ayala, 1993).

Fabrication variables studied during preparation are shown in Table 1. For all formulations, calcination time and temperature were varied as necessary to achieve the best combination of chemical and mechanical properties. Pellet size was held constant at $5 \mathrm{~mm}$. When calcining mixtures of $\mathrm{ZnO}$ and $\mathrm{TiO}_{2}$ powders at high temperature, three crystalline structures of zinc titanate may form depending on the ratio of zinc to titanium: $\mathrm{ZnTiO}_{3}, \mathrm{Zn}_{2} \mathrm{Ti}_{3} \mathrm{O}_{8}$, or $\mathrm{Zn}_{2} \mathrm{TiO}_{4}$. The highest zinc-to-titanium molar ratio zinc titanate, $\mathrm{Zn}_{2} \mathrm{TiO}_{4}$, would be the most desired crystalline phase for its higher sulfur capacity. However, other phases could also be desirable in principle if they provide higher strength to the calcined sorbent pellet.

Table 1.- Chemical composition of initial zinc titanate formulations

\begin{tabular}{lcccc}
\hline Composition & 1 & 2 & 3 & 4 \\
\hline Zn:Ti Molar Ratio & 2.0 & 2.0 & 1.5 & 1.5 \\
Binder type & $3 \%$ Bentonite & $\mathrm{CaSO}_{4}+3 \%$ & $\mathrm{CaSO}_{4}+3 \%$ & $3 \%$ Bentonite \\
& & $\mathrm{Bentonite}$ & $\mathrm{Bentonite}$ & \\
Additives & $2.5 \% \mathrm{MoO}_{3}$ & $2.5 \% \mathrm{MoO}_{3}$ & $2.5 \% \mathrm{MoO}_{3}$ & $2.5 \% \mathrm{MoO}_{3}$ \\
Calcination Temperature & $\mathrm{TBD}$ & $\mathrm{TBD}$ & $\mathrm{TBD}$ & $\mathrm{TBD}$ \\
Calcination Time & $\mathrm{TBD}$ & $\mathrm{TBD}$ & $\mathrm{TBD}$ & $\mathrm{TBD}$ \\
\hline
\end{tabular}

$\mathrm{TBD}=$ to be determined during preparation

Several guidelines were used to assess sorbent performance and to identify superior formulations for moving-bed systems. Among the guidelines, a formulation had to meet mechanical strength requirements (crush strength and attrition resistance), chemical reactivity requirements (as measured by single-pellet thermo-gravimetric analysis, (TGA)), and pellet physical morphology requirements (size, shape, and pore structure).

Crush strength is defined as the maximum dead-weight load a pellet withstands on compression prior to fracture; for rounded pellets, the crush strength is presented as force per pellet since the contact area between the flat plates and the pellet is not easily measured and varies depending on the pellet aspect ratio. Attrition resistance is defined as $100 \%$ minus the attrition loss when measured according to the ASTM D4058-81 method. 
The pellet internal structure (pore size distribution) was measured by mercury porosimetry at RTI, and reported as median pore diameter (MPD) and specific pore volume (SPV) in cc of void volume/g of sorbent. Single-pellet TGA chemical reactivity was measured also at RTI. The rest of this section provides more details on the experimental procedures followed.

\subsection{CHARACTERIZATION TECHNIQUES}

\subsubsection{Kinetic Performance}

\subsubsection{TGA Chemical Reactivity}

Chemical reactivity of single-pellet sorbent samples was determined by measuring pellet sulfur capacity and regenerability in a thermogravimetric analyzer at RTI. The rate of sulfidation or regeneration was determined indirectly by relating pellet weight gained or lost as a function of time. Details of the procedure have been described elsewhere (Woods et al., 1989).

The TGA uses a Cahn Instrument Model 1000 balance having the same capacity o up to 100 $\mathrm{g}$, and capable of measuring weight changes with an accuracy of $\pm 1 \mu \mathrm{g}$. The gas composition used for sulfidation and regeneration in the Option 3 program are shown in Table 2 . The sulfidation gas compositions simulated oxygen-blown, entrained-bed gasifier gas; the regeneration gas composition did not include any $\mathrm{SO}_{2}$ to achieve the highest level of regeneration in the absence of zinc sulfate formation. The test procedure consists of a 30 minute reduction at $1022^{\circ} \mathrm{F}\left(550^{\circ} \mathrm{C}\right)$ in clean reducing gas (i.e., no $\left.\mathrm{H}_{2} \mathrm{~S}\right)$ prior to each sulfidation. Sulfidation is then conducted at $1022^{\circ} \mathrm{F}\left(550^{\circ} \mathrm{C}\right)$ with $3 \% \mathrm{H} 2 \mathrm{~S}$ for both the halfcycle (i.e., sulfidation) runs and the $11 / 2$-cycle (i.e., sulfidation-regeneration-sulfidation) runs. Tests are conducted for a minimum of three hours or until no weight change occurs.

After full sulfidation, oxidative regeneration is carried out at $1250^{\circ} \mathrm{F}$ with $4 \% \mathrm{O}_{2}$ in $\mathrm{N}_{2}$. At this point the run is interrupted, if necessary, to remove one pellet from the screen for characterization of pore size distribution. The remaining pellets are then subjected to a second reduction and sulfidation prior to termination of the run. All tests were conducted at $1 \mathrm{~atm}$ pressure. All of the sample pellets tested were selected to be of nearly equivalent size so that the comparison of results would be meaningful. 
Table 2.- Gas Compositions (vol \%) used in TGA tests

\begin{tabular}{lccc}
\hline & $\begin{array}{l}\text { Simulated } \\
\text { air-blown } \\
\text { gasifier gas }\end{array}$ & $\begin{array}{l}\text { Simulated } \\
\mathrm{O}_{2} \text {-blown } \\
\text { gasifier gas }\end{array}$ & Regeneration gas \\
\hline $\mathrm{H}_{2}$ & 15.0 & 25.1 & \\
$\mathrm{CO}$ & 8.0 & 60.9 & \\
$\mathrm{CO}_{2}$ & 11.0 & 3.0 & \\
$\mathrm{H}_{2} \mathrm{O}$ & 30.0 & 3.0 & \\
$\mathrm{H}_{2} \mathrm{~S}$ & 3.0 & 3.0 & 96.0 \\
$\mathrm{~N}_{2}$ & 33.0 & 5.0 & 4.0 \\
$\mathrm{O}_{2}$ & & & \\
\hline
\end{tabular}

\subsubsection{Bench-Scale Reactor Testing}

Chemical reactivity was also determined by measuring sorbent sulfur loading (defined as grams of sulfur absorbed per $100 \mathrm{~g}$ of fresh sorbent) in fresh and in cycled (i.e., spent) samples from the bench-scale reactor. Only formulations that exhibited a good balance of chemical and mechanical performance as fresh pellets were selected for further cyclic testing in a benchscale reactor system. Details of the bench-scale reactor and procedures associated with it have been given before (Ayala, 1993).

The important aspect of the bench-scale testing is that both absorption and regeneration are conducted in a packed-bed reactor simulating the time/temperature environment in which the sorbent would be exposed in a typical full-scale moving-bed system. Absorption was carried out at $1000^{\circ} \mathrm{F}\left(538^{\circ} \mathrm{C}\right)$ using the gas composition shown in Table 3 , which is similar to that of an oxygen-blown gasifier. The $1 \% \mathrm{H}_{2} \mathrm{~S}$ concentration used is artificially high in order to accelerate the rate of sulfur loading and reduce testing time.

Table 3.- Simulated Coal Gas Composition for Bench-Scale Testing

\begin{tabular}{lr}
\hline Component & $(\%)$ \\
\hline $\mathrm{CO}$ & 39 \\
$\mathrm{CO}_{2}$ & 10 \\
$\mathrm{H}_{2}$ & 30 \\
$\mathrm{H}_{2} \mathrm{O}$ & 20 \\
$\mathrm{H}_{2} \mathrm{~S}$ & 1 \\
$\mathrm{~N}_{2}$ & 0 \\
\hline
\end{tabular}

The oxidative regeneration was carried out between $1000^{\circ} \mathrm{F}\left(538^{\circ} \mathrm{C}\right)$ and $1250^{\circ} \mathrm{F}\left(677^{\circ} \mathrm{C}\right)$ and $1-21 \%$ oxygen during the early phases of regeneration, and at $1400^{\circ} \mathrm{F}\left(760^{\circ} \mathrm{C}\right)$ during 
the final phase simulating the temperature rise of the sorbent bed (triggered by the exothermic oxidation reaction) in the large-scale system. Two types of bench reactor tests were performed (standard 10-cycle tests and accelerated absorption/regeneration tests). More details of the test conditions are provided in the results section so that the reader has the procedural information closer to the test results

\subsubsection{Chemical Composition}

Chemical composition analyses were conducted on both fresh sorbents and sorbents extracted from the bench-scale reactor system after multicycle testing. Analyses concentrated on the determination of the elemental composition, solid crystalline phase composition, and microstructure.

The crystalline phase composition of the sorbent was determined using $\mathrm{x}$-ray diffraction (XRD). The instrument used for analysis is a Rigaku $\theta / \theta$ automated diffractometer with a 43position sample changer. The lower detection limit for most constituents is of the order of $1 \%$. Sometimes a Laue camera was used to obtain x-ray diffractograms over a 24-hr period, especially when the diffraction reflections were weak.

Quantitative average elemental analysis of whole pellets was determined by inductivelycoupled plasma (ICP) atomic emission spectroscopy or proton-induced $x$-ray emission (PIXE) spectroscopy; qualitative and quantitative elemental analyses for whole pellets was determined by $x$-ray fluorescence (XRF) spectrometry. The average content of total carbon and total sulfur in single pellets was determined by total carbon and total sulfur analyses by Commercial Testing and Engineering, Co. (CTE, South Holland, Illinois) using a LECO induction furnace analyzer. Sulfate sulfur was also determined at CTE following the ASTM D2492 procedure.

\subsubsection{Mechanical Strength}

The mechanical strength of sorbents, crush strength, and attrition resistance, was measured by GE Environmental Services, Inc. (GEESI) or GE-CRD. Crush strength (i.e., deadweight load) was measured by subjecting single pellets to an increasing load until breakage occurred, and the measured force was averaged over a minimum of 20 pellets. Attrition tests were performed at ambient temperature in a rotating cylinder, and the weight loss of sorbent on attrition was measured according to a modified ASTM D4058-81 method, "Attrition and Abrasion of Catalysts and Catalysts Carriers." Modifications of the test apparatus to withstand high temperature have been described previously (Ayala, 1991, Ayala and Gal, 1991). In this study, attrition resistance is defined as $100 \%$ minus the percent loss on attrition. Percent loss on attrition is defined in the above ASTM D4058-81 method by calculating the percent difference in measured weight of the sample retained in a No. $20(850 \mu \mathrm{m})$ ASTM sieve before and after rotating the cylinder at $60 \mathrm{rpm}$ for 30 minutes. The word attrition will be used in this report as being equivalent to the definition of percent loss on attrition, as defined in the ASTM D4058-81 method. 


\subsubsection{Physical Morphology}

\subsubsection{Pore Size Distribution by Mercury Porosimetry}

Pellet pore size distributions, including the calculation of median pore diameter (MPD) (i.e., diameter at $50 \%$ intrusion) and specific pore volume (SPV) (i.e., pore or void volume per unit mass of sorbent) were determined by RTI using a Micromeritics (Model AutoPore 9220II) mercury porosimeter (Woods et al., 1989).

\subsubsection{Sieving}

Sieving was performed using ASTM standard sieves in order to determine the size distribution of solids before and after attrition tests. Pellet size classification was divided into three categories: whole pellets, broken pellets or aggregates (i.e., those particles or pellet pieces larger than 20 mesh but smaller than whole pellets), and fines (i.e., powder material below 850 $\mu \mathrm{m}$, or $20 \mathrm{mesh}$ ). This classification allowed us to quantify the degree of degradation that whole pellets had experienced by fracture or other means even if not resulting in the formation of fines as defined by the ASTM D4058-81 test. 


\section{SECTION 3 \\ RESULTS AND DISCUSSION}

\subsection{CHARACTERIZATION AND SCREENING OF FRESH FORMULATIONS}

UCI delivered thirteen formulations of rounded 5-mm ellipsoidal pellets. All of the Option 2 formulations had been previously prepared using laboratory-size rounding equipment, while all of the Option 3 formulations were prepared using the pilot-plant rounding equipment. Three calcination temperatures were tested for each chemical composition. The choice of calcination temperature and time was initially left open to UCI, the sorbent vendor, to optimize the desired mechanical and physical properties of the fresh sorbent, i.e., porosity, attrition resistance, and crush strength. The assessment of chemical performance (i.e., reactivity towards $\mathrm{H}_{2} \mathrm{~S}$ removal) was done at RTI and GE-CRD. The final formulation compositions as delivered are as shown in Table 1:

Table 1.- Calcination temperatures for various zinc titanate formulations

\begin{tabular}{lllc}
\hline Formulation & $\begin{array}{l}\text { Zn:Ti Molar } \\
\text { Ratio }\end{array}$ & Additives & $\begin{array}{c}\text { Calcination } \\
\text { Temperature, }\end{array}$ \\
\hline $\mathrm{L}-4103-\mathrm{F} 1$ & $2: 1$ & & 1500 \\
$\mathrm{~L}-4103-\mathrm{B} 2$ & $2: 1$ & & 1550 \\
$\mathrm{~L}-4103-\mathrm{B} 3$ & $2: 1$ & & 1600 \\
$\mathrm{~L}-4104-\mathrm{B} 1$ & $2: 1$ & $10 \% \mathrm{CaSO}_{4}$ & 1500 \\
$\mathrm{~L}-4104-\mathrm{B} 2$ & $2: 1$ & $10 \% \mathrm{CaSO}_{4}$ & 1550 \\
$\mathrm{~L}-4104-\mathrm{B} 3$ & $2: 1$ & $10 \% \mathrm{CaSO}_{4}$ & 1600 \\
$\mathrm{~L}-4105-\mathrm{B} 1$ & 1.5 & & 1500 \\
$\mathrm{~L}-4105-\mathrm{B} 2$ & 1.5 & & 1550 \\
$\mathrm{~L}-4105-\mathrm{B} 3$ & 1.5 & & 1600 \\
$\mathrm{~L}-4106-\mathrm{B} 1$ & 1.5 & $10 \% \mathrm{CaSO}_{4}$ & 1500 \\
$\mathrm{~L}-4106-\mathrm{B} 2$ & 1.5 & $10 \% \mathrm{CaSO}_{4}$ & 1550 \\
$\mathrm{~L}-4106-\mathrm{B} 3$ & 1.5 & $10 \% \mathrm{CaSO}_{4}$ & 1600 \\
\hline
\end{tabular}

All formulations were prepared as nominal 5-mm pellets although there are variations in size distribution depending on the additive used. All formulations contain approximately $3 \%$ bentonite binder and $2.5 \%$ wt. molybdenum oxide (the method of addition of molybdenum is proprietary to United Catalysts, Inc. UCI). All formulations have $2.5 \%$ equivalent $\mathrm{MoO}_{3}$. Formulations $\mathrm{L} 4103$ and $\mathrm{L} 4104$ (with added $10 \% \mathrm{CaSO}_{4}$ ) are 2.0 zinc titanates while $\mathrm{L} 4105$ and $\mathrm{L} 4106$ (with added $10 \% \mathrm{CaSO}_{4}$ ) are 1.5 zinc titanates. The suffix $\mathrm{B} 1, \mathrm{~B} 2$, and $\mathrm{B} 3$ refer to the three calcination temperatures of $1500^{\circ} \mathrm{F}, 1550^{\circ} \mathrm{F}$, and $1600^{\circ} \mathrm{F}$.

In addition, a sample of the GE pilot plant zinc titanate formulation T-2535M2 was also characterized in the laboratory. T-2535M2 is the second batch of UCl's formulation T$2535 \mathrm{M}$ having approximately $2.5 \% \mathrm{MoO}_{3}$ as pore modifier and $3 \%$ bentonite binder. It was produced in 1993 as a large batch $(6,000 \mathrm{lb})$ for use in the $\mathrm{GE}$ moving-bed pilot plant in 
Schenectady, New York. The chemical composition of T-2535M2 is identical to that of LA103-B2.

\subsubsection{Mechanical Durability of fresh formulations}

The formulations were characterized in terms of mechanical properties (crush strength and

Table 2.- Properties of Option 3 Zinc Titanate Formulations

\begin{tabular}{ccccccccc}
\hline ID & $\begin{array}{c}\text { Calc. } \\
\text { Temp }{ }^{\circ} \mathrm{F}\end{array}$ & $\begin{array}{c}\text { Density } \\
\mathrm{g} / \mathrm{cc}\end{array}$ & $\begin{array}{c}\text { Crush } \\
\text { Strength } \\
\text { lb/pellet }\end{array}$ & $\begin{array}{c}\text { Attrition } \\
\text { Resistance } \\
\%\end{array}$ & $\begin{array}{c}\text { Surface } \\
\text { Area } \\
\mathrm{m}^{2} / \mathrm{g}\end{array}$ & $\begin{array}{c}\text { SPV } \\
\mathrm{cc} / \mathrm{g}\end{array}$ & $\begin{array}{c}\text { MPD } \\
\AA\end{array}$ \\
\hline $\mathrm{L}-4103$ & 1500 & 97.7 & 27.8 & 4 & 1.2 & 0.167 & 10110 \\
& 1550 & 107.3 & 21.8 & 5 & 1.2 & 0.094 & 12550 \\
& 1600 & 112.2 & 22.7 & 7 & 0.8 & 0.143 & 11050 \\
L-4104 & 1500 & 100.1 & 24.6 & 2.5 & $\ldots$ & 1.3 & 0.185 & 7901 \\
& 1550 & 110.0 & 33.7 & 4 & 1.0 & 0.149 & 8268 \\
& 1600 & 114.6 & 31.8 & 6 & 0.8 & 0.138 & 9523 \\
L-4105 & 1500 & 109.0 & 27.6 & 2 & 1.0 & 0.142 & 7872 \\
& 1550 & 112.0 & 30.9 & 3.5 & 0.8 & 0.138 & 10830 \\
& 1600 & 115.4 & 22.1 & 9 & 0.9 & 0.138 & 11350 \\
L-4106 & 1500 & 94.8 & 15.7 & 4 & 1.3 & 0.244 & 6095 \\
& 1550 & 99.7 & 23.1 & 2 & 1.0 & 0.156 & 7538 \\
& 1600 & 109.6 & 29.9 & 1.5 & 1.0 & 0.145 & 8672 \\
L-4120 & 1550 & 108 & 45.2 & 4 & 0.5 & 0.150 & 6219 \\
\hline
\end{tabular}

All formulations contain molybdenum oxide and bentonite

SPV: specific pore volume; MPD: median pore diameter

attrition resistance), pellet morphology (pellet density, surface area, specific pore volume, and median pore diameter) and results summarized in Table 2 . The main differences between these and previous formulations are higher densities, higher pore diameters and lower specific pore volumes. The combination of these properties is expected to result in further enhancement of the mechanical strength of the pellets over long-term bench-scale testing.

The comparison of mechanical performance of Option 3 sorbents with the Option 2 sorbent L$3787 \mathrm{M}$ is shown in Figure 1. Measurements were made at UCI and GEESI to cross-correlate results and determine variability of the technique. L-3787M is the best formulation found under the Option 2 Program [Ayala, 1993]. 
The main conclusion is that addition of $10 \%$ calcium sulfate to the 2.0 zinc titanate sorbents increases the crush strength of the fresh pellets by about $40-50 \%$ to $30 \mathrm{lb} /$ pellet. For the case of $1.5 \mathrm{Zn}$ :Ti sorbents, no difference was observed. Also shown in Figure 1 is the attrition resistance of the Option 3 formulations and the comparison again with L-3787M. Overall there is no trend seen in the level of attrition resistance of fresh formulations with respect to zinc-to-titanium ratio or the presence of calcium sulfate.
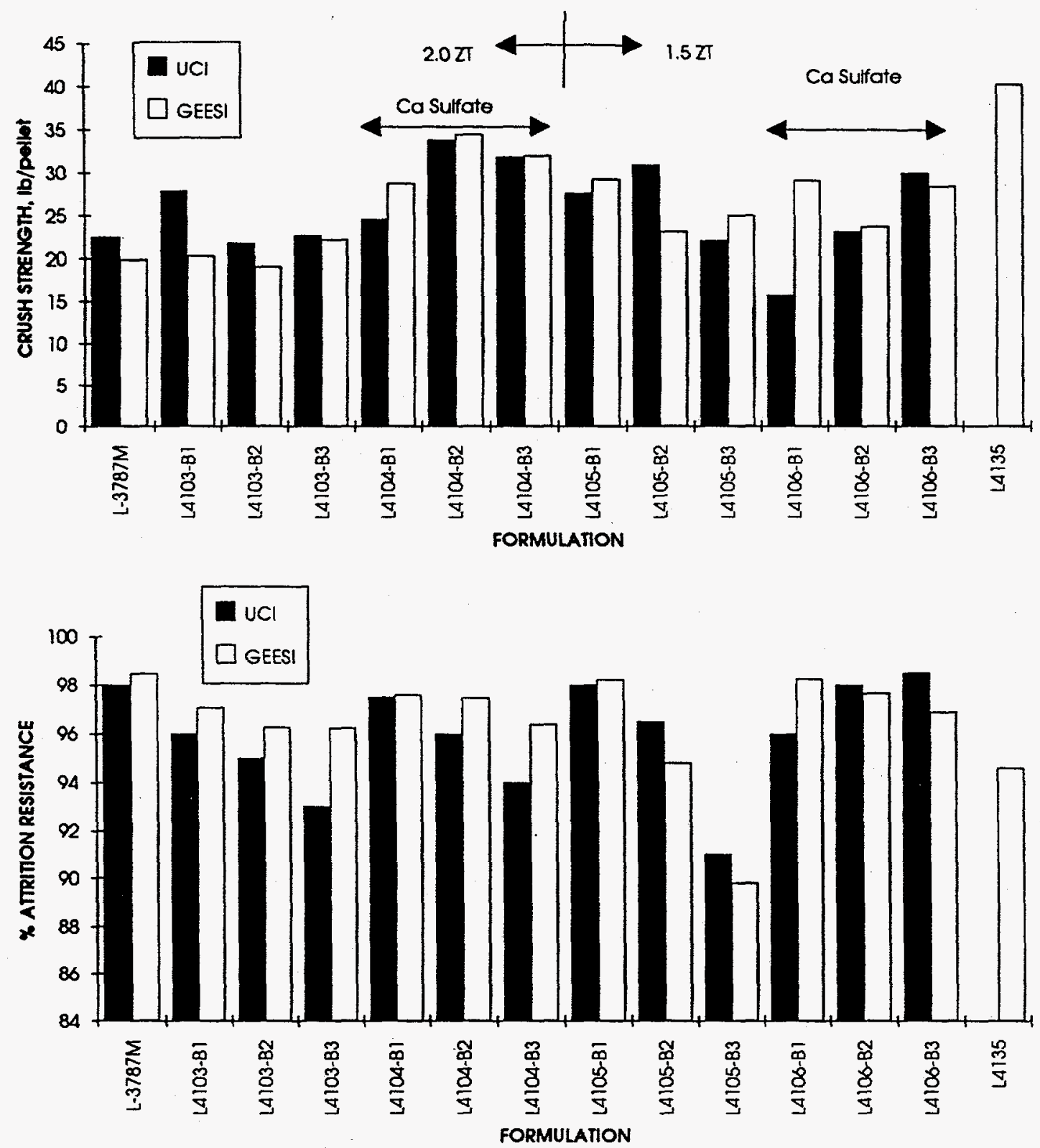

Figure 1.- Crush Strength (top) and Attrition Resistance (bottom) of Fresh Sorbents 


\subsubsection{TGA Chemical Reactivity of fresh formulations}

Figure 2 shows the comparison of TGA chemical reactivity for the L-3787M formulation tested under the Option 2 program with the first two bench-scale sorbents tested under the Option 3 program. $\mathrm{L}-3787 \mathrm{M}$ has the same chemical composition as $\mathrm{L} 4103-\mathrm{B} 2\left(2.5 \% \mathrm{MoO}_{3}+\right.$ $3 \%$ bentonite additives).Comparison of performance between L-3787M and L4103-B2 gives a direct way of assessing the effect of rounding equipment. As seen in Figure 2, both formulations exhibit a theoretical sulfidation of about $44 \%$ at 180 minutes. Formulation L4104-B2, having $10 \%$ calcium sulfate in addition to the other additives) shows only $27.5 \%$ of theoretical sulfidation at the same 180 minutes and, hence, it is less reactive.

Figure 3 shows the results of the standard TGA chemical reactivity test $\left(3 \% \mathrm{H}_{2} \mathrm{~S}\right)$ of selected fresh formulations presented as fractional conversion versus time. In this plot the specific pore volume, SPV, of each sorbent has been measured and added to the figure. Using the definition of theoretical sulfur capacity as the maximum amount of sulfur that a given amount of fresh sorbent will absorb, the fractional conversion is defined as the ratio of the mass of sulfur captured by the sorbent at any given time divided by the theoretical the theoretical sulfur capacity. A fractional conversion equal to 1.0 is equivalent to 23 to $25 \mathrm{lb}$ of sulfur captured per $100 \mathrm{lb}$ of fresh zinc titanate sorbent, depending on the amount of inert binder available.

The rate of sulfur capture is given by the slope of the curves in Figure 3. Premature pore plugging is undesired and is signaled by a very low or zero slope. As seen from Figure 3, except for formulation L4105-B2, no signs of premature pore plugging are seen in all the formulations. The chemical composition of the formulations is as follows: L4103-B2 (2.0 ZT), $\mathrm{L} 4104-\mathrm{xx}\left(2.0 \mathrm{ZT}+10 \% \mathrm{CaSO}_{4}\right), \mathrm{L} 4105-\mathrm{B} 2(1.5 \mathrm{ZT})$, and L4106-B1 $(1.5 \mathrm{ZT}+10 \%$ $\mathrm{CaSO}_{4}$ ). Also shown for each curve is the SPV for each fresh sorbent. The rate of sulfur capture does not correlate with chemical composition but, rather, with the SPV of the fresh sorbent.

Modeling of the chemical reactivity of single pellets by thermogravimetric analysis (TGA) was performed on data for fresh pellets. A typical TGA curve is shown in Figure 4, where the raw TGA data, as collected by RTI, is presented at the top. An initial exposure of the pellet to simulated coal gas with no $\mathrm{H}_{2} \mathrm{~S}$ was performed during the first 30 minutes to ascertain that no weight changes occur in the absence of $\mathrm{H}_{2} \mathrm{~S}$, or that the weight changes are accountable and will not interfere with assessment of weight changes during sulfidation. 

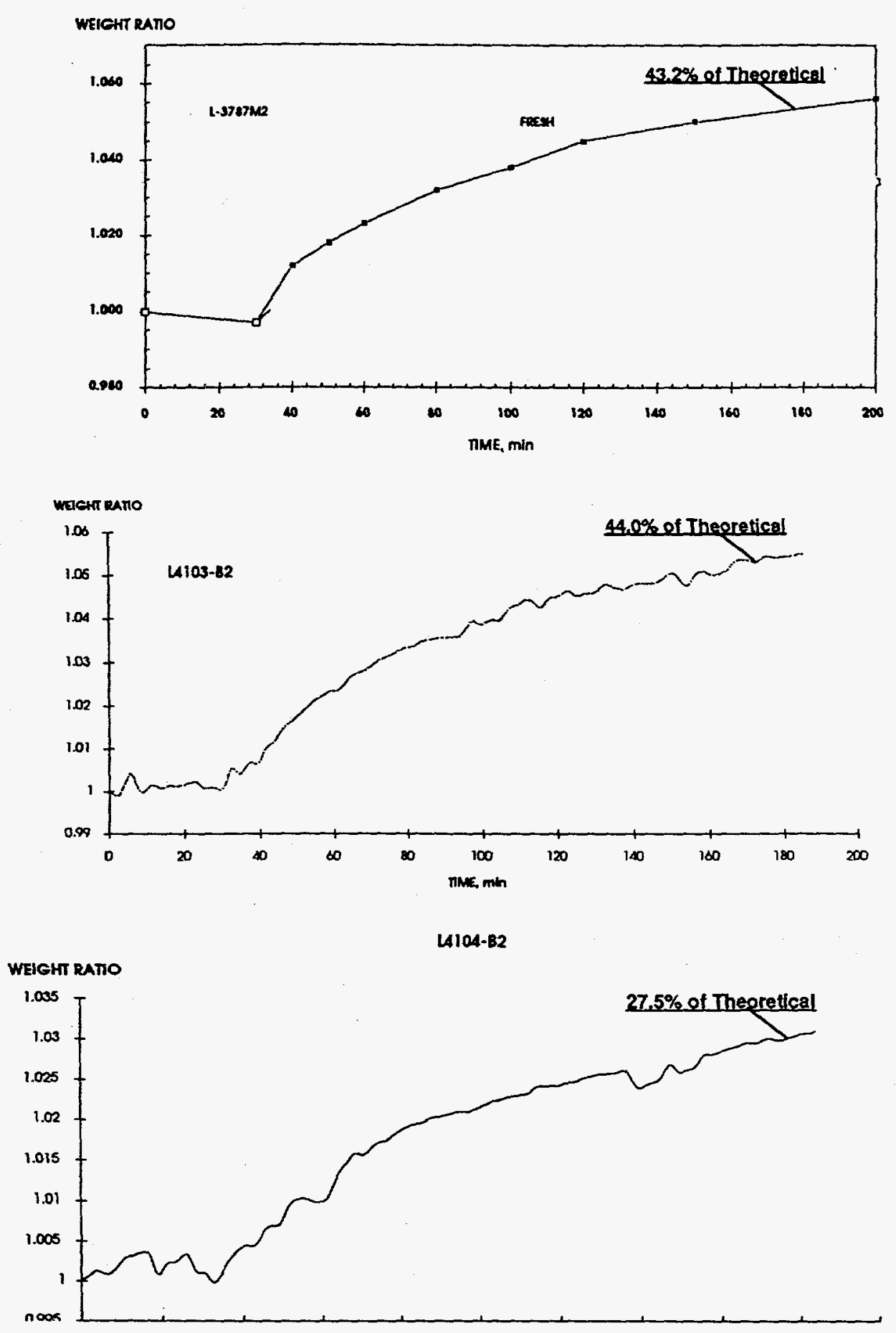

Figure 2.- TGA Chemical Reactivity of Option 2 sorbent L-3787M (top, labeled 2A1.7M2) and Option 3 sorbents L-4103-B2 (middle) and L4104-B2 (bottom) 


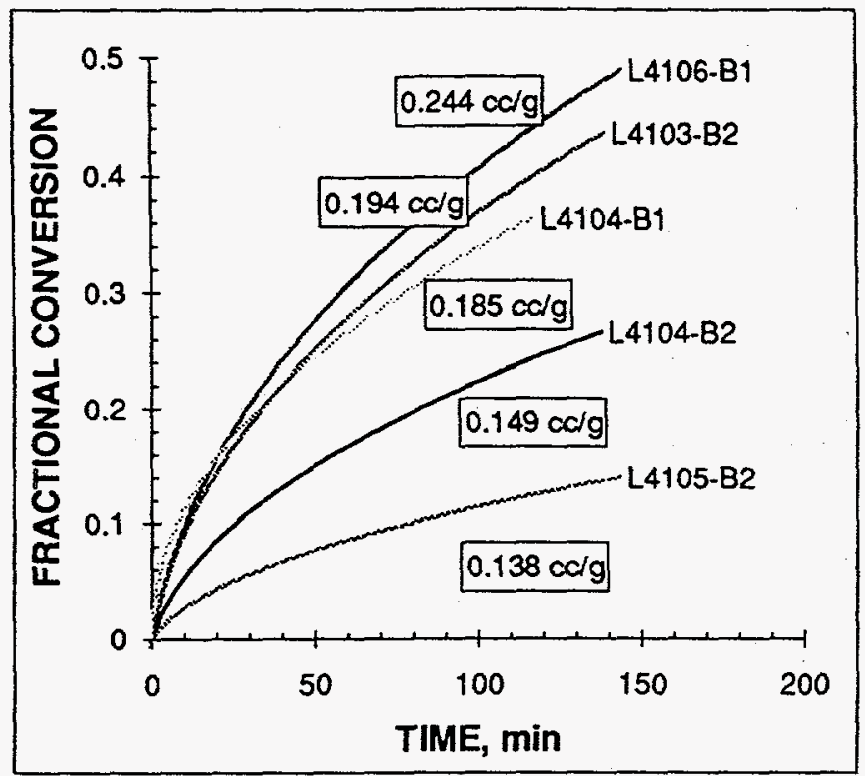

Figure 3.- TGA chemical reactivity of fresh sorbents 

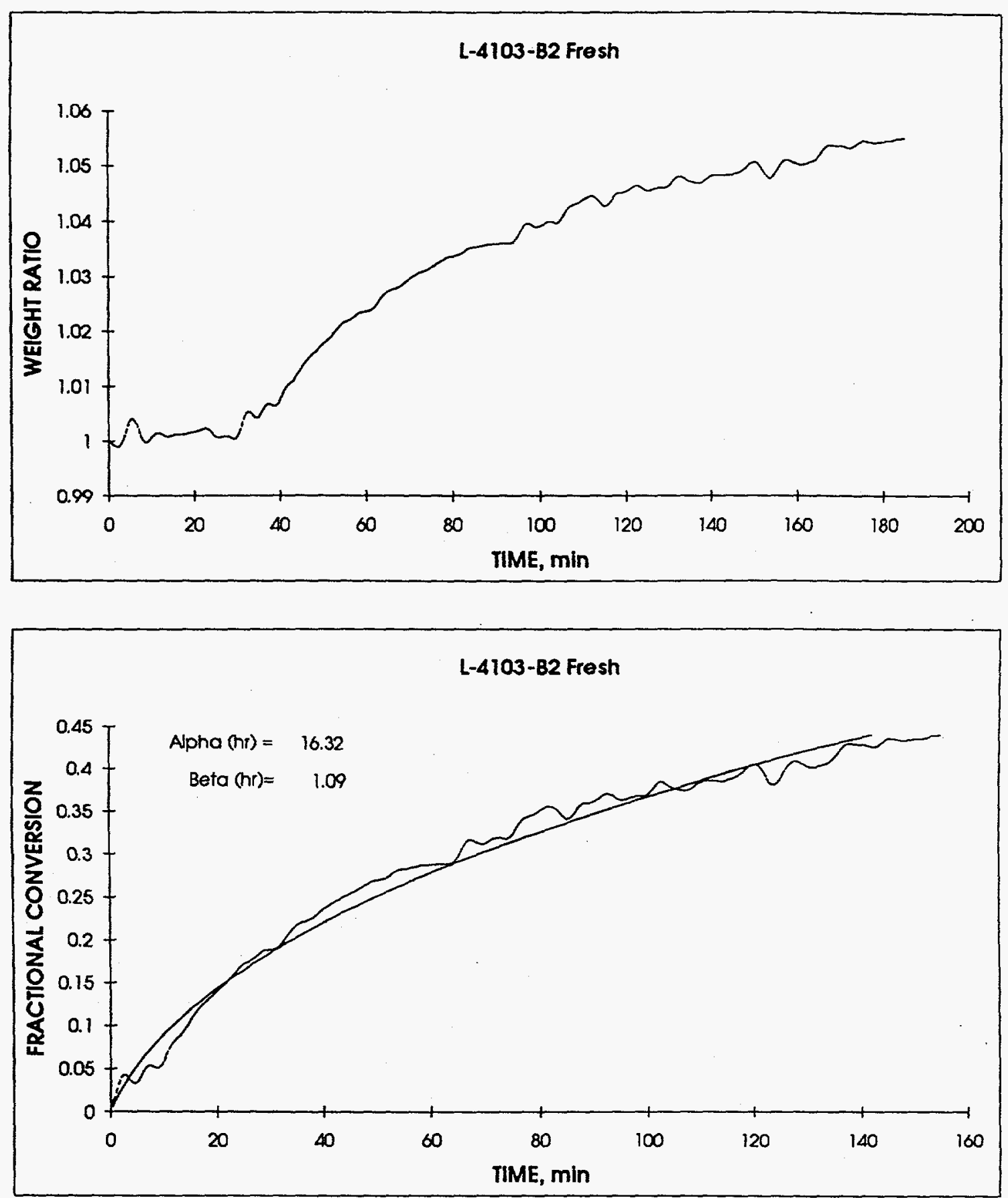

Figure 4.- TGA curve of fresh L4103-B2 (2.0 Zinc titanate) sorbent.

The lower portion of Figure 4 presents the sulfidation portion of the TGA test where the raw data has been fit to the theoretical equation for sulfidation: 
$t=\alpha[x+(1-x) \ln (1-x)]+\beta x$

where

$$
\begin{aligned}
& t=\text { time } \\
& \alpha=\text { coefficient containing the pore diffusion coefficient } \\
& \beta=\text { coefficient containing the gas-phase mass transfer coefficient } \\
& x=\text { fractional conversion of oxide to sulfide (range: } 0-1 \text { ) }
\end{aligned}
$$

The parameters $\alpha$ and $\beta$ are functions of temperature and gas composition among other factors. The description of the $\alpha$ and $\beta$ factors is useful for the analysis and design of the absorber configurations to calculate required residence times for a given sulfur removal duty ' on the sorbent. This analysis is based on the development of the unreacted core model for chemical reactions in cylindrical extrudates [Levenspiel, 1972] and modified to account for nonidealities in rounded ellipsoidal pellets. The top three formulations shown in Figure 3 (L4103-B2, L4104-B2 and L4106-B1) exhibit fractional conversions above $30 \%$ after $2 \mathrm{hr}$, or equivalently above 7 to $7.5 \mathrm{lb}$ sulfur/100 lb of sorbent, which is acceptable for moving-bed systems. No signs of pore plugging are observed for the top formulations while the lower cases appear to lack the porosity necessary for higher total sulfur loading.

\subsection{BENCH-SCALE REACTOR TESTS}

\subsubsection{Bench Reactor Test Conditions}

Two types of bench reactor tests were conducted in the laboratory: one is the standard 10cycle tests and the other is the accelerated sulfidation/regeneration tests. In the standard 10cycle tests, the main objective was to compare the relative sorbent performance over repetitive absorption and regeneration reactions when all cycles of absorption and regeneration were identical. In the accelerated tests, the objective was to test sorbent formulations over several cycles at increasingly more difficult process conditions of sulfur loading and sulfate formation and progressively "accelerate" the rate of sorbent degradation to the point where severe pellet breakage was observed. In this way, a faster assessment could be made of the conditions that are detrimental to each particular sorbent formulation. The emphasis of the accelerated tests was in measuring resistance to pellet degradation under conditions of high sulfidation rate or high sulfate formation/decomposition.

The conditions used during $\mathrm{H}_{2} \mathrm{~S}$ absorption for both the standard and the accelerated tests are presented in Table 3 . In the standard 10-cycle tests, absorption was carried out in an $800 \mathrm{ml}$ bed at $1000^{\circ} \mathrm{F}$, either until the effluent $\mathrm{H}_{2} \mathrm{~S}$ concentration from the bed reached $200 \mathrm{ppmv}$, or until 2 hours had elapsed. In the accelerated tests, the first five cycles were carried out similar to the standard test, but the subsequent cycles were modified. First, the bed size was reduced to $200 \mathrm{ml}$ (because part of the sorbent originally in the bed was used for characterization and analysis after 5 cycles). Second, the $\mathrm{H}_{2} \mathrm{~S}$ concentration and exposure time during absorption were increased to $3.8 \%$ and 3 hours, respectively. The exposure time was constant, 
regardless of outlet $\mathrm{H}_{2} \mathrm{~S}$ concentration, to provide a higher degree of sulfidation at more or less constant $\mathrm{H}_{2} \mathrm{~S}$ concentration throughout the bed.

Table 3.- Conditions during bench reactor absorption

\begin{tabular}{|c|c|c|}
\hline & $\begin{array}{l}\text { Standard } \\
10 \text {-cycle absorption }\end{array}$ & $\begin{array}{l}\text { Accelerated } \\
\text { Absorption } \\
\end{array}$ \\
\hline $\mathrm{CO}$ & $39 \%$ & $37.9 \%$ \\
\hline $\mathrm{CO}_{2}$ & $10 \%$ & $9.7 \%$ \\
\hline $\mathrm{H}_{2}$ & $30 \%$ & $29.2 \%$ \\
\hline $\mathrm{H}_{2} \mathrm{O}$ & $20 \%$ & $19.4 \%$ \\
\hline $\mathrm{H}_{2} \mathrm{~S}$ & $1 \%$ & $3.8 \%$ \\
\hline Temperature & $1000^{\circ} \mathrm{F}$ & $1000^{\circ} \mathrm{F}$ \\
\hline Pressure & $1 \mathrm{~atm}$ & $1 \mathrm{~atm}$ \\
\hline Bed size & $800 \mathrm{ml}$ & $800-200 \mathrm{ml}$ \\
\hline Exposure time & $2 \mathrm{hr}$ & $6 \mathrm{hr}$ \\
\hline
\end{tabular}

Table 4 presents the conditions used during the standard regeneration. Regeneration was carried out in two stages. In the first stage, regeneration gases contained enough (1-2\%) oxygen to maintain the bed temperature below $1250^{\circ} \mathrm{F}$; in the second and final stage the oxygen concentration was increased from 2 to $21 \%$ and the furnace temperature increased to $1400^{\circ} \mathrm{F}$ for at least one hour to monitor formation and decomposition of any zinc sulfate formed in the first stage. This regeneration scheme was meant to simulate the possible temperature history that a sorbent would see during regeneration in a moving-bed regenerator.

Table 4.- Conditions during standard bench reactor regeneration

\begin{tabular}{lcc}
\hline & $\begin{array}{l}\text { Standard } \\
\text { 1st stage regeneration }\end{array}$ & $\begin{array}{c}\text { Standard } \\
\text { 2nd stage regeneration }\end{array}$ \\
\hline $\mathrm{O}_{2}$ & $0.5-2 \%$ & $2-21 \%$ \\
$\mathrm{~N}_{2}$ & balance & balance \\
$\mathrm{SO}_{2}$ & - & - \\
Initial Temperature & $1000^{\circ} \mathrm{F}$ & $1250^{\circ} \mathrm{F}$ \\
Max Temperature & $1250^{\circ} \mathrm{F}$ & $1400^{\circ} \mathrm{F}$ \\
Pressure & $1 \mathrm{~atm}$ & $1 \mathrm{~atm}$ \\
\hline
\end{tabular}

During the accelerated sulfidation/tegeneration tests, the regeneration conditions were modified (Table 5) to subject the sorbent to harsher conditions of sulfate formation and determine the optimum conditions, if any, to preserve the sorbent mechanical performance (i.e., strength, attrition, and pellet integrity). The regeneration gases introduced $\mathrm{SO}_{2}$ in the 
inlet gas simulating the recycle $\mathrm{SO}_{2}$ concentration present in the moving-bed regeneration process.

Table 5.- Conditions during accelerated bench reactor regeneration

\begin{tabular}{llc}
\hline Cycle Number: & \multicolumn{1}{c}{ Regeneration gas } & $\begin{array}{c}\text { Regeneration } \\
\text { Temperature }\end{array}$ \\
\hline $1-5$ & $0.5-21 \% \mathrm{O}_{2}$, bal. $\mathrm{N}_{2}$ & $1000-1300^{\circ} \mathrm{F}$ \\
$6-8$ & $0.5-21 \% \mathrm{O}_{2}, 5 \% \mathrm{SO}_{2}$, bal. $\mathrm{N}_{2}$ & $1000-1300^{\circ} \mathrm{F}$ \\
$8+$ Temp. ramp to $1400^{\circ} \mathrm{F}$ & $20 \% \mathrm{O}_{2}, 5 \% \mathrm{SO}_{2}$, bal. $\mathrm{N}_{2}$ & $1400^{\circ} \mathrm{F}$ \\
\hline
\end{tabular}

\subsubsection{Standard 10-cycle Tests in Bench Reactor}

Two formulations were originally selected for standard bench scale testing: formulation $\mathrm{L}$ $3787 \mathrm{M}$ (also called 2A1.7M2 in the Option 2 Report [Ayala, 1993], fresh pore volume 0.2 $\mathrm{cc} / \mathrm{g}$ ) and formulation L4103-B2 (fresh pore volume $0.09 \mathrm{cc} / \mathrm{g}$ ). Formulation L-3787M was rounded with laboratory equipment, while LA103-B2 and all formulations in the Option 3 program were rounded with commercial-scale equipment. The comparison of performance gives an indication of the variations in fabrication from scale up of rounding equipment.

Figure 5 and Figure 6 show the breakthrough curves for the two formulations after the standard 10-cycle tests. A breakthrough curve is defined as the trace of outlet $\mathrm{H}_{2} \mathrm{~S}$ concentration during absorption as a function of time. The breakthrough point is defined as the time at which the outlet $\mathrm{H}_{2} \mathrm{~S}$ concentration in the breakthrough curve exceeds $200 \mathrm{ppm}$. All reactors were loaded to the same volume $(-800 \mathrm{ml})$ and tested at the same gas conditions. Because of density differences among the formulations, the mass of loaded sorbent is different and the calculated dimensionless time is different even for the formulations with the same chemical composition. Formulations L-3787M and L4103-B2 had different breakthrough curves. The fresh TGA tests were similar for these two formulations, other changes may have taken place during the preparation. For instance, variability of the TGA was greater in the L4103-B2 formulation (prepared with commercial-scale equipment) than in the L3787M formulation 
TIME, $\mathrm{min}$

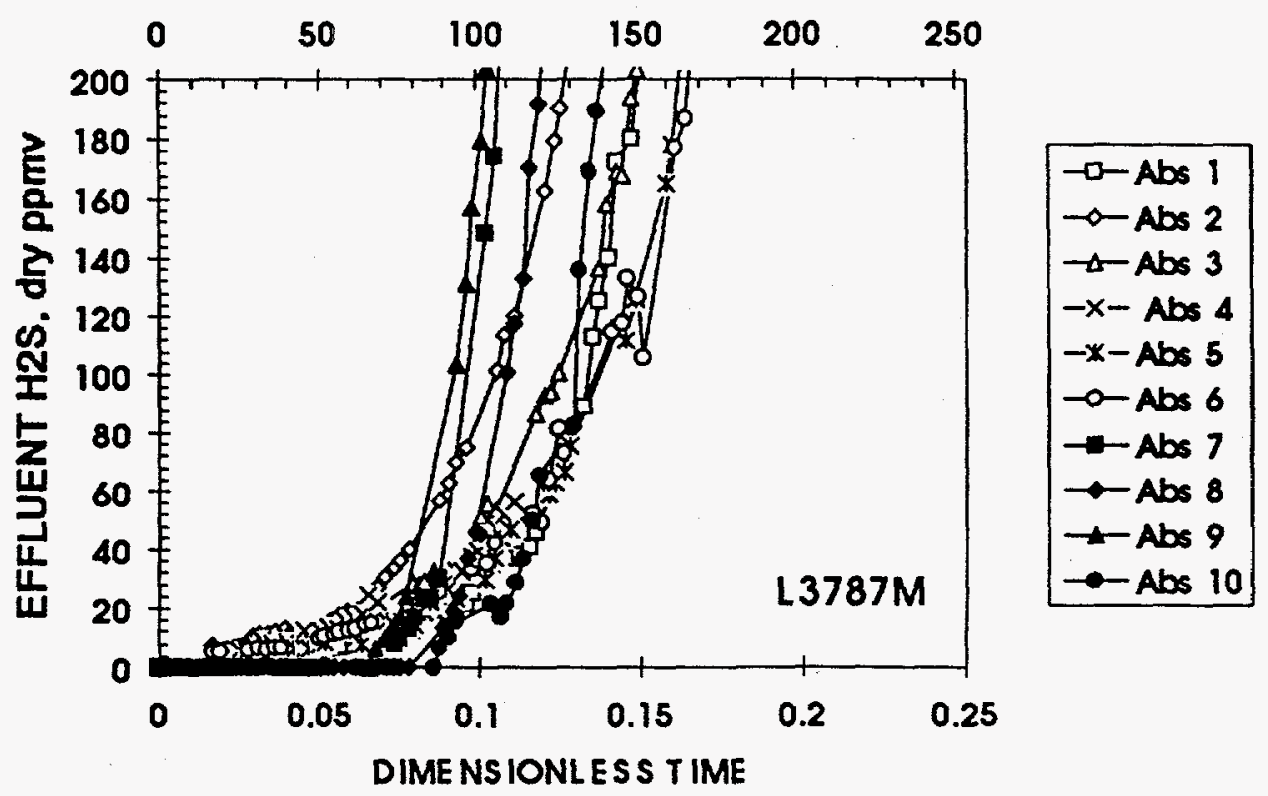

Figure 5 Breakthrough curves of L-3787M

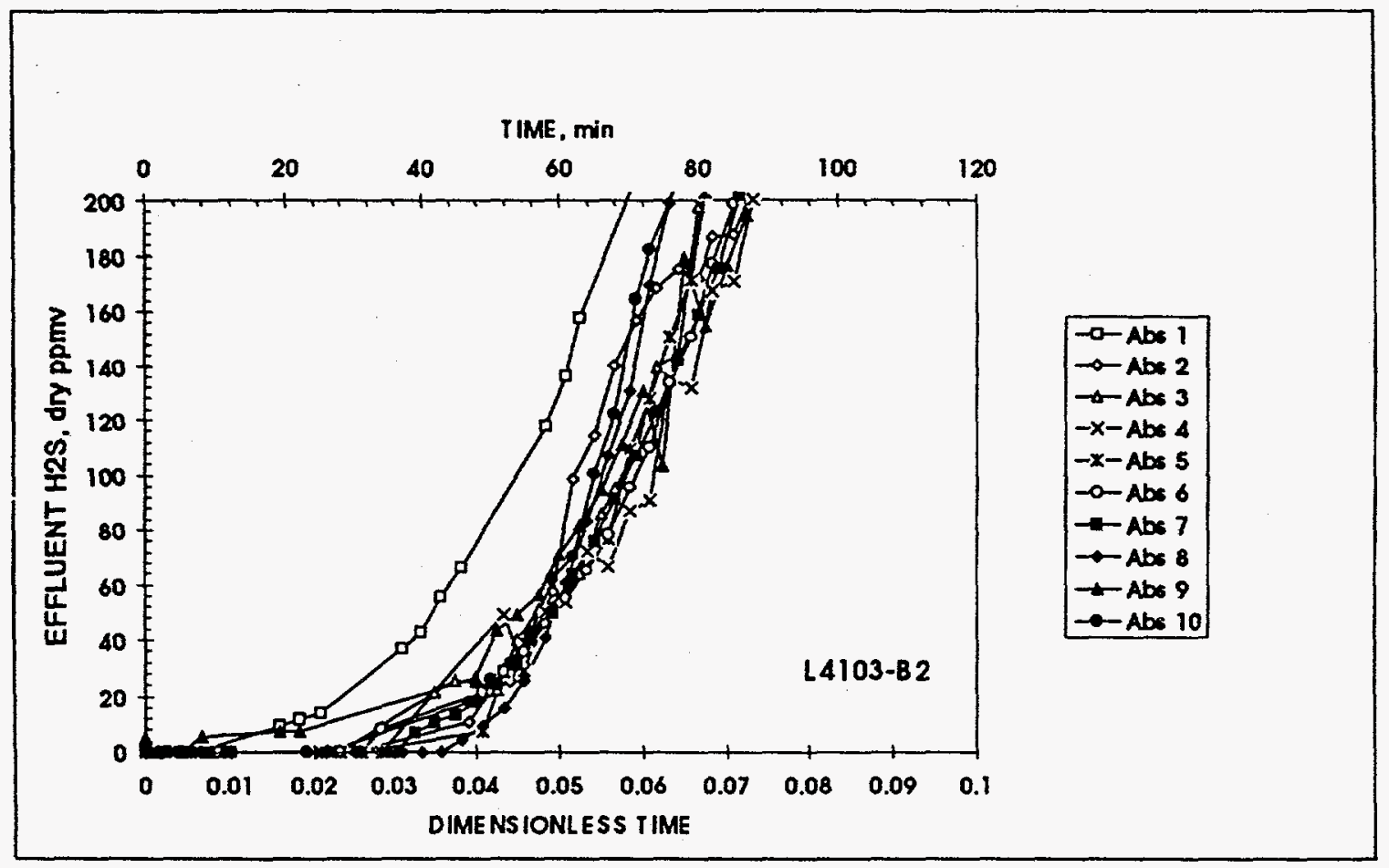

Figure 6.- Breakthrough curves for L4103-B2 sorbents 
Four additional sorbent formulations were also selected for testing under standard 10-cycle tests to assess effect of calcination temperature and effect of calcium sulfate addition:

- L4104-B1 (2:1 $\mathrm{Zn}:$ Ti ratio $+2.5 \% \mathrm{MoO}_{3}+10 \%$ calcium sulfate sorbent calcined at 1500 $\left.{ }^{\circ} \mathrm{F}\right)$

- L4104-B2 (2:1 Zn:Ti ratio $+2.5 \% \mathrm{MoO}_{3}+10 \%$ calcium sulfate sorbent calcined at 1550 $\left.{ }^{\circ} \mathrm{F}\right)$

- L4105-B2 (1.5:1 Zn:Ti ratio $+2.5 \% \mathrm{MoO}_{3}$ sorbent calcined at $\left.1550^{\circ} \mathrm{F}\right)$

- L4106-B1 (1.5:1 $\mathrm{Zn}$ :Ti ratio + 2.5\% $\mathrm{MoO}_{3}+10 \%$ Calcium sulfate sorbent calcined at $\left.1500^{\circ} \mathrm{F}\right)$

These sorbents were sulfided for $2 \mathrm{hr}$. regardless of the time taken for the effluent $\mathrm{H}_{2} \mathrm{~S}$ concentration to reach $200 \mathrm{ppm}$. Samples were removed from the sulfided bed at the 200 ppm breakthrough time and at the $2 \mathrm{hr}$-sulfidation time also. All -B2 sorbents were calcined at $1550^{\circ} \mathrm{F}$, or $50^{\circ} \mathrm{F}$ higher than the $-\mathrm{B} 1$ sorbents.

Figure 7 to Figure 10 present the corresponding breakthrough curves. Formulation L4104-B2, containing calcium sulfate calcined at higher temperature, has the lowest capacity and the 200 ppmv breakthrough occurs much earlier than in the other formulations. When the Option 3 sorbents were taken out of the reactor vessels, L4103-B2 showed signs of spalling at the gas inlet location while L-3787M and L4104-B2 did not. Two potential reasons can explain this observation:

1. The level of sulfidation or composition influences the strength of the formulations (from a comparison of Option 3 formulations), or

2. The rounding method and equipment used influences the properties of the resulting formulations (from the comparison of the Option 2 and Option 3 formulations having the same chemical composition).

The dimensionless time for the $200 \mathrm{ppm}$ breakthrough point is seen to be related to the calcination temperature of the sorbent $\left(B 1=1500^{\circ} \mathrm{F}, \mathrm{B} 2=1550^{\circ} \mathrm{F}\right)$ and the resulting pellet porosity. Overall, it appears that the porosity is the major driver for the differences in reactivity in relatively fresh sorbents, rather than the addition of calcium sulfate. 


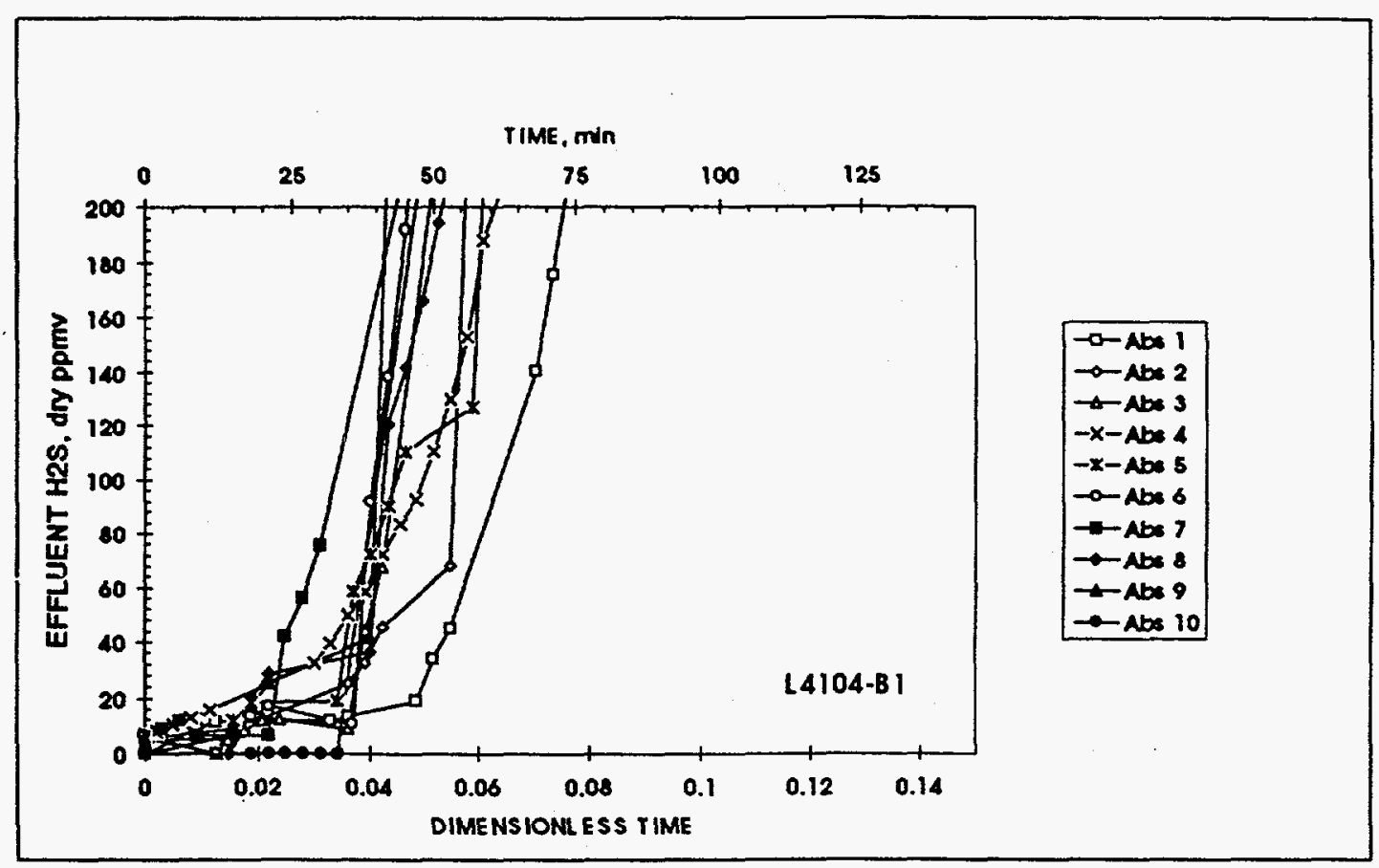

Figure 7.- Breakthrough curves for L4104-B1 (10\% Ca sulfate) sorbent

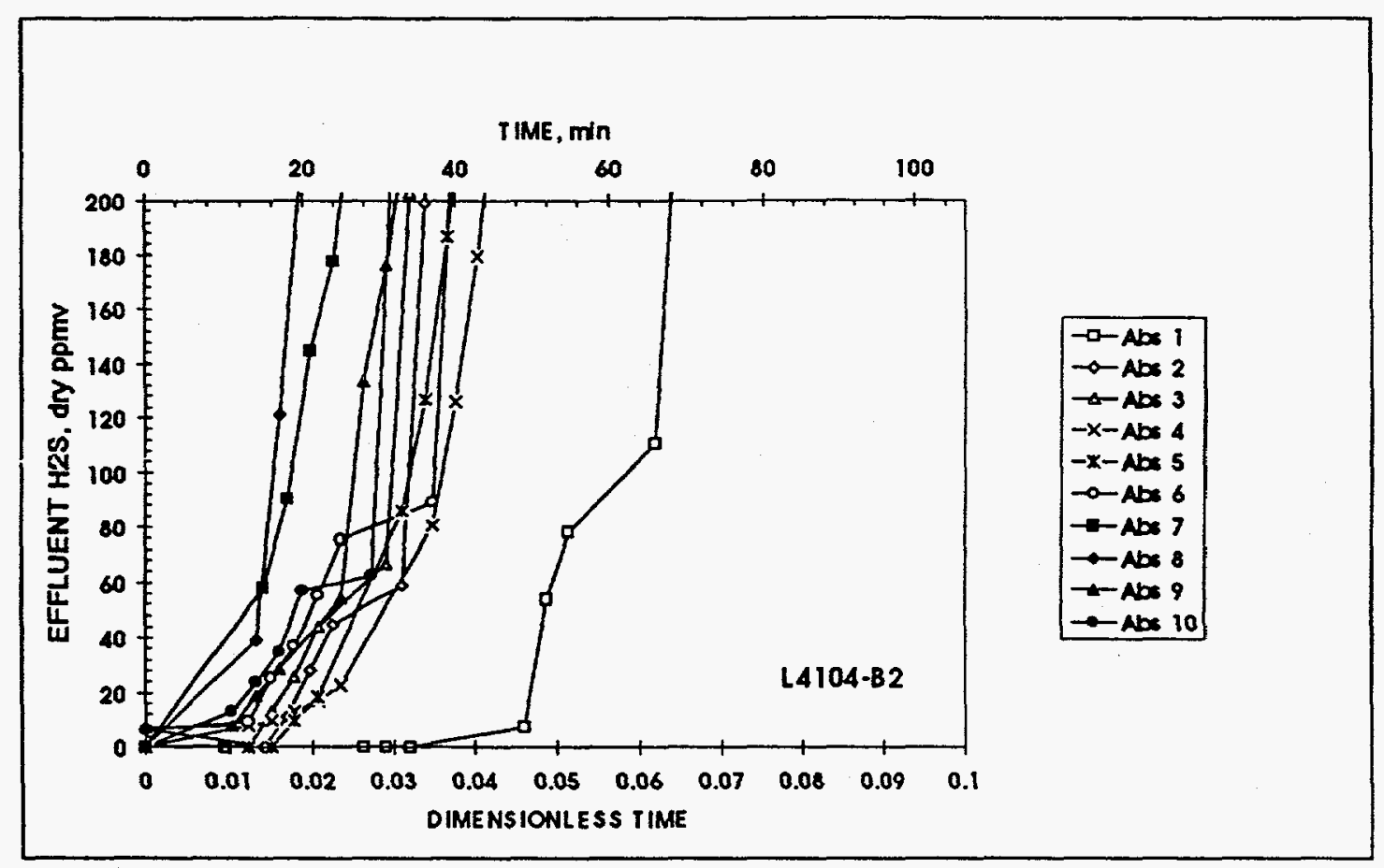

Figure 8.- B reakthrough curves for L4104-B2 (10\% Ca sulfate) sorbent 


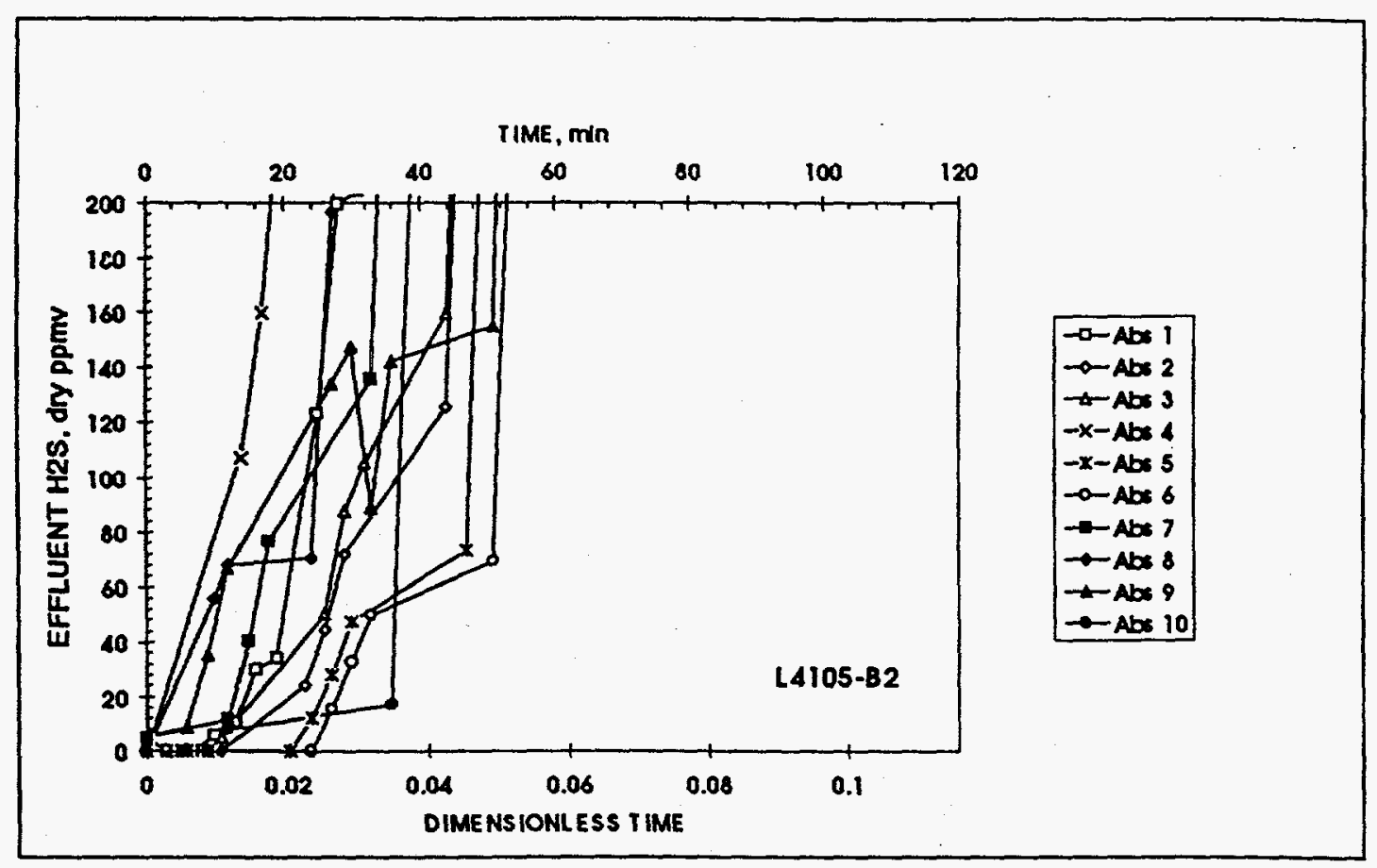

Figure 9.- Breakthrough curves for L4105-B2

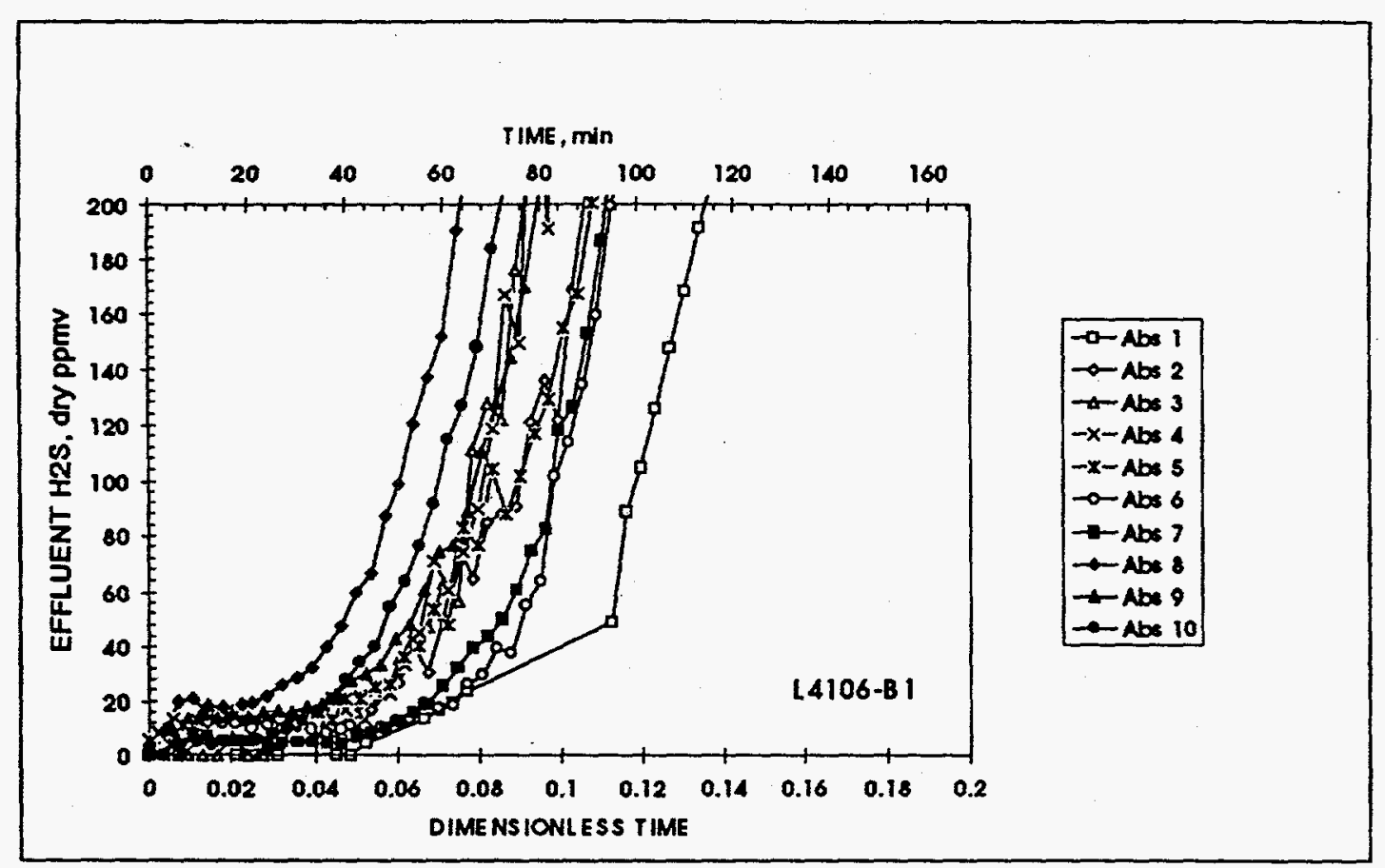

Figure 10.- Breakthrough curves for L4106-B1 (10\% Ca sulfate) 


\subsubsection{Sulfur analysis of cycled samples}

Chemical analyses for sulfur loadings of bench-scale sorbents were tabulated (Table 6). The sulfur measurements were done on samples removed after two hours of sulfidation (i.e., exposure to $\mathrm{H}_{2} \mathrm{~S}$ was done for a fixed length of time regardless of outlet $\mathrm{H}_{2} \mathrm{~S}$ ). The measured sulfur loadings at the gas inlet location were between 14 and $24 \%$ of the theoretical capacity, and this measured value will, of course, depend on the chosen exposure time of the sorbents to the coal gas. Comparable sulfur loadings were obtained when pellets were exposed for longer times and higher total pressures/lower $\mathrm{H}_{2} \mathrm{~S}$ fractional compositions in the simulated coal gases so that the $\mathrm{H}_{2} \mathrm{~S}$ partial pressures were roughly the same.

Table 6.- Sulfur loading on samples removed from the bench reactor system

\begin{tabular}{lccc}
\hline Sorbent & $\begin{array}{c}\text { \% S in } \\
\text { Sulfided } \\
\text { Pellet }\end{array}$ & $\begin{array}{c}\text { \% of } \\
\text { Theoretical } \\
\text { Capacity* }\end{array}$ & $\begin{array}{c}\text { Theoretical Capacity } \\
\text { (g S/100 g of } \\
\text { Sorbent) }\end{array}$ \\
\hline L4103-B2-10th Abs. (Gas Inlet) & 5.18 & 23.5 & 25.0 \\
L4103-B2-10th Abs. (Gas & 0.25 & 1.1 & 25.0 \\
Outlet) & & & \\
L4104-B1-10th Abs. (Gas Inlet) & 5.73 & 17.1 & 22.3 \\
L4104-B1-10th Abs. (Gas & 3.85 & 7.6 & 22.3 \\
Outlet) & & & \\
L4104-B2-10th Abs. (Gas Inlet) & 5.06 & 13.7 & 22.3 \\
L4104-B2-10th Abs. (Gas & 2.83 & 0.5 & 22.3 \\
$\begin{array}{l}\text { Outlet) } \\
\text { L4105-B2-10th Abs. (Gas Inlet) }\end{array}$ & 2.96 & 14.7 & 22.5 \\
L4105-B2-10th Abs. (Gas & 0.80 & 4.0 & 22.5 \\
$\begin{array}{l}\text { Outlet) } \\
\text { L4106-B2-10th Abs. (Gas Inlet) }\end{array}$ & 4.93 & 14.3 & 20.1 \\
L4106-B2-10th Abs. (Gas & 3.34 & 2.6 & 20.1 \\
Outlet) & & & \\
* After subtracting background sulfur in sulfur-containing binders (i.e., calcium sulfate)
\end{tabular}

Since several formulations had been doped with calcium sulfate as a binder for added strength, an attempt was made to determine if $\mathrm{SO}_{2}$ was released to the coal gas in greater amounts than in the case of straight zinc titanates. Results are shown in Figure 11.

Formulations L4103 and L4105 do not contain any calcium sulfate binder while formulations L4104 and L4106 contain 10\% calcium sulfate. For all cases of reductive regeneration, when the regenerated sorbent is exposed to clean simulated coal gas (i.e., no $\mathrm{H}_{2} \mathrm{~S}$ ) there is a release of $\mathrm{SO}_{2}$ during the first ten minutes of reductive regeneration. Even though the peak $\mathrm{SO}_{2}$ concentrations were not measured, it appears that the L4104 formulation containing calcium sulfate released the most $\mathrm{SO}_{2}$ from sulfate decomposition. $\mathrm{SO}_{2}$ was measured by either of two instruments: a GC and an IR analyzer. Because of our limitations in the continuous measurement of $\mathrm{SO}_{2}$ above 2000 ppmv, Figure 11 does not give the maximum concentration 
evolved. Our experimental limitations were: (i) the range of $\mathrm{SO}_{2}$ measurement for a continuous IR analyzer was $0-2000 \mathrm{ppm}$ (which is low for the amount evolved), and (ii) the time required for a single $\mathrm{SO}_{2}$ measurement by gas chromatography was at least 7 minutes and did not allow for multiple measurements in the first ten minutes of operation. Sulfatecontaining sorbents appear to evolve higher $\mathrm{SO}_{2}$ levels and to take longer for the $\mathrm{SO}_{2}$ to be reduced to lower base values during reductive regeneration. Since calcium sulfate-containing sorbents had initially smaller MPD's (Table 2), the effect of pore size alone on $\mathrm{SO}_{2}$ evolution could not be separated at this point. No COS levels were monitored by the existing instrumentation.

For all cases shown in Figure 11, $\mathrm{SO}_{2}$ evolution does not occur after 10 minutes, and continuous production of $\mathrm{SO}_{2}$ from calcium sulfate decomposition does not happen.

However, we fear that sulfate accumulation may occur over extended cyclic testing when not all the $\mathrm{SO}_{2}$ is immediately evolved, particularly from small pores. In addition, since sulfate formation/decomposition is driven by the partial pressure of $\mathrm{SO}_{2}$ (in the presence of excess $\mathrm{O}_{2}$ ) in the gas, it is not unrealistic to assume that some reduction of calcium sulfate may occur, even in amounts too small to measure by solid phase sulfate analysis. For instance, a $0.1 \%$ sulfate sulfur decomposition will release $\mathrm{SO}_{2}$ during reductive regeneration to produce several hundred ppm of $\mathrm{SO}_{2}$ and $\mathrm{H}_{2} \mathrm{~S}$ in the clean coal gas.

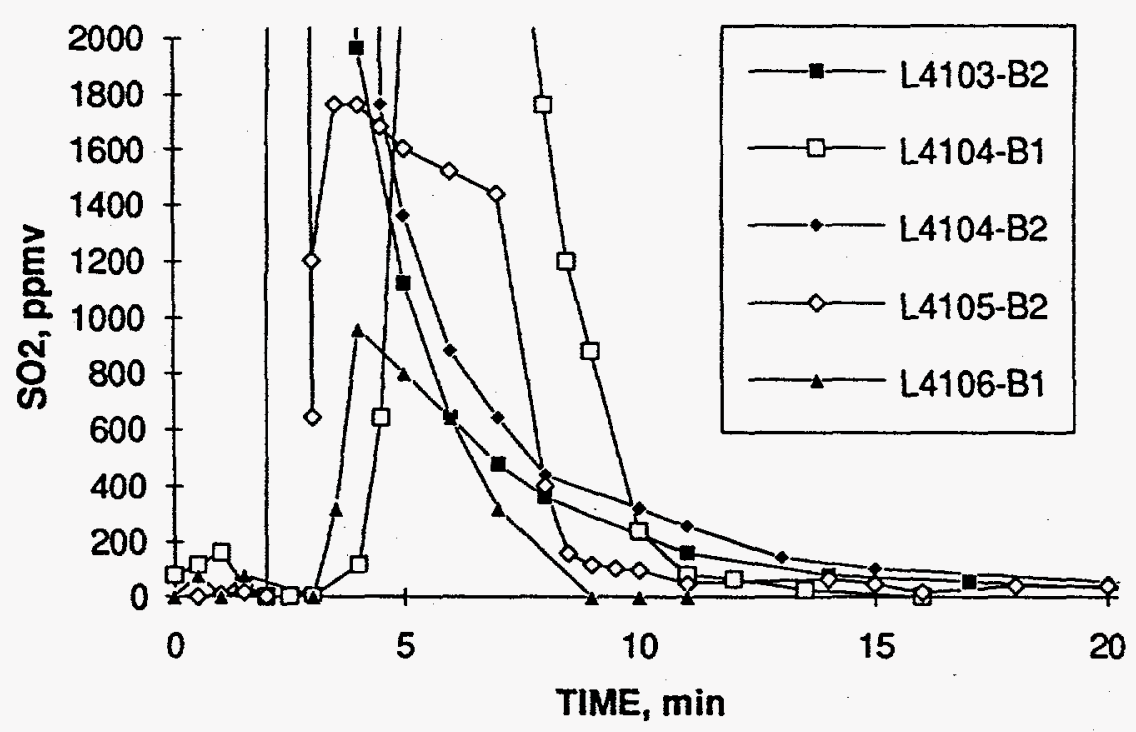

Figure 11.- $\mathrm{SO} 2$ evolution during reductive regeneration of bench sorbents 


\subsubsection{Pellet quality analysis of cycled samples}

At the end of the standard ten-cycle test, each sorbent was removed from the reactor and the pellets assessed for physical appearance (i.e., degree of spalling or cracking). The pellets were classified by size and appearance into whole pellets, aggregates (i.e., broken pellets plus granules greater than 20 mesh or $850 \mu \mathrm{m}$ ), and fines (i.e., dust less than 20 mesh or $850 \mu \mathrm{m}$ ). Our definition of fines corresponds to the ASTM definition of "loss on attrition" for catalyst and catalyst carriers according to the ASTM test D4058-81.

The results are summarized in Figure 12, where the percentage of whole pellets is shown on the left $y$ axis and the corresponding amount of aggregates and fines are presented on the right $y$ axis. The total of whole pellets, aggregates and fines adds to $100 \%$.

Formulations with a 2:1 $\mathrm{Zn}$ :Ti ratio and $10 \%$ calcium sulfate (i.e., formulations L4104-B1 and L4104-B2) had the lowest amounts of aggregates (less than $0.1 \%$ ) and virtually no fines (less than $0.01 \%$ ), suggesting that this combination of $\mathrm{Zn}$ :Ti ratio, molybdenum, and calcium sulfate produced formulations that had higher durability than the other chemical compositions tested. Formulation L4106-B1 had also $10 \%$ calcium sulfate but only a $1.5 \mathrm{Zn}$ :Ti ratio and showed one order of magnitude $(\sim 1 \%)$ more aggregates than the L4104 series. Formulation L4103-B2 has the same chemical composition as the baseline material and exhibited the higher percentages of aggregates and fines of all five.

Since the sulfur loadings on the bench sorbents were comparable (Table 6), as shown in Figure 12 addition of $10 \%$ calcium sulfate to the $2: 1$ zinc titanate was beneficial for maintaining pellet integrity. However, this beneficial effect has to be weighed against the lower reactivity (as measured by breakthrough curves) and $\mathrm{SO}_{2}$ evolution during reductive regeneration (as shown in Figure 11). 


\section{PELLET SIZE DISTRIBUTION OF 10-CYCLE SORBENTS}

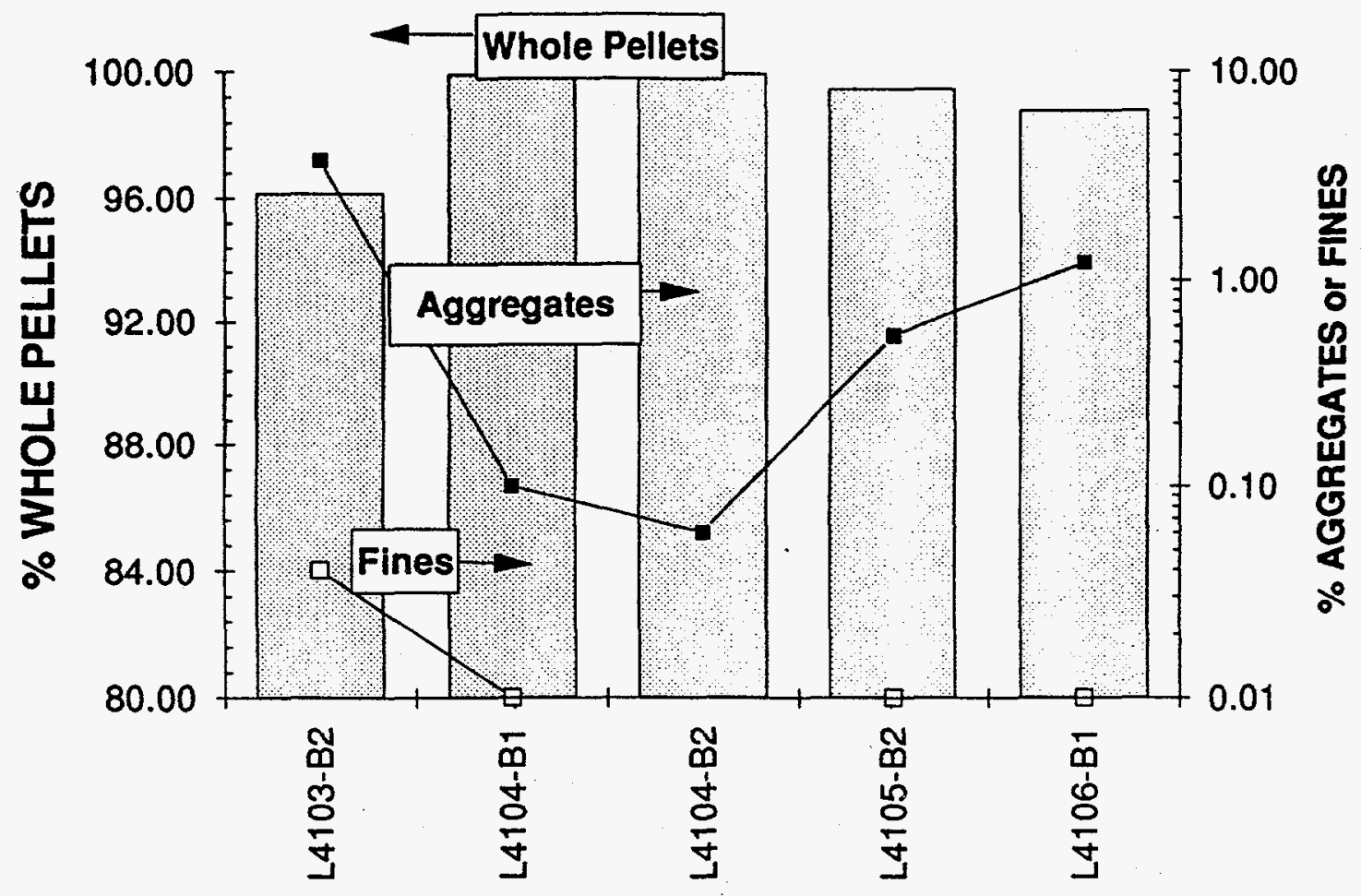

Figure 12.-Pellet Size Distribution of 10-Cycle Sorbents

\subsubsection{Pore size distribution analysis of cycled samples}

Having the results of chemical performance and pellet quality for physical deterioration, the next property needed for complete analysis was the pellet internal pore size distribution, which controls both the pellet strength and reactivity.

Analysis of pore structure characteristics of the first two sample formulations tested in the bench-scale reactor during previous months was performed. Figure 13 shows the variations in pore size distribution of the fresh $\mathrm{L} 4103$ sorbent formulation with respect to calcination temperature. The suffix $\mathrm{B} 1, \mathrm{~B} 2$, and $\mathrm{B} 3$, refer to the three calcination temperatures of $1500^{\circ} \mathrm{F}, 1550^{\circ} \mathrm{F}$, and $1600^{\circ} \mathrm{F}$. As the calcination temperature increases the relative proportion of the most likely pore size and the pores at the median pore diameter decreases. Similar behavior is observed for all formulations as the calcination temperature increases. As it 
Table 7.- Pore size analysis of sorbents cycled in the bench reactor

\begin{tabular}{lcccc}
\hline & $\begin{array}{l}\text { Fresh } \\
\text { (UCI) }\end{array}$ & $\begin{array}{l}\text { 10th Absorption } \\
\text { Gas Inlet: } \\
\text { 200-ppm point }\end{array}$ & $\begin{array}{l}\text { 10th Absorption } \\
\text { Gas inlet: } \\
\text { after 2-hr }\end{array}$ & $\begin{array}{l}\text { 10th } \\
\text { Regeneration: } \\
\text { Gas Inlet }\end{array}$ \\
\hline L4103-B2: & & & & \\
MPD, $\mu \mathrm{m}$ & 1.255 & 1.3176 & 1.1387 & 1.431 \\
SFV, cc/g & 0.094 & 0.135 & 0.130 & 0.167 \\
\hline L4104-B2: & & & & \\
MPD, $\mu \mathrm{m}$ & 0.827 & 1.0458 & 0.968 & 0.944 \\
SPV, cc/g & 0.149 & 0.114 & 0.098 & 0.124 \\
\hline
\end{tabular}

MPD: median pore diameter, SPV: specific pore volume.

has been shown in the past, this effect results in a lower chemical reactivity but added mechanical strength.

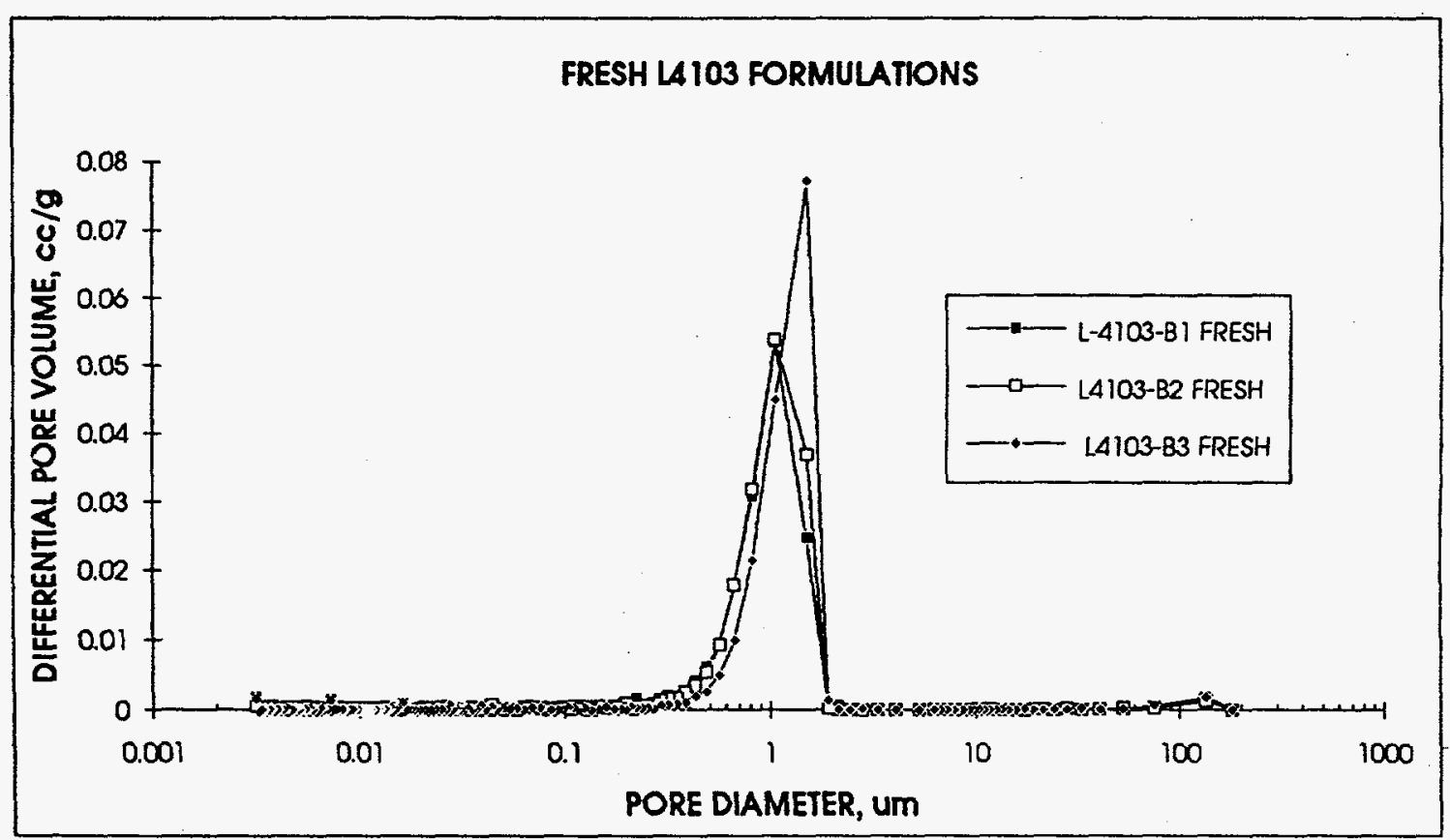

Figure 13.- Pore Size Distribution of 10-Cycle Sorbents

Samples removed from the reactor at the 200-ppm breakthrough point and at the 2-hr absorption point were analyzed for pore size distributions. Table 7 shows the results.

Formulation L4103-B2 is the equivalent formulation of the previously tested L-3787M (prepared under the Option 2 program) and exhibited some degree of spalling at the gas inlet 
location. The median pore diameter, MPD, and the specific pore volume have both increased, probably as a result of fissures formed during testing that ultimately become cracks where the pellet spalls. Formulation L4104-B2, containing additional 10\% calcium sulfate, also increased in MPD, probably as a result of small pores retaining sulfate, but the specific pore volume, SPV, did not increase after ten cycles. This formulation did not exhibit signs of spalling or formation of cracks, as determined by the SPV measurements.

Samples removed from the reactor at the 200-ppm breakthrough point and at the 2-hr absorption point were analyzed for pore size distributions. Figure 14 and Figure 15 show the results of the pore size distribution of $\mathrm{L} 4103-\mathrm{B} 2$ and $\mathrm{L} 4104-\mathrm{B} 2$ (i.e., with $10 \% \mathrm{CaSO}_{4}$ ). Figure 14 shows the results for $\mathrm{L} 4103-\mathrm{B} 2$, where the fresh material has a median pore diameter of $0.9133 \mu \mathrm{m}$ that increases to $1.3176 \mu \mathrm{m}$ at the end of the 200-ppmv breakthrough time and becomes $1.1387 \mu \mathrm{m}$ after the longer $2 \mathrm{hr}$-absorption time. The corresponding specific pore volume decreases from $0.18 \mathrm{cc} / \mathrm{g}$ (fresh) to $0.135 \mathrm{cc} / \mathrm{g}$ (200-ppmv absorption) to $0.130 \mathrm{cc} / \mathrm{g}$ (2-hr absorption). The corresponding pore size distributions for fresh and 10th regeneration materials are shown at the bottom of the same figure and show that, probably as a result of the production of aggregates (i.e., spalling), the distribution of pores for the regenerated sorbent has higher porosity (i.e., higher median pore size and higher total void volume per gram). 

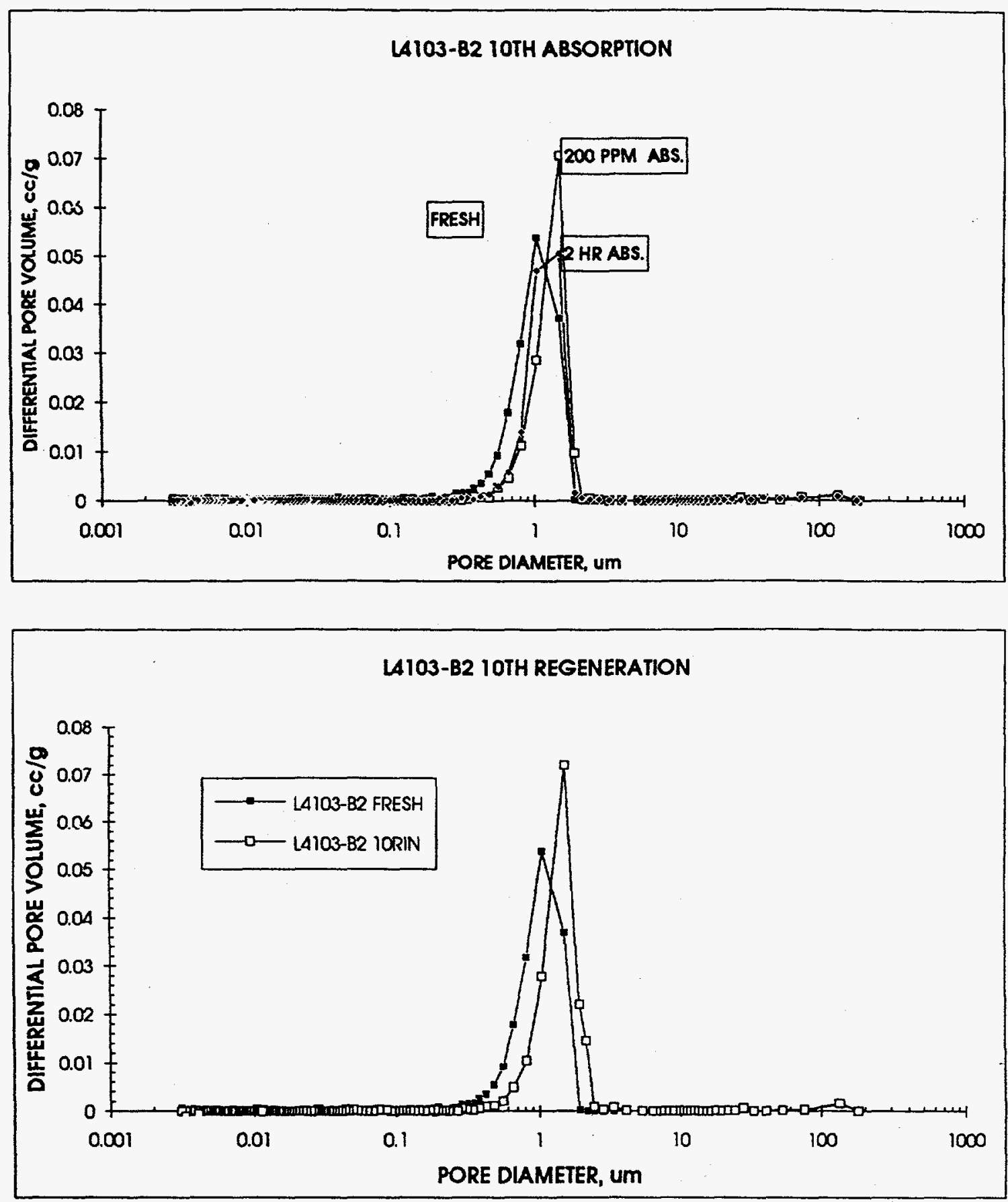

Figure 14.- Pore Size Distribution of L4103-B2 Sorbent 
The equivalent pore size distributions for L4104-B2 (containing 10\% calcium sulfate) are shown in Figure 15. This material exhibited the lowest degree of spalling after the 10 cycles. Again, the magnitude of the most-likely pore size decreases as sulfidation proceeds (top figure) and no new pore volume is created during regeneration. In fact, the material has become denser, as shown by the lower pore volume under the curve. Heavy spalling is typically associated by an increase in specific pore volume due to crack and crevice formation. In conclusion, SPV and MPD are good indicators of the degree of pellet deterioration and vary as the degree of cracking occurs in regenerated sorbents. 

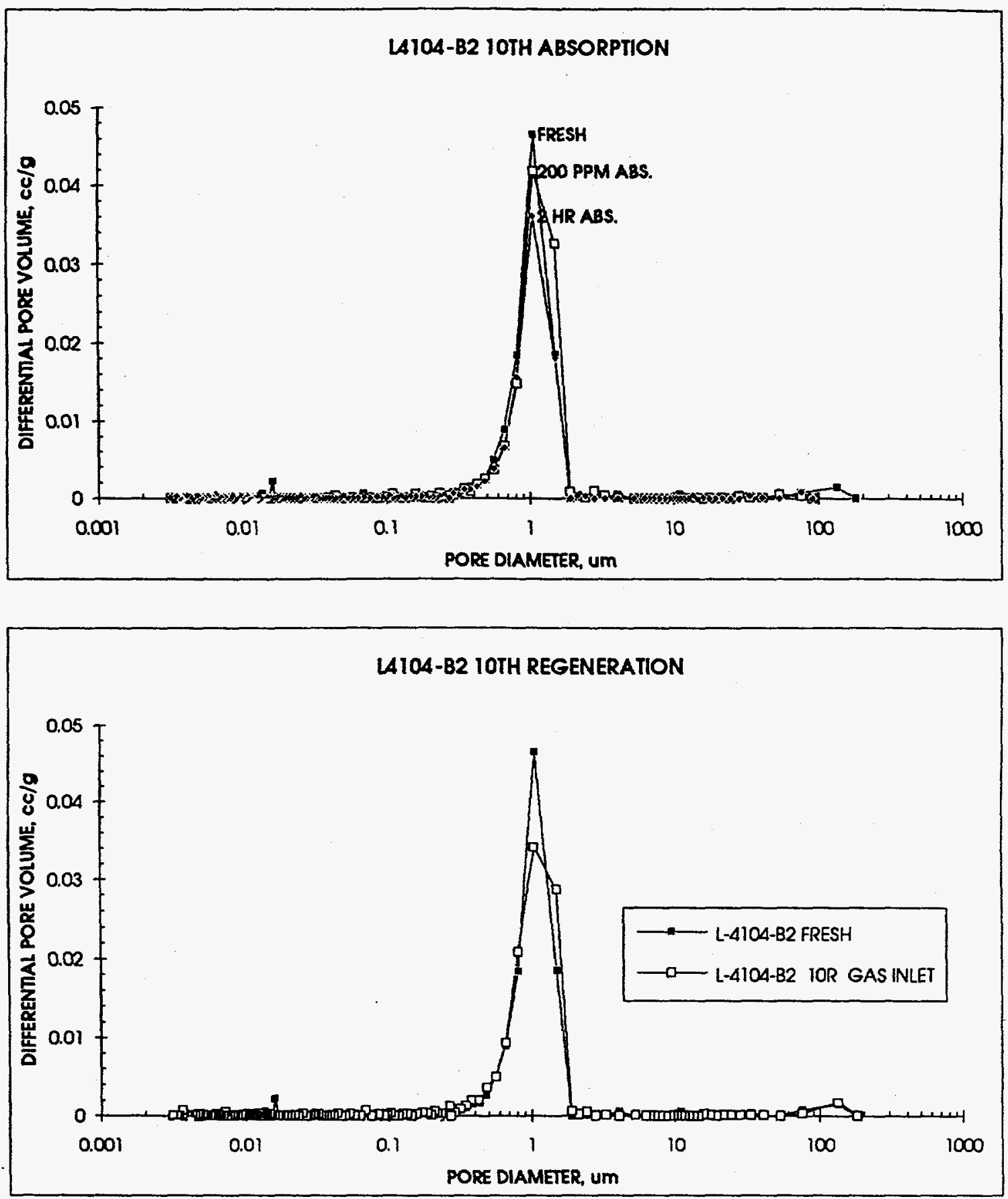

Figure 15.- Pore Size Distribution of L4104-B2 Sorbent 


\subsubsection{Accelerated Sulfidation/Regeneration Tests in Bench Reactor}

In general, higher levels of spalling and pellet cracking are observed usually at the gas inlet location of the fixed-bed laboratory reactor. At this location, the sorbent experiences higher levels of sulfur loading, and sees higher $\mathrm{O}_{2}$ and $\mathrm{SO}_{2}$ concentrations simultaneously with higher temperatures (due to the exothermic nature of the oxidation reactions). Pore size distribution changes usually result from some degree of spalling cracking, spalling, or accumulation of sulfur species in the pellet. These observations prompted us to investigate further the effect of sulfidation/regeneration level on sorbent durability. The tests were conducted as a series of multicycle accelerated sulfidation/regeneration tests in the bench reactor system for three formulations. The accelerated sulfidation/regeneration tests consist of five cycles under standard conditions ( $800 \mathrm{ml}$ of sorbent, $1 \% \mathrm{H}_{2} \mathrm{~S}$ in the simulated coal gas, and $2 \mathrm{hr}$ sulfidation time), followed by three cycles of accelerated sulfidation/sulfate formation using $3.3 \% \mathrm{H}_{2} \mathrm{~S}$ (sulfidation) and various conditions of regeneration with and without $\mathrm{SO}_{2}$ present in the inlet feed gas (Table 8). It was suspected that the simultaneous presence of $\mathrm{SO}_{2}$ and $\mathrm{O}_{2}$ exacerbate the formation of zinc sulfate and promote pellet cracking in weak/soft materials or promote pore closure in strong, non-brittle materials. The complete set of conditions was described in detail in Section 3.2.1 Bench Reactor Test Conditions.

Table 8.- Regeneration conditions for accelerated bench tests

\begin{tabular}{lll}
\hline Cycle Number: & \multicolumn{1}{c}{ Regeneration gas } & $\begin{array}{c}\text { Regeneration } \\
\text { Temperature }\end{array}$ \\
\hline $1-5$ & $0.5-21 \% \mathrm{O}_{2}$, bal. $\mathrm{N}_{2}$ & $1000-1300{ }^{\circ} \mathrm{F}$ \\
$6-8$ & $0.5-21 \% \mathrm{O}_{2}, 5 \% \mathrm{SO}_{2}$, bal. $\mathrm{N}_{2}$ & $1000-1300^{\circ} \mathrm{F}$ \\
$8+\left(1400^{\circ} \mathrm{F} / 2 \mathrm{hr}.\right)$ & $20 \% \mathrm{O}_{2}, 5 \% \mathrm{SO}_{2}$, bal. $\mathrm{N}_{2}$ & $1400^{\circ} \mathrm{F}$ \\
\hline
\end{tabular}

The accelerated tests were also performed with absorption at $1000^{\circ} \mathrm{F}$ but for three hours and at a higher $\mathrm{H}_{2} \mathrm{~S}$ concentration (3.8\%). These tests introduced a total amount of $\mathrm{H}_{2} \mathrm{~S}$ over a time equal to about three times that of the standard $2 \mathrm{hr}$ test and equal to that needed for saturation of the entire sorbent bed. The purpose of conducting the accelerated sulfidation test was to determine the combined effect of higher sulfur loading and regeneration below $1300^{\circ} \mathrm{F}$ without the final regeneration step at $1400^{\circ} \mathrm{F}$ where thermal decomposition of zinc sulfate may occur.

The initial intent of the accelerated absorption/regeneration bench tests was to conduct up to 10 cycles to force premature weakening of the sorbent by cracking or spalling. However, as will be presented below, the level of spalling observed at the $8+$ cycle was significant and occurred over a few hours that it was decided at that point to characterize the material by means of the routine destructive tests (e.g., attrition and crush strength), rather than continuing testing until the 10 th cycle. 


\subsubsection{Mechanical and Chemical Characterization}

Samples were collected after $3,5,8$, and $8+$ cycles and subjected to the usual characterization tests.

\section{3-Cycle characterization}

Analyses are divided into mechanical (morphological) properties and chemical composition Figure 16 shows the comparison of the amounts of aggregates (i.e., cracked and broken pellets) and fines collected after the first three cycles of accelerated sulfidation tests and the standard 10-cycle tests.

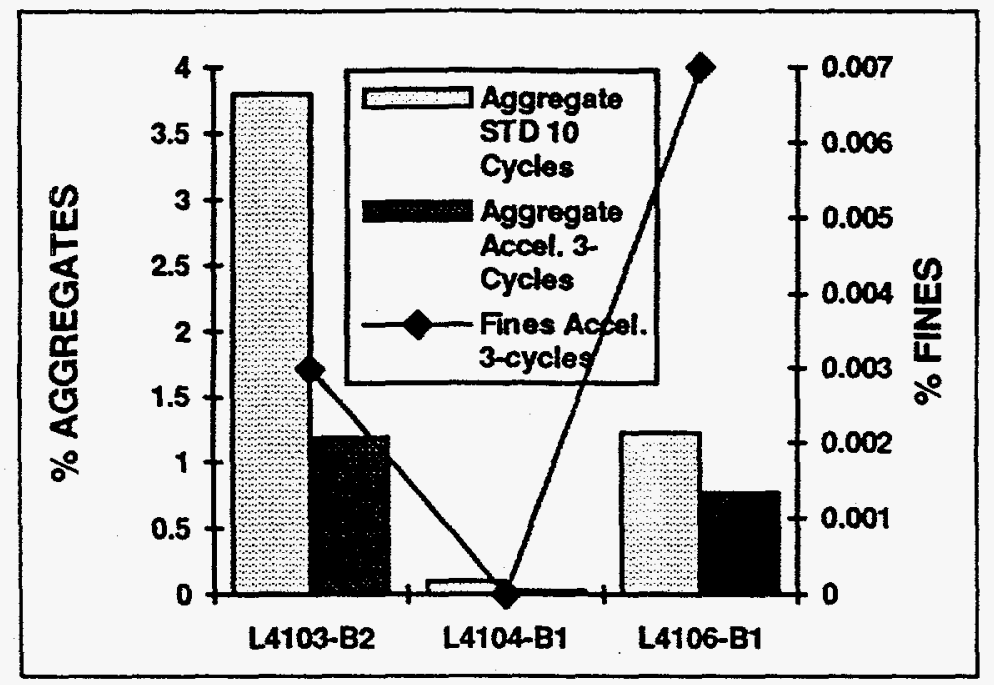

Figure 16.- Results of the accelerated sulfidation tests after 3 cycles

The level of aggregates and fines obtained after three cycles for the three sorbents is at least one third of that obtained after 10 cycles of the standard test suggesting the two tests should yield the same results if the rate of spalling is linear with time and the conditions throughout the 10 cycles were the same. Under optimistic conditions, no difference in total aggregate and fines generation would be obtained at the end of 10 cycles. However, pellet degradation would be expected to get worse, in general, as time progresses for the accelerated tests.

\section{5-Cycle characterization}

Before starting cycling the sorbents under $\mathrm{SO}_{2}$-containing regeneration gases (cycle 6 and beyond), it was decided to characterize one of them (LA103-B2) for chemical (sulfur loading) and mechanical (attrition and crush strength) properties (Table 9). Several conclusions can be drawn from Table 9: 
- Zinc titanate does not catalyze the formation of carbon (coking) at $20 \% \mathrm{H}_{2} \mathrm{O}$ in the coal gas, based on the low carbon contents in the 5th absorption samples.

- Sulfur loadings were as expected ( $>6 \%$ wt. sulfur) which correspond to $25-33 \%$ of theoretical loading for zinc titanate.

- In the absence of added $\mathrm{SO}_{2}$ during regeneration, the amounts of sulfate found in both samples are small despite the lower regeneration temperatures $\left(1200-1350^{\circ} \mathrm{F}\right)$ to which the sorbents were exposed.

- The mechanical durability of the sorbents either remained constant or increased with respect to the fresh materials.

Given the positive results obtained, the testing continued with the addition of $\mathrm{SO}_{2}$ to the feed gas to study the effect of sulfate formation on mechanical durability.

Table 9.- Chemical and Mechanical Properties of 5-Cycle Zinc Titanate

\begin{tabular}{|l|c|c|}
\hline & \multicolumn{2}{|c|}{ L-4103-B2 } \\
\hline & 5th. Absorption & 5th. Regeneration \\
\hline \% Carbon: & & \\
Gas inlet & 0.14 & 0.14 \\
Gas Outlet & 0.18 & 0.13 \\
\hline \% Total Sulfur: & & \\
Gas inlet & 8.87 & 1.41 \\
Gas Outlet & 6.03 & 0.76 \\
\hline \% Sulfate: & & \\
Gas inlet & & 0.15 \\
Gas Outlet & & 0.12 \\
\hline \% Attrition Resist: & & \\
Fresh & & 96.3 \\
Gas inlet & & 96.41 \\
Gas Outlet & & 96.18 \\
\hline Crush Strength, & & \\
lb/pellet: & & 19.1 \\
Fresh & & 28.0 \\
Gas inlet & & 27.4 \\
Gas Outlet & & \\
\hline
\end{tabular}

\section{6-Cycle Characterization}

After six cycles of accelerated sulfidation test the reactor was opened again and pellets were analyzed for spalling; the results of six cycles were compared with previous results after three cycles (Table 10). Formulations containing calcium sulfate showed a lesser degree of aggregate formation. For all three sorbent formulations being tested, the degree of aggregate 
formation decreased as the number of cycles increased (i.e., more attrition was observed in the first three cycles than in the subsequent three); this was an unexpected result since one could think that as pellets had spalling in the first few cycles, the rate of deterioration would only worsen. An initial higher degree of spalling occurs during the first three cycles, and then the pellets deteriorate to a lesser rate thereafter. This observation can be explained in the following fashion. If the population of fresh pellets has a fraction of them that are flawed or weak, one would expect that once the weak pellets have cracked the remaining pellets are stronger as a group than the original pellet population. Of course, this result only applies for the two-hour accelerated sulfidation where the sulfur loading was less than $25 \%$ of the theoretical. It also appears that increasing the $\mathrm{H}_{2} \mathrm{~S}$ concentration at constant on-line time (2 $\mathrm{hr}$ ) does not result in increasing degree of spalling nor does it result in a significantly much higher level of sulfidation at the gas inlet.

Table 10.- Comparison of degrees of spalling after 6 cycles of accelerated bench tests

\begin{tabular}{lccc}
\hline Sorbent & $\begin{array}{c}\text { Differential } \\
\text { Aggregates } \\
\text { (3 Cycles), \% }\end{array}$ & $\begin{array}{c}\text { Differential } \\
\text { Aggregates } \\
\text { (6 Cycles), \% }\end{array}$ & $\begin{array}{c}\text { Cumulative } \\
\text { Aggregates } \\
\text { (6 cycles), \% }\end{array}$ \\
\hline L4103-B2 & 1.18 & 1.09 & 2.26 \\
L4104-B1 & 0.03 & -0 & 0.03 \\
L4106-B1 & 0.76 & 0.24 & 1.00 \\
\hline
\end{tabular}

The percentage of aggregates in each case represents the incremental percentage of the mass at the end of each period that was removed as spalled, or broken pellets. The cumulative percentage of aggregates or broken pellets can be calculated from the addition of the incremental values adjusted by the amounts of material that were taken for analysis at intermediate points. These amounts of broken pellets are relative small. It is worth noting that the amount of aggregates or broken pellets observed here is not necessary bad for moving-bed systems, as long as the aggregates are large enough to be recirculated and reused again for additional absorption and regeneration cycles. Only when the broken pellets are small enough (i.c., approaching dust or $<20$ mesh) that the screening removes them from the system at each cycle do they represent a sorbent loss to the system.

\section{$8+$ cycle characterization}

A comparison of the levels of sulfate found in the L4103-B2 pellets is also shown in Table 11. No measurements of sulfate are presented here on the calcium sulfate-containing sorbents because the variability of the baseline sulfate $(10 \%)$ in the fresh sorbent was higher than the differences in sulfate that we were trying to measure in the cycled sorbent, especially after five cycles. In addition, transformation of $\mathrm{CaSO}_{4}$ to $\mathrm{CaS}$ would also affect the conclusions on sulfate accumulation. 
Table 11.- Sulfate levels and other characteristics of the cycled L4103-B2 zinc titanate

\begin{tabular}{clll}
\hline & $\begin{array}{c}\text { After 5th } \\
\text { Regeneration } \\
\left(\text { No } \mathrm{SO}_{2}\right)\end{array}$ & \multicolumn{1}{c}{$\begin{array}{c}\text { After 8th } \\
\text { Regeneration } \\
\left(\mathrm{T}<1300^{\circ} \mathrm{F}\right)\end{array}$} & $\begin{array}{c}\text { After 8th. } \\
\text { Regeneration } \\
\left(\mathrm{T}=1400^{\circ} \mathrm{F} / 2 \mathrm{hr} \text { ) }\right.\end{array}$ \\
\hline \% Sulfide & $\sim 0$ & $<0.2$ & 0 \\
\% Sulfate & 0.15 & 1.9 & 3.9 \\
$\begin{array}{c}\text { Pellet color } \\
\text { white }\end{array}$ & $\begin{array}{l}\text { gray } \\
\text { none }\end{array}$ & $\begin{array}{l}\text { light gray/yellow } \\
\text { more than 40\% }\end{array}$ \\
$\begin{array}{c}\text { Degree of hairline } \\
\text { cracking }\end{array}$ & none & 1.04 & 3.52 \\
$\begin{array}{c}\text { \% Aggregates } \\
\text { (incremental) }\end{array}$ & 2.77 & 1.04 & \\
\hline
\end{tabular}

The levels of sulfate were higher with the pellets exposed to $1400^{\circ} \mathrm{F}$ at high $\mathrm{SO}_{2}$ and high $\mathrm{O}_{2}$ concentrations. This result confirms the suspicion that the final step in regeneration in should not be include pure air at $1400^{\circ} \mathrm{F}$ if $\mathrm{SO}_{2}$ is still present.

The atmospheric tests were conducted with and without $\mathrm{SO}_{2}$ in the regenerant gas, and with and without a temperature ramp to $1400^{\circ} \mathrm{F}$. All zinc titanates performed very well in the first five cycles when the temperature was held below $1300^{\circ} \mathrm{F}$ during regeneration, even in the presence of $21 \% \mathrm{O}_{2}$, but with no $\mathrm{SO}_{2}$ added. The sorbents also performed well up to the eighth cycle when the $5 \% \mathrm{SO}_{2}$ was introduced and the temperature was also maintained below $1300^{\circ} \mathrm{F}$ during regeneration. No signs of spalling were observed except for a few pellets. On the other hand, when the temperature was increased to $1400^{\circ} \mathrm{F}$ after the 8 th cycle with pure air and $5 \% \mathrm{SO}_{2}$ flowing, the zinc titanate underwent a significant level of decrepitation and spalling. The amount of sulfate doubled with the $2-\mathrm{hr} 1400^{\circ} \mathrm{F}$ exposure, all else being equal. This observation suggests that the final regeneration should be done more carefully under $\mathrm{O}_{2}$ /high temperature conditions when $\mathrm{SO}_{2}$ is present.

The overall conclusion regarding mechanical strength during accelerated bench tests is that there was very little pellet mechanical degradation in the first five cycles, and this stability appears to be a result of the absence of $\mathrm{SO}_{2}$ in the regenerating gas and the absence of formation of significant amounts of zinc sulfate. Cycles 6-8 (regeneration below $1300^{\circ} \mathrm{F}$ under $5 \% \mathrm{SO}_{2}$ ) yielded similar results, perhaps some incipient level of degradation of zinc titanate. In contrast, when the 8th cycle was followed by a $2-$ hr period at $1400^{\circ} \mathrm{F}$ and air $\left(20 \% \mathrm{O}_{2}\right)$ the level of spalling and cracking became significant. The results suggests that the level of spalling was exacerbated by the combination of temperature and air in the gas, rather than by the presence of $\mathrm{SO}_{2}$ alone.

3.2.3.2 Correlation of sulfate analyses by TGA reactivity and gravimetric methods 
Figure 17 shows the TGA chemical reactivity of $L 4103$ B2 zinc titanate after the 5 th and 8 th regenerations in the 8-cycle test. The reactivity after the 5th cycle was measured in the condition the sorbents came out from the reactor, i.e., without any sulfate decomposition pretreatment whatsoever prior to TGA. Those after the 8th regeneration were pretreated by a combination of $\mathrm{N}_{2}$ and $\mathrm{O}_{2}$ to attempt to decompose sulfate found on the materials prior to measuring the chemical reactivity.

Pretreatment A was conducted by exposing the pellet to $\mathrm{N}_{2}$ at $1350^{\circ} \mathrm{F}$ for $2.5 \mathrm{hrs}$ to decompose sulfate until the weight stabilized, followed by introduction of $2 \% \mathrm{O}_{2}$ to oxidize any residual sulfide. At this point, the pellet was exposed to the standard simulated coal gases. This reactivity is labeled Reg 8 (PTA) in

Figure 17.

Similar to pretreatment $A$, other pellets taken after the 8th regeneration were subjected to $\mathrm{N}_{2}$ at $1300{ }^{\circ} \mathrm{F}$ for 10 hours, rather than $2 \mathrm{hr}$, followed by $5 \% \mathrm{O}_{2}$ in $\mathrm{N}_{2}$. Again, the purpose was to decompose sulfate under the $\mathrm{N}_{2}$ and oxidize the sulfide under the $\mathrm{O}_{2}$. This procedure is labeled Reg 8 (PTB) in the same figure. The result of using pretreatment A or B was the same in that the reactivity of the pellets was not regained, as it happened with the 5th regeneration case. One possible conclusion is that when large amounts of sulfate are formed in the internal pores of the pellets, the thermal decomposition of sulfate does not occur readily, either because the sulfate is no longer zinc sulfate alone, or there is a capillary vapor pressure equilibrium in the internal pores that slows down the sulfate decomposition (i.e., the Kelvin effect).

Finally, samples after the $8+$ step were also tested for reactivity. The results are also presented in the same

Figure 17. At this point, zinc titanate had suffered from severe spalling and mechanical cracking. The increase in reactivity in zinc titanate is, thus, a result of increased surface area caused by sulfate decomposition and the presence of cracks and spalling. Fast or abrupt sulfate decomposition burst the pellets into pieces, probably as a result of the pressure produced by the $\mathrm{SO}_{2}$ vapor. The behavior of the other two zinc titanates containing calcium sulfate, L4104-B1 and L4106-B1, was similar in terms of gaining back the reactivity, but not as pronounced. Hence the improvement in strength by the presence of the calcium sulfate binder also has a penalty of more difficulty in the decomposition of zinc sulfate.

The main conclusion from this regeneration study is that small amounts of sulfate formed can be tolerated in the pore structure of the pellets, but large or abrupt decomposition results in bursting and spalling of the sorbent pellets. Any selected regeneration scheme has to consider the mechanisms of sulfate formation and decomposition to avoid loss of reactivity or pellet degradation. 


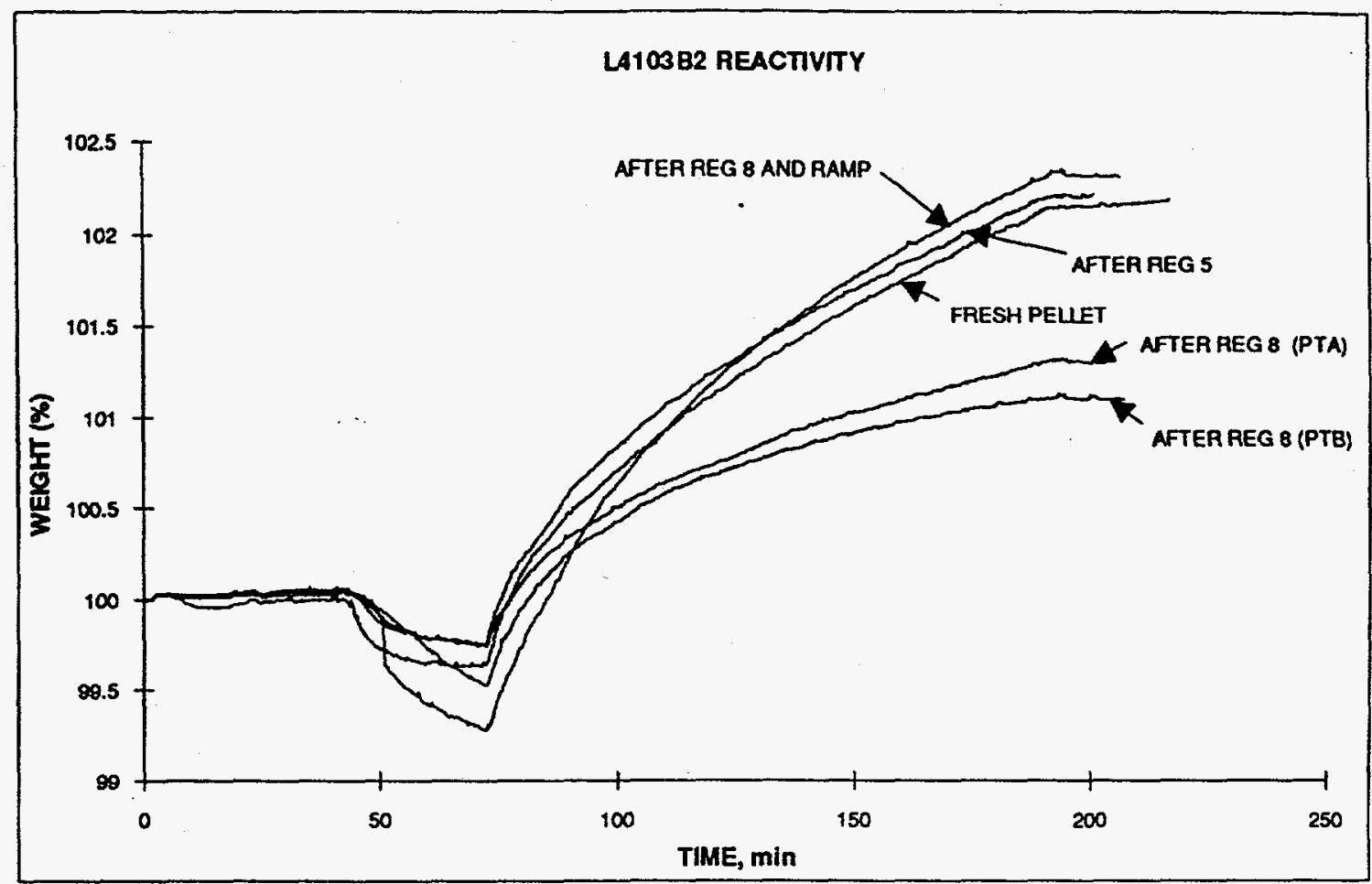

Figure 17.- TGA Chemical Reactivity of Sorbents

Since the presence of zinc sulfate during or after regeneration determines to a large extent the long-term durability of the sorbents, we decided to check the reproducibility of the sulfate analyses on regenerated sorbents by analyzing sulfates by two separate methods: TGA thermal decomposition and the standard ASTM test. The TGA method involves heating the powder under $\mathrm{N}_{2}$ up to $1350^{\circ} \mathrm{F}$ and measuring the weight loss due to sulfate thermal decomposition. The percent weight loss corresponds to 2.5 times the weight percent of sulfate sulfur. The ASTM D-2492 test is a gravimetric test relying on the dissolution and precipitation of sulfate as barium sulfate and was done by Commercial Testing and Engineering in South Holland, Illinois.

The results of sulfate sulfur concentrations on the powdered samples by both methods are shown in Table 12. All samples were taken from the gas inlet location, where the most sulfidation took place, and ground to powder. Note that there is an excellent agreement on sulfate prediction from TGA weight changes. Between the 8th regeneration and the temperature ramp, we took partial samples from the powder batch, ground them, and subjected them to a sulfate decomposition step $\left(\mathrm{N}_{2} @ 1350^{\circ} \mathrm{F}\right.$ for 2.25 hours). The sulfate from powder samples seems to decompose fairly quickly under these conditions. However, we found that sulfate decomposition in a pellet it is not as fast as it is in powdered samples. The slower rate of decomposition is probably a result of the Kelvin effect, where the vapor pressure of the produced $\mathrm{SO}_{2}$ is higher in the pores and the rate of sulfate decomposition is limited to the rate at which $\mathrm{SO}_{2}$ diffuses out of the pores. 
Based on the excellent agreement of sulfate analysis between the two methods, the TGA method for sulfate analysis can be used on zinc titanate for on-line monitoring of GE-CRD pilot plant run regeneration since the method is as accurate on zinc titanate, and the results can be obtained faster than gravimetric methods. The ASTM test, of course, will still be used for post-test correlations and data validation.

Table 12.- Sulfate Analysis of Zinc Titanate

\begin{tabular}{lcc}
\hline & \multicolumn{2}{c}{ L-4103 B2 Zinc Titanate } \\
\hline Cycle Number: & $\begin{array}{c}\text { \% Sulfate S } \\
\text { by TGA }\end{array}$ & $\begin{array}{c}\text { \% Sulfate S } \\
\text { by ASTM } \\
\text { Test }\end{array}$ \\
\hline After 5th Reg. & 0.15 & 0.17 \\
After 8th Reg. & 1.9 & 1.86 \\
After 8th Reg. $+\mathrm{N}_{2} / 1350$ & $\mathrm{NM}$ & 0.01 \\
oF & & \\
After 8th Reg. $+\mathrm{SO}_{2} / \mathrm{Air}$ & 3.9 & 3.56 \\
@ 1400 ${ }^{\circ} \mathrm{F}$ & & \\
\hline n/m: not measured. & &
\end{tabular}

\subsubsection{Modifications of the bench reactor for pressurized operation}

After the 8 cycles of atmospheric testing were completed, the bench reactor system was disassembled to convert it from an atmospheric to a pressurized system capable of operation up to $10 \mathrm{~atm}$. These modifications were performed under Task $19-$ Bench-Scale Modifications and Testing.

After modifications, the system has the capability of doing absorption at 10 atmospheres and regeneration at 7 atmospheres to incorporate high-pressure effects on the sorbent performance. There is no technical advantage at this point in performing the absorption at 20 atm (commercial-scale pressure) instead of the proposed 10 atm since the percent $\mathrm{H}_{2} \mathrm{~S}$ content in the bench-test absorption gas mixture can be held artificially high to simulate an equivalent molar $\mathrm{H}_{2} \mathrm{~S}$ concentration (i.e., partial pressure) to that at $20 \mathrm{~atm}$ while minimizing operating costs. Regeneration will be carried out at approximately 7 atm or less, the current design pressure for regeneration in the moving-bed system at the Tampa Electric Co./Clean Coal Technology Demonstration Program. 


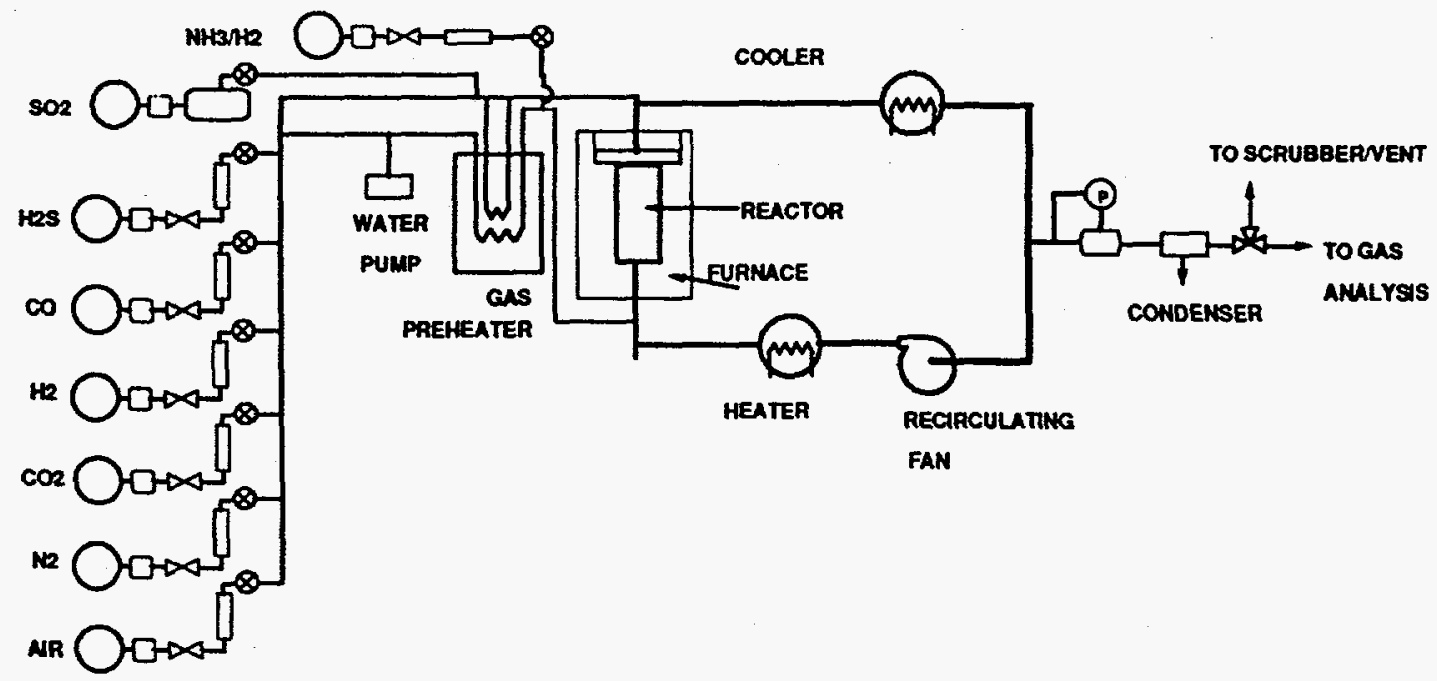

GAS MXJNG MANFOLD

Figure 18.- Schematic Diagram of Bench-Scale Reactor System with Recycle

The procedure to be followed for pressurized operation of the bench reactor was as follows. Gases will be mixed in a manifold and preheated prior to entering the reactor vessel. The gas composition chosen will be that of an oxygen-blown, entrained-flow gasifier (i.e., a Texacotype gas) with a water concentration of (10-20\%) to minimize carbon deposition in the stainless steel pipes. Duration of the absorption and regeneration reactions will be determined by adjusting the sorbent bed volume, the level of sulfur in the absorption gases, or the level of oxygen in the regeneration. A typical absorption test will be accomplished in 1 day while regeneration will be accomplished in approximately 2 days. The gases will enter the reactor and will be recirculated using a gas compressor/pump. The pressure in the system will be controlled by a back-pressure regulator valve. It is estimated that a $95 \%$ recycle of the gases will be more than sufficient for the size and operation of the recycle loop in relation to the sorbent bed in the reactor while maintaining low feed gas usage and low effluent gas treatment.

A major technical advantage of using a recycle loop during regeneration is that allows to monitor the buildup of $\mathrm{SO}_{2}$, chlorides, or any other species that are present on the sorbent bed and which can desorb, evaporate or alter the performance of the sorbent over multiple cycles. In addition, the cost of gases used at pressure is minimized compared with the oncethrough systems, where the total gas flow rate is ten times that of a single once-through reactor. By using a recycle loop at pressure, the make-up feed gas mass flow rate at pressure is only about $25 \%$ of that used in a once-through test at atmospheric conditions.

Some problems were encountered in the operation of the recirculating pump over extended time. The shaft coupling was found to fail after several days of operation. The problem happened at various points where the system pressure was increased to $10 \mathrm{~atm}$. 
A few initial problems were encountered with the operation of the recirculating pump Noise and vibration levels were originally high and prompted us to do several changes in startup/shutdown procedures. After fabrication and installation of a flywheel to counterbalance the vibration and "knocking" of the pump shaft at high pressure/high temperature the operation was smoother. The recirculating pump is a bellows pump capable of handling gas temperatures up to $400^{\circ} \mathrm{F}$ and exceed $10 \mathrm{~atm}$ pressure.

As will be explained in the next section, the pressurized system was used to perform extended multicycle tests on Z-Sorb III@, a proprietary sorbent fabricated by Phillips Petroleum.

The reported vibration problems were again encountered in the extended pressurized operation in addition to encountering failures of the metal bellows within the pump. The bellows system was not very reliable at the temperatures and pressures required to operate. According to the manufacturer, steam condensation within the coal-gas side of the bellows produced a pin-size hole that leaked and prevented the system to achieve full pressure/full flow. A replacement bellows part was procured and the problem fixed temporarily, but the problem persisted during the cyclic testing. To correct the problem, we bought a replacement and modified the pressure casing with heated nitrogen to prevent potential condensation of steam on the coal gas side. The pressurizing $\mathrm{N}_{2}$ source was diverted to the preheater furnace to heat the $\mathrm{N}_{2}$ to $400-500^{\circ} \mathrm{F}$ and then injected into the pressure casing pointing right at the bellows. The flowing $\mathrm{N}_{2}$ keeps the bellows hot and prevents steam condensation on the inner side of the bellows (the coal gas dew point with $20 \%$ steam at 10 atm is $\sim 250^{\circ} \mathrm{F}$ ). Changes were made to the hardware, and testing was resumed. However, because of low reliability in the pump operation, pressurized testing was carried at times under single-pass flow of the gases, thus injecting the desired $5 \% \mathrm{SO}_{2}$ directly into the gas inlet location to mimic recirculation and buildup of $\mathrm{SO}_{2}$ in the regeneration step.

\subsubsection{Kinetics of sulfate formation at pressure}

Zinc titanate sorbent formulations were also tested at pressure both at RTI's high-pressure TGA apparatus and in the GE-CRD refurbished bench-scale reactor, the objective of the pressurized testing is to characterize the sulfate formation kinetics during pressurized regeneration and be able to strengthen the pellet structure against sulfate-induced attrition. Tests at pressure are designed to provide additional data on the sorbent performance at conditions similar to those to be encountered at the Tampa Electric Co.'s Polk Station, where regeneration will be conducted at up to 7 atmospheres. 
For the tests of sulfate formation at pressure, the T-2535M zinc titanate formulation tested at the GE pilot plant during 1993 was used as a basis for comparison. Table 13 shows the physical properties of T-2535M zinc titanate sorbent prepared by UCI. Preparation methods for UCI's zinc titanate sorbents have been described before (Ayala, 1993).T-2535M2 zinc titanate is the GE designation for second batch of formulation T-2535M having approximately $2.5 \% \mathrm{MoO}_{3}$ as pore modifier and 3\% bentonite binder. It was produced in 1993 as a large batch $(6,000 \mathrm{lb})$ for use in the GE moving-bed pilot plant in Schenectady, New York.

Bench-scale reactor tests on T-2535M zinc titanate have been re-initiated to determine its

Table 13.- Physical Properties of T-2535M2 Zinc Titanate Sorbent

\begin{tabular}{lc}
\hline & T-2535M2 \\
\hline Pellet Length, mm & 6.1 \\
Pellet Diameter, mm & 4.9 \\
Pellet Mass, mg & 214 \\
Crush Strength, lb/pellet & 17.1 \\
ASTM Attrition Resistance, \% & 98.5 \\
Bulk Density, lb/ft ${ }^{3}$ & $\sim 100$ \\
\hline
\end{tabular}

performance under pressurized regeneration in the laboratory. Figure 20 shows the breakthrough curve for T-2535M as a function of dimensionless time, or average bed sulfur loading. The outlet $\mathrm{H}_{2} \mathrm{~S}$ prior to breakthrough was measured at less than $10 \mathrm{ppmv}$. For the size of bed used $(800 \mathrm{ml})$, the dimensionless time at breakthrough is about 0.25 of the theoretical, or $25 \%$ average sulfur loading on the bed, which is the design target (i.e., $6 \mathrm{lb}$ sulfur $/ \mathrm{ft}^{3}$ of bed) for pilot plant and large scale operation.

TGA reactivity tests at pressure on zinc titanate were conducted at RTI. Figure 19 shows the pellet performance as a function of pressure at constant $1.4 \% \mathrm{H}_{2} \mathrm{~S}$ in the feed gas. Note that this $\mathrm{H}_{2} \mathrm{~S}$ concentration is less than the concentration used in standard screening at $\mathrm{GE}$ under atmospheric conditions. If the curves are adjusted to the same starting point in the vertical axis, there is no significant difference in performance between $1 \mathrm{~atm}$ and $20 \mathrm{~atm}$; furthermore, performance for all three pressures falls within the variation in reactivity from pellet to pellet. Hence, no significant trends from pressure effects are seen in this sorbent. This small pressure dependence is typical of gas bulk diffusion systems. 


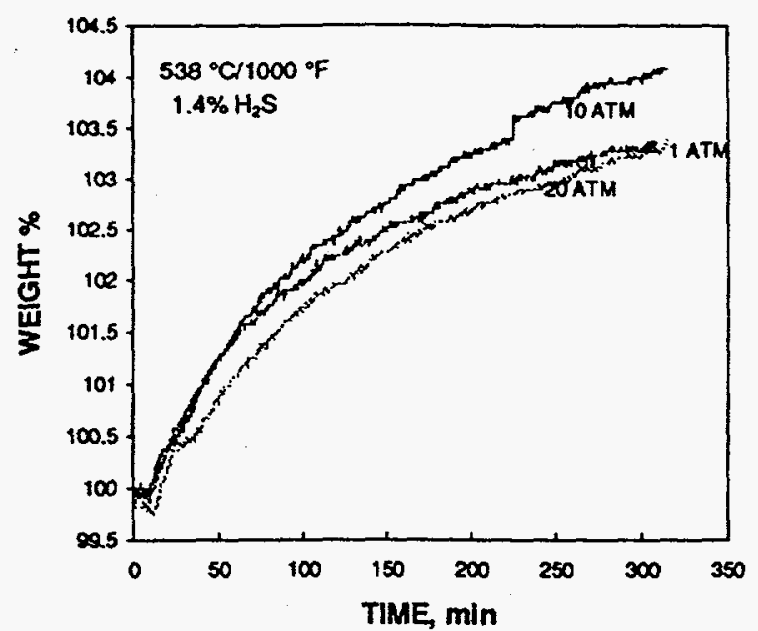

Figure 19.- TGA reactivity of T-2535M2 zinc titanate as a function of sulfidation pressure

For regeneration, two additional TGA reactivity tests were performed. One in which sulfate was allowed to form during regeneration at $5 \mathrm{~atm}$ pressure, and the other in which sulfate was inhibited from forming, also at pressure. In Figure 21 (left), fresh pellets were sulfided during the first 300 minutes according to the procedure shown in Figure 19. Then, by switching

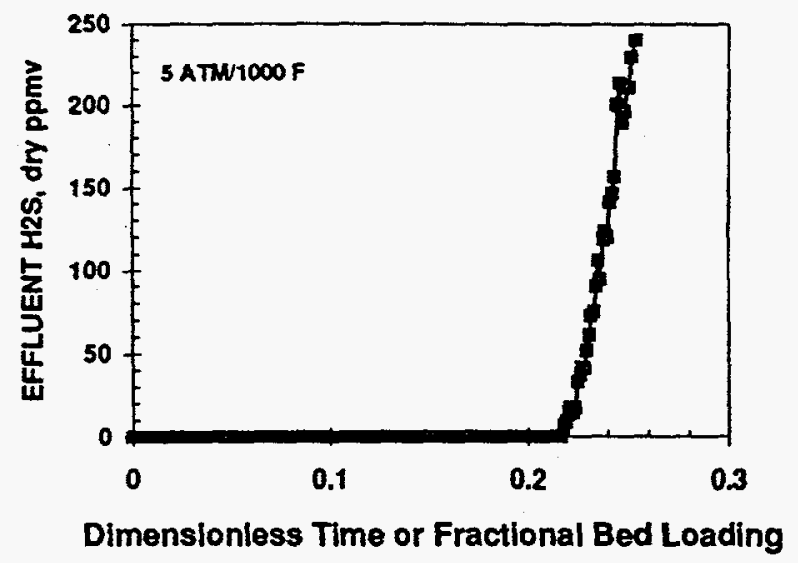

Figure 20.- Bench reactor testing of T-2535M zinc titanate

between regeneration condition $A\left(10 \% \mathrm{SO}_{2}, 2 \% \mathrm{O}_{2}, 88 \% \mathrm{~N}_{2}\right.$ at $\left.650^{\circ} \mathrm{C}\right)$ and regeneration condition $B\left(100 \% \mathrm{~N}_{2}\right.$ at $\left.730^{\circ} \mathrm{C}\right)$, zinc sulfate was allowed to form and decompose, as given by the weight gain/loss during transition from $A$ to $B$ to $A$ condition. In Figure 21 (right), the same process was performed, except that condition $A$ did not contain any $\mathrm{O}_{2}$. The result is a 
lack of sulfate formation. This experiment demonstrates that the conditions that control the level of sulfate formation and decomposition during regeneration can be adjusted to prevent pellet decrepitation.
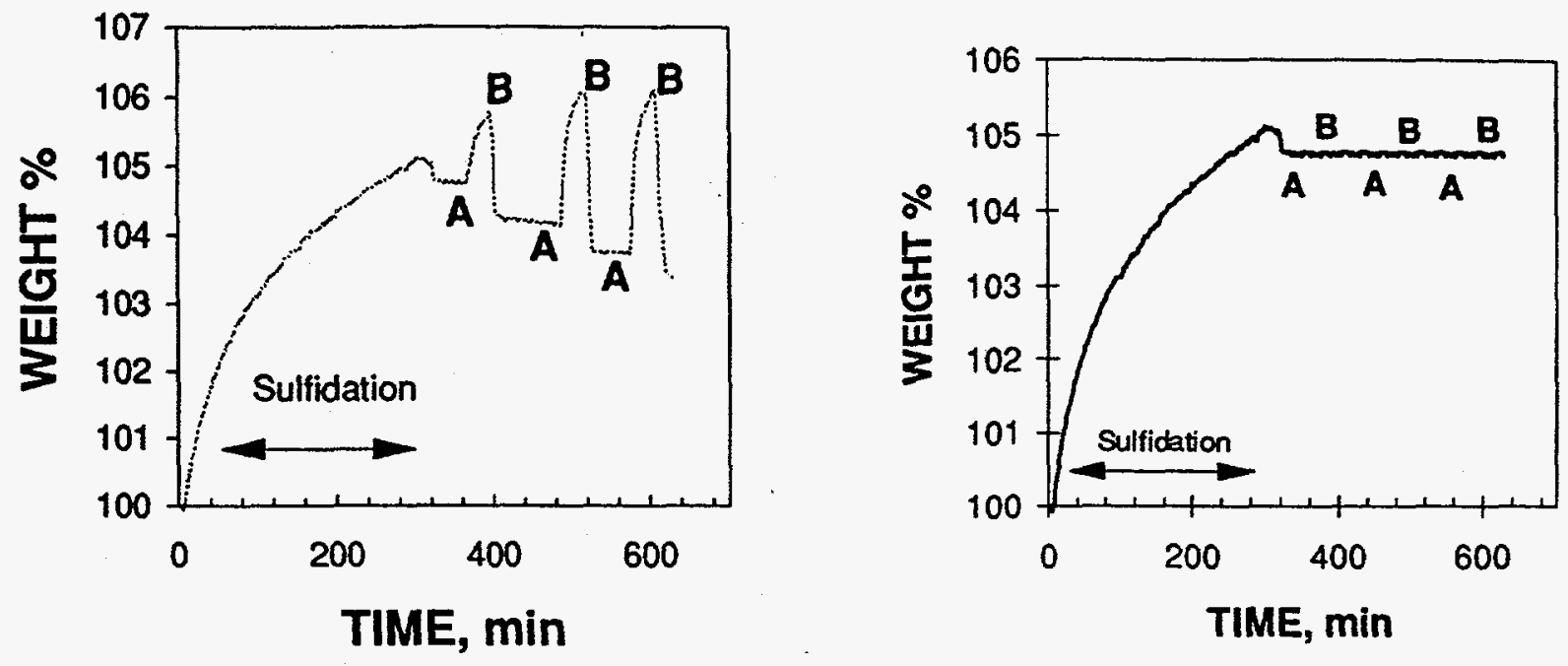

Figure 21.- TGA regeneration of T-2535M2 in the presence (left) or absence (right)of $\mathrm{O}_{2}$ 


\subsubsection{Additional Bench Reactor Tests with Z-Sorb III $^{\mathrm{TM}}$}

These section summarizes the Z-Sorb ${ }^{\mathrm{TM}}$ III test results in the GE-CRD bench reactor. Due to the proprietary nature of the sorbent, only non-proprietary information is presented here as reviewed and approved for publication by the Phillips Petroleum Co.

After the bench-scale reactor was upgraded to conduct tests of sorbents at pressure (10 atm), a 50-cycle bench test was planned using Z-Sorb ${ }^{\mathrm{TM}}$ III sorbent given that it had been shown to be more attrition resistant during side-by-side $(1 \mathrm{~atm})$ tests against zinc titanate sorbents (Ayala et al., 1994). Preparation methods for Z-Sorb ${ }^{\mathrm{TM}}$ sorbent formulations are considered proprietary to PPC, and only analyses that describe performance in hot gas desulfurization will be presented here.

Table 14 shows the properties of the Z-Sorb ${ }^{\mathrm{TM}} \mathrm{III}$ sorbent formulation used in this study. These properties correspond to the GE designation "Z-Sorb E", which distinguishes it among various Z-Sor ${ }^{\mathrm{TM}}$ III sorbent formulations provided in previous years that differed primarily in pellet size and reactivity (see, for instance, Ayala et al., 1994).

Table 14.- Physical Properties of Z-Sorb ${ }^{\mathrm{TM}}$ III Sorbent

\begin{tabular}{lc}
\hline & Z-SORB E \\
\hline Pellet Length, mm & 6.4 \\
Pellet Diam., mm & 4.3 \\
Pellet Mass, mg & 114 \\
Crush Strength, lb/pellet & 10.2 \\
(ASTM) Attrition Loss*, \% & 1.6 \\
Bulk Density, lb/ft ${ }^{3}$ & $\sim 60$ \\
\hline * Attrition losses of the fresh sorbent at the GE-CRD Pilot Plant are typically a factor \\
of 10 lower.
\end{tabular}

Samples of Z-Sorb ${ }^{\mathrm{TM}} \mathrm{III}$ sorbent, prepared as 4-mm ellipsoidal pellets by PPC, were used for the bench tests using wet regeneration $\left(2 \% \mathrm{H}_{2} \mathrm{O}\right)$ and dry regeneration procedures. Wet regeneration tests were terminated early (after 12 cycles) due to loss of sorbent capacity that was assumed to be a combination of steam regeneration and sulfate formation effects arising from use of $20 \%$ oxygen in the final step of the second regeneration. This regeneration step was abandoned thereafter; hence the data did not allow proper analysis of each process parameter separately. Only results corresponding to the dry regeneration tests will be presented here.

During dry regeneration multicycle tests, absorption was conducted in an $800 \mathrm{ml}$ sorbent bed at $5 \mathrm{~atm}$ and $538^{\circ} \mathrm{C}\left(1000^{\circ} \mathrm{F}\right)$, with a simplified gas composition similar to that of an 
(Dry Regeneration)

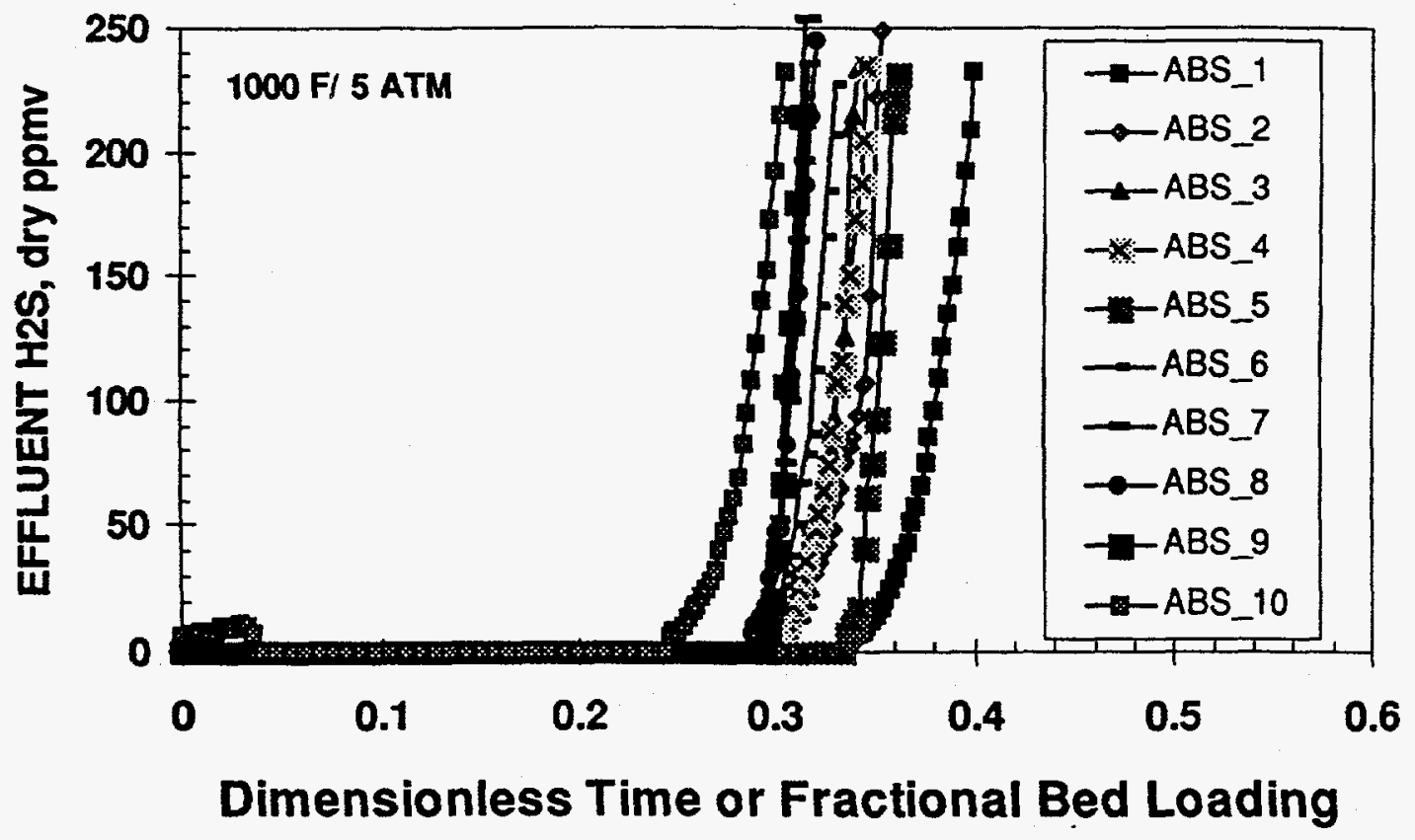

Figure 22 .- Absorption Breakthrough Curves for Z-Sorb ${ }^{\mathrm{TM}}$ III Sorbent

oxygen-blown gasifier with high $\mathrm{H}_{2} \mathrm{~S}\left(39 \% \mathrm{CO}, 10 \% \mathrm{CO}_{2}, 30 \% \mathrm{H}_{2}, 20 \% \mathrm{H}_{2} \mathrm{O}, 1 \% \mathrm{H}_{2} \mathrm{~S}\right)$. Space velocity was $1000 \mathrm{scc} / \mathrm{cc} \bullet \mathrm{hr}\left(25^{\circ} \mathrm{C}, 1 \mathrm{~atm}\right)$. Regeneration was conducted also at 5 atm, $538^{\circ} \mathrm{C}\left(1000^{\circ} \mathrm{F}\right)$, maintaining the peak bed temperature below $732^{\circ} \mathrm{C}\left(1350^{\circ} \mathrm{F}\right)$; gas composition was $0-4 \% \quad \mathrm{O}_{2}$ in nitrogen. A final step in regeneration included depressurization of the reactor to $1 \mathrm{~atm}$ under nitrogen at $732^{\circ} \mathrm{C}\left(1350^{\circ} \mathrm{F}\right)$ to decompose zinc sulfates formed during regeneration. $\mathrm{No} \mathrm{SO}_{2}$ was added to the regeneration gas (which would have simulated recycled $\mathrm{SO}_{2}$ in pilot plant operation). The direction of flow of gases was the same in both absorption and regeneration.

Figure 22 shows the results of ten cycles of bench testing of Z-Sorb ${ }^{\mathrm{TM}} \mathrm{III}$ sorbent at the GE$\mathrm{CRD}$ reactor unit using a dry regeneration scheme. The first cycle shows a higher sulfur bed capacity than cycles two to seven. This is a result of the sulfidation of nickel during the first cycle that increases the overall sulfur capacity of the bed. After nickel is sulfided, the bed desulfurization capacity is a result of zinc-only desulfurization. Cycle ten shows a loss in bed capacity with respect to cycles two to five, which would be a concern if a stable operation is to be maintained.

Small samples were taken from the reactor bed after 5 cycles to conduct single-pellet TGA chemical reactivity tests. Figure 23 shows the thermogravimetric analyzer (TGA) chemical reactivity of pellets after the fifth and tenth cycles. The weight gained by the pellet is proportional to the sulfur loading in the pellet. The first forty minutes are exposure to pure nitrogen ( 30 minutes) and clean (i.e., no $\mathrm{H}_{2} \mathrm{~S}$ ) simulated coal gas ( 10 minutes). $\mathrm{H}_{2} \mathrm{~S}$ is 
introduced 40 minutes after start. Pellet weights are stable under $\mathrm{N}_{2}$, and a small weight loss is observed when clean simulated coal gas is introduced, suggesting decomposition of small amounts of sulfate. Fresh pellets did not exhibit this weight loss upon exposure to coal gas. These reactivity tests were performed under a standard GE procedure using a simulated coal gas having $3 \% \mathrm{H}_{2} \mathrm{~S}$ at $538^{\circ} \mathrm{C}\left(1000^{\circ} \mathrm{F}\right)$. The high $\mathrm{H}_{2} \mathrm{~S}$ concentration is used to expedite the testing, such that pellet saturation with sulfur occurs in two to three hours. Full sulfidation of $\mathrm{Z}_{\text {-Sorb }}{ }^{\mathrm{TM}} \mathrm{III}$ sorbent pellets corresponds to a weight gain of approximately $10 \%$. For the samples after the fifth cycle, the results suggest that the samples that were sulfided heavily at each cycle (i.e., the gas inlet location) did not suffer loss in reactivity (given by the slope of the curve) and capacity (given by the final weight of the pellet), while those at the gas outlet location, where the pellets are partially sulfided, did. These results follow similar trends observed in pilot plant tests. For the gas outlet samples, reactivity is higher very early in the test (during the external sulfidation of the pellets), but decreases with time; capacity after two hours of sulfidation was about 60 to $65 \%$ of that of fresh pellets.

Design conditions for sorbent performance at Tampa Electric Co.'s moving-bed system require a sulfur loading of $6 \mathrm{lb} / \mathrm{ft}^{3}$ on any sorbent. For Z-Sorb ${ }^{\mathrm{TM}} \mathrm{III}$ sorbent, this requirement translates into $50 \%$ of theoretical sulfur loading or $5 \%$ weight gain under TGA testing.

Another operating scheme tested in the laboratory was the feasibility of decomposing sulfates during regeneration. Figure 24 shows the last step in the regeneration sequence where the sorbent is at $1350^{\circ} \mathrm{F}$ under nitrogen at $5 \mathrm{~atm}$. Some $\mathrm{SO}_{2}$ is evolved as a result of sulfate decomposition. By depressurizing the reactor to $1 \mathrm{~atm}$, still under $\mathrm{N}_{2}$, the sulfate decomposition is further accelerated, as given by the sudden burst of additional $\mathrm{SO}_{2}$ evolved. This step is beneficial because less residual sulfate in the sorbent is carried to the absorption step, where it converts to $\mathrm{SO}_{2}$ and $\mathrm{H}_{2} \mathrm{~S}$, thus resulting in lower overall desulfurization efficiency.
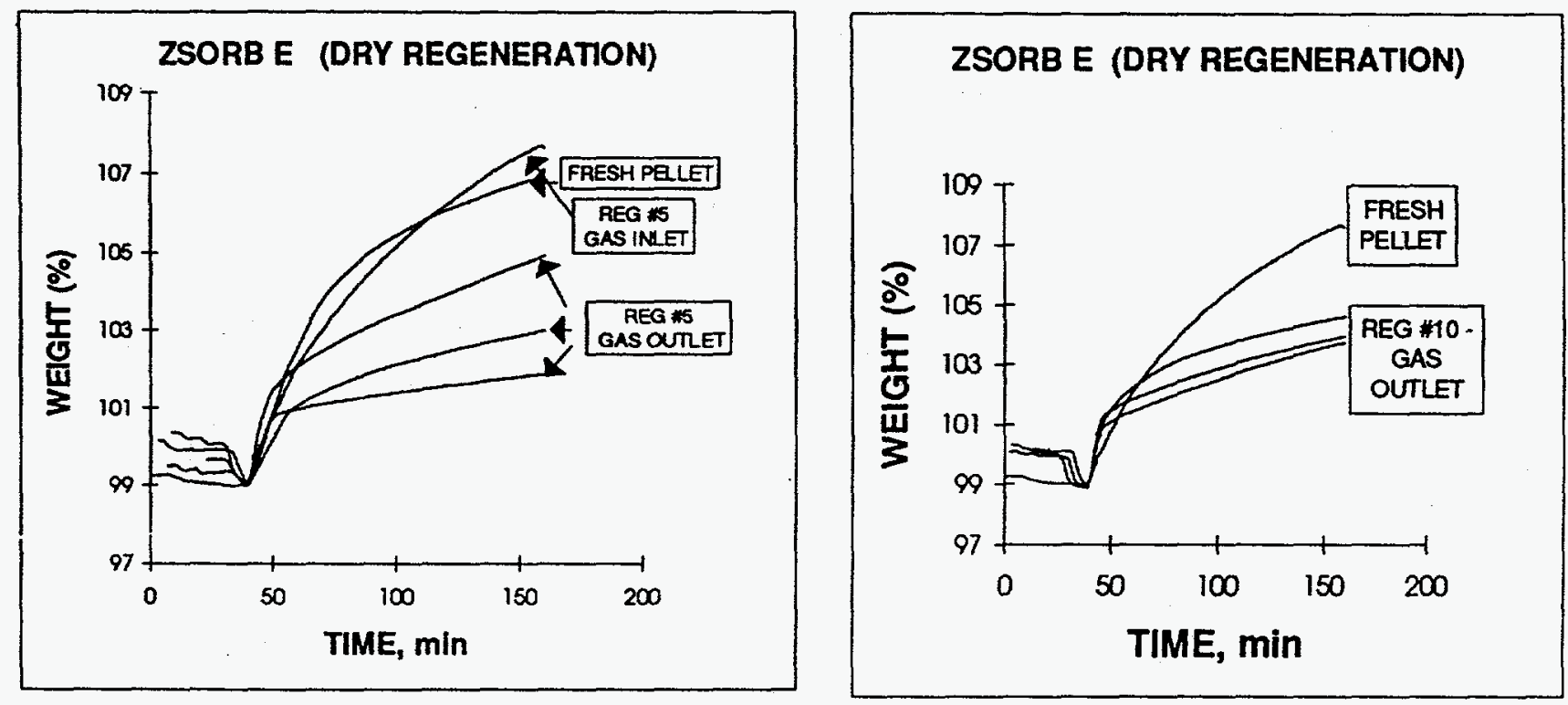

Figure 23.- TGA chemical reactivity of Z-Sorb ${ }^{\text {TM }}$ III sorbent samples after 5 and 10 cycles 


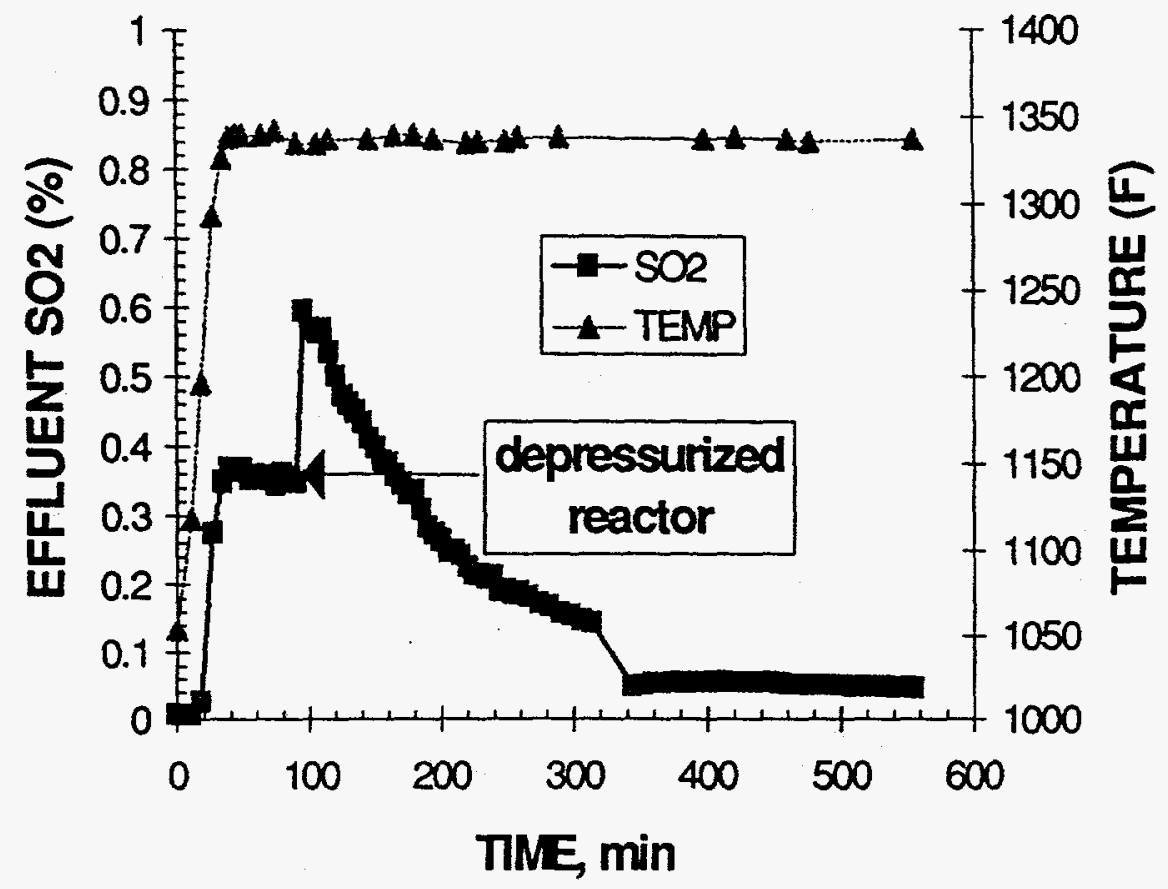

Figure 24.- $\mathrm{SO}_{2}$ evolution during regeneration at $5 \mathrm{~atm}$ and $1 \mathrm{~atm}$

The effect of sulfate decomposition and subsequent $\mathrm{SO}_{2}$ evolution can be explained from thermodynamic principles. Figure 25 shows the phase stability diagram for the ternary system $\mathrm{Zn}-\mathrm{S}-\mathrm{O}$ at two temperatures $550^{\circ} \mathrm{C}\left(1022^{\circ} \mathrm{F}\right)$ and $732^{\circ} \mathrm{C}\left(1350^{\circ} \mathrm{F}\right)$. A typical regeneration gas composition at $550^{\circ} \mathrm{C}$ and 1-7 atm of pressure in the presence of $\mathrm{O}_{2}$ and $\mathrm{SO}_{2}$ is shown by the point marked $\mathrm{X}$. This point falls in the region of stable formation of $\mathrm{ZnO}_{2} 2 \mathrm{ZnSO}_{4}$ (zinc oxysulfate). As the temperature is increased to $732^{\circ} \mathrm{C}$, the pressure reduced to $1 \mathrm{~atm}$, and the gas composition changed to $\mathrm{N}_{2}$ only, the system moves to point $\mathrm{O}$, where the zinc oxysulfate is unstable and decomposes into zinc oxide. This operation mode is achieved during lockhopper operation in the moving-bed process, thus preventing carryover of sulfate into the absorption step. 


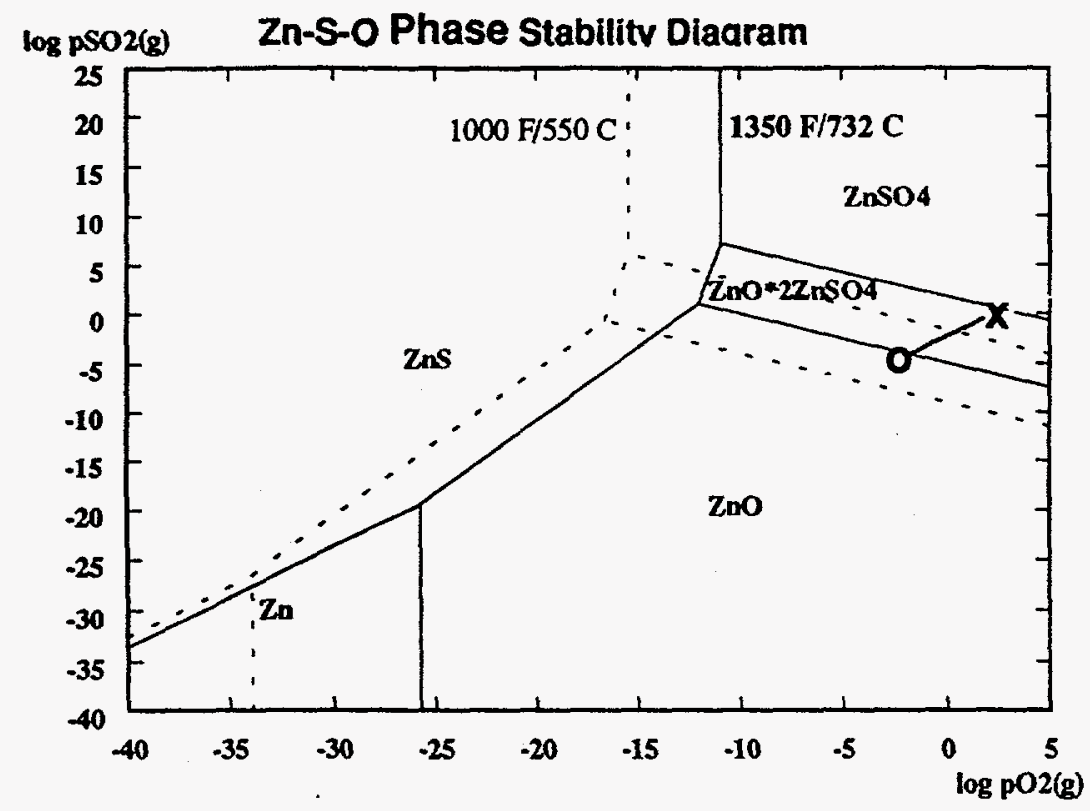

Figure 25.- Phase stability diagram for the system $\mathrm{Zn}-\mathrm{S}-\mathrm{O}$ at $550^{\circ} \mathrm{C}$ and $732{ }^{\circ} \mathrm{C}$ 


\section{SECTION 4 CONCLUSIONS AND RECOMMENDATIONS}

\subsection{CONCLUSIONS}

The following conclusions can be drawn from the characterization and screening of fresh formulations:

- Addition of $10 \%$ calcium sulfate to the 2.0 zinc titanate formulations increases the crush strength of the fresh sorbents by about $40-50 \%$ to $30 \mathrm{lb} /$ pellet. For the case of $1.5 \mathrm{Zn}: \mathrm{Ti}$ zinc titanates, no difference was observed.

- There is no trend seen in the level of attrition resistance of fresh formulations with respect to the zinc-to-titanium ratio or the addition of $10 \%$ calcium sulfate

- The rate of sulfur capture, or reactivity, of fresh formulations does not correlate with chemical composition, but, rather, with the specific pore volume (SPV) of the fresh sorbent. No signs of pore plugging are observed for the formulations having higher SPV's while the lower cases appear to lack the porosity necessary for higher total sulfur loading.

- Higher calcination temperatures resulted in lower SPV's for most of the formulations tested. The lower SPV's resulted in lower reactivity, in general.

The following conclusions can be drawn from standard 10-cycle bench reactor tests:

- During standard 10-cycles tests (where no $\mathrm{SO}_{2}$ was present in the inlet regeneration gas), formulations that had the same chemical composition but different rounding method and equipment (laboratory versus commercial-scale equipment) had differences in the performance over 10 cycles. Laboratory formulations (prepared under Option 2 of the program) exhibited less attrition and less variability from pellet to pellet.

- The level of sulfidation influences the measured durability of the formulations. The $\mathrm{H}_{2} \mathrm{~S}$ breakthrough time during bench absorption tests is seen to be related to the calcination temperature of the sorbent and the resulting pellet porosity. Higher calcination times had earlier breakthrough times and lower pellet porosities (i.e., specific pore volumes, SPV). Overall, it appears that the porosity is the major driver for the differences in reactivity in relatively fresh sorbents, rather than the addition of sulfate. 
- Calcium sulfate-containing sorbents appear to evolve higher levels of $\mathrm{SO}_{2}$ and to take longer for the $\mathrm{SO}_{2}$ to decrease to low base levels during reductive regeneration. Since calcium sulfate-containing sorbents had initially smaller median pore diameters (MPD), the effect of pore size on $\mathrm{SO}_{2}$ evolution cannot be separated from the presence of calcium sulfate at this point.

- Formulations with a 2:1 $\mathrm{Zn}$ :Ti molar ratio and $10 \%$ calcium sulfate (i.e., formulations L4104-B1 and L4104-B2) had the lowest amounts of aggregates (less than $0.1 \%$ and virtually no fines (less than $0.01 \%$ after 10 standard cycles, suggesting that this combination of $\mathrm{Zn}: \mathrm{Ti}$, molybdenum, and calcium sulfate produced formulations that had higher durability than the other chemical compositions tested. Formulation LA106-B1 had also $10 \%$ calcium sulfate but only a $1.5 \mathrm{Zn}: T i$ ratio and showed one order of magnitude $(\sim 1 \%)$ more aggregates than the L4104 series. Formulation L4103-B2 did not have any calcium sulfate and exhibited higher percentages of aggregates and fines of all five formulation tested. Optimization of mechanical durability with calcium sulfate is still necessary.

- The beneficial effect of adding calcium sulfate for improved mechanical durability has to be weighed against the lower reactivity (as measured by breakthrough curves) and $\mathrm{SO}_{2}$ evolution during reductive regeneration. Sulfate decomposition appears to be slower in calcium sulfate-containing sorbents.

- Comparison of the pore size distributions for fresh and 10th-regeneration sorbents shows that, probably as a result of the production of aggregates (i.e., broken and cracked pellets), the pore size distribution for the regenerated sorbent was higher in terms of both higher median pore diameter (MPD) and higher SPV. Changes in MPD and SPV are good indicators of the degree of pellet deterioration or sulfate accumulation.

The following conclusions can be drawn from accelerated absorption/regeneration bench reactor tests

- During the first five cycles, in the absence of added $\mathrm{SO}_{2}$ to the inlet regeneration gas, there is very littler mechanical degradation on the sorbents, very likely as a result of formation of very small amounts of sulfates.

- During cycles 6 to 8 , (regeneration under $5 \% \mathrm{SO}_{2}$ in the inlet gas, but keeping temperatures below $1300^{\circ} \mathrm{F}$ ), the results on mechanical degradation were very similar to the first cycles, perhaps with some incipient measurable accumulation of zinc sulfate.

- In contrast, when the 8th cycle was followed by a two-hour period of exposure to $20 \% \mathrm{O}_{2}, 5 \% \mathrm{SO}_{2}$ at $1400{ }^{\circ} \mathrm{F}$, the level of spalling, cracking and pellet deterioration 
became significant. The results suggest that the level of spalling was exacerbated by the combination of temperature and air in the regeneration gas, rather than by the presence of $\mathrm{SO}_{2}$ alone.

The following conclusions can be drawn from studies of sulfate formation at pressure:

- When large amounts of sulfate are formed in the internal pores of the pellets, the thermal decomposition of sulfate does not occur readily, either because the sulfate I no longer zinc sulfate alone, or there is a capillary vapor pressure equilibrium in the internal pores that slows down the sulfate decomposition (i.e., equivalent to the Kelvin effect in porous media).

- The improvement in strength by the presence of added calcium sulfate to the sorbents also has the penalty of more difficulty in the decomposition of zinc sulfate. Any selected regeneration scheme has to consider the mechanisms of sulfate formation and decomposition to avoid loss of reactivity or pellet physical degradation.

- Pressurized TGA regeneration demonstrated that conditions that control the level of sulfate formation and decomposition during regeneration can be adjusted to prevent pellet mechanical deterioration. These conditions are primarily temperature and oxygen concentration, rather than the presence of $\mathrm{SO}_{2}$ alone.

- The refurbishment of the bench reactor for pressurized operation allowed the performance of pressurized testing of zinc titanate and Z-Sorb $\mathrm{II}^{\mathrm{TM}}$ sorbent at pressure. However, the reliability of the bellows pump operation was less than desired, forcing operation at times on a single-pass flow of gases rather than the desired operation of a true recycle-loop regeneration mode.

The following conclusions can be drawn from the testing of Z-Sorb $\mathrm{II}^{\mathrm{TM}}$ in the pressurized bench scale reactor:

- Tests performed on Z-Sorb ${ }^{T M}$ III showed that the sorbent is capable of reducing $\mathrm{H}_{2} \mathrm{~S}$ levels below a target of $20 \mathrm{ppm}$ during desulfurization of simulated coal gases. During regeneration, sulfate can be decomposed by adjusting the process conditions that lead to thermodynamic instability and thermal decomposition of zinc sulfates

\subsection{RECOMMENDATIONS}

The presence of calcium sulfate as an additive to zinc titanates certainly looks promising to bring improvements to the mechanical properties of zinc titanate sorbent. The fresh formulations exhibited higher attrition resistance (i.e., lower attrition losses) than the formulations lacking the additive. The development of stronger formulations has certainly 
moved in the right direction of increasing the mechanical durability of zinc titanate sorbents. However, further tests are required to determine the feasibility of its use in view of the differences in the rate of sulfidation, sulfate decomposition, and the amount of $\mathrm{SO}_{2}$ released during reductive regeneration.

In view of the current improvements in the GE pilot-plant development and operation, it is feasible to think that higher sorbent bed reactivity and higher mechanical durability may be achieved by changing the current $5-\mathrm{mm}$ pellet size, as tested in this Option 3 program, to smaller sizes. We consider by no means that we have arrived at the optimum pellet size is as it was tested in this program, nor that commercial sorbent vendors cannot produce stronger pellets at a different pellet size, say $3-4 \mathrm{~mm}$ instead of $5 \mathrm{~mm}$. Further work should be done to test the effect of pelletization size on mechanical durability once a chemical formulation has been chosen.

At this point, we cannot assess the intrinsic rate of sulfate decomposition in comparison with other zinc titanates without calcium sulfate, since formulations with added calcium sulfate also exhibited lower pore sizes that also affect the zinc sulfate decomposition. Different concentrations of zinc sulfate should be explored for optimum properties.

Further work is also needed to understand the stability of calcium sulfate in reducing and oxidizing atmospheres. Within the scope of the current program, it was not feasible to determine whether some of the calcium sulfate underwent transition to calcium sulfide during exposure to simulated coal gases and back to calcium sulfate during exposure to oxidizing regeneration gases. Oxygen consumption or release during those steps will certainly affect the controllability of the process in large scale where the oxygen fed to the system will have to be metered more closely to avoid incomplete regeneration or excessive sulfate formation from excess oxygen.

With respect to the regeneration characteristics of zinc titanate sorbents, it is our view that further work is needed to develop a true understanding of the allowable conditions for regeneration in terms of maximum permissible temperatures at various $\mathrm{SO}_{2}$ and $\mathrm{O}_{2}$ concentrations to minimize zinc sulfate formation. Furthermore, the presence of steam in the regeneration gases may further exacerbate the formation of zinc sulfate when calcium sulfate is present, thus increasing pellet deterioration. A better understanding of the above concerns will allow to develop a process more suitable to the operating regime of zinc titanate sorbents containing calcium sulfate additives. 


\section{REFERENCES}

Anderson, G.L., and F.O. Berry. 1987. Development of a Hot Gas Cleanup System. In Proceedings of the Seventh Annual Gasification and Gas Stream Cleanup Systems Contractors Review Meeting, Vol 2. p. 642. DOE/METC-87/6079.

NTIS/DE87006496. Springfield, Va.: National Technical Information Service.

Ayala, R.E. 1991. Enhanced Durability of High Temperature Desulfurization Sorbents for Moving-Bed Applications. Base Program: Development and Testing of Zinc Ferrite Sorbents. Topical Report. DOE/MC/25003-3045. NTIS/DE92001121. Springfield, Va.: National technical Information Service.

Ayala, R.E. 1993. Enhanced Durability of High-Temperature Desulfurization Sorbents for Moving-Bed Applications. Option 2 Program: Development and Testing of Zinc Titanate Sorbents. Contract DE-AC21-88MC25003. Topical Report. Springfield, Va.: National technical Information Service.

Ayala, T. Chuck, E. Gal, and R.P. Gupta. 1994. Development of High Temperature Desulfurization Sorbents for Moving-Bed Systems. In Proceedings of the Coal-Fired Power Systems 94 -Advances in IGCC and PFBC Review Meeting, p. 637. DOE/METC-94/1008. NTIS/DE94012252. Springfield, Va.: National Technical Information Service.

Ayala, R.E. T.L. Chuck, and R.P. Gupta. 1995a. . Moving-Bed Sorbents. In Proceedings of the Advanced Coal-Fired Power Systems '95 Review Meeting, Vol II , pp 591600. DOE/METC-95/1018 Vol 2. NTIS/DE95009733. Springfield, Va.: National Technical Information Service.

Ayala, R.E., V.S. Venkataramani, J. Abbasian, and A.H. Hill. 1995b. Advanced LowTemperature Sorbents. In Proceedings of the Advanced Coal-Fired Power Systems '95 Review Meeting, Vol I, pp 407-416. DOE/METC-95/1018 Vol. 1. NTIS/DE95009732. Springfield, Va.: National Technical Information Service.

Bevan, S., D.J. Najewicz, E. Gal, A.H. Furman, R. Ayala, and A. Feitelberg. 1994. Integrated Operation of a Pressurized Gasifier, Hot Gas Desulfurization System and Turbine Simulator. In Proceedings of the Coal-Fired Power Systems 94 -Advances in IGCC and PFBC Review Meeting, p. 222. DOE/METC-94/1008. NTIS/DE94012252. Springfield, Va.: National Technical Information Service. 
Bevan, D.J. Najewicz, R.E. Ayala, A. Feitelberg, and A. Furman. Integrated Operation of a Pressurized Gasifier, Hot Gas Desulfurization System and Turbine Simulator. In Proceedings of the Advanced Coal-Fired Power Systems '95 Review Meeting, Vol I , pp. 187-201. DOE/METC-95/1018. NTIS/DE95009732. Springfield, Va.: National Technical Information Service.

Bossart, S.J., D.C. Cicero, C.M. Zeh, and R.C. Bedick. 1990. Gas Stream Cleanup. Technology Status Report. DOE/METC-91/0273. NTIS/DE91002037. Springfield, Va.: National Technical Information Service.

Buchanan, T.L., H.T. Chen, M.G. Klett, M.D. Rutkowski, and R. Zaharchuk. 1994. Optimization of Gas Stream Cleanup in Three IGCC Systems. Final Report to the U.S. Department of Energy/Morgantown Energy Technology Center by Gilbert/Commonwealth, Inc. Contract DE-AC01-88FE61660. March 1994.

Cook, C.S., R. Hamilton, E. Gal, A.H. Furman, and R. Ayala. 1991. Integrated Operation of a Pressurized Fixed-Bed Gasifier and Hot Gas Desulfurization System. In Proceedings of the Eleventh Annual Gasification and Gas Stream Cleanup Systems Contractors Review Meeting, ed. V.K. Venkataraman, L.K. Rath, J.W. Martin, and R.C. Bedick. Vol 1.p. 45. DOE/METC-91/6123. NTIS/DE92001102. Springfield, Va.: National Technical Information Service.

Corman, J.C. 1986. System Analysis of Simplified IGCC Plants, Topical Report. U.S. Dept of Energy, DOE/ET/14928-2233.

Droog, H.A., A. Delwel, and R. Assink. 1993. Comparison of High-Temperature Gas Treatment Options with Low-Temperature Gas Treatment in IGCC's following Entrained Flow Gasification. In Proceedings 12th EPRI Conference on Gasification Power Plants.San Francisco, CA, Oct 27-29, 1993

Everitt, C.E., and S.J. Monaco. 1994. Data Summary Report for M.W. Kellogg Z-Sorb Sorbent Tests (Z-Sorb-01, Z-Sorb-02, Z-Sorb-03). Final Topical Report. Contract DE-AC21-90MC26328. Report No. 33FF-R93-003.

Flytzani-Stephanopoulos, G.R. Gavalas, and S.S. Tamhankar. 1984. Novel Sorbents for High Temperature Regenerative $\mathrm{H}_{2} \mathrm{~S}$ Removal. Topical Report prepared by Jet Propulsion Laboratory, California Institute of Technology, Pasadena, CA, to U.S Dept. of Energy. DOE/MC-87/20407-2. JPL F-1750. July 1984.

Flytzani-Stephanopoulos, M, K. Johtimurugesan, S. Lew, G.R. Gavalas, and V. Patrick. 1987. Detailed Studies of Novel Regenerable Sorbents for High-Temperature CoalGas Desulfurization. In Proceedings of the Seventh Annual Gasification and Gas Stream Cleanup Systems Contractor's Review Meeting. ed. M. Ghate, K. Markel, L. 
Jarr, S. Bossart, Vol 1, p. 726. DOE/METC-87/6079. NTIS/DE87006496.

Springfield, Va.: National Technical Information Service.

Gangwal, S.K., and Harkins, S.M. 1987. Bench-Scale Testing of Novel High-Temperature Desulfurization Sorbents. In Proceedings of the Seventh Annual Gasification and Gas Stream Cleanup Systems Contractor's Review Meeting. ed. M. Ghate, K. Markel, L. Jarr, S. Bossart, Vol 2, p. 749. DOE/METC-87/6079. NTIS/DE87006496. Springfield, Va.: National Technical Information Service.

Gangwal, S.K., and Harkins, S.M. 1988. Bench-Scale Testing of Novel High-Temperature Desulfurization Sorbents. In Proceedings of the Eighth Annual Gasification and Gas Stream Cleanup Systems Contractor's Review Meeting. ed. V.P. Kothari, J.R. Longanbach, Vol 1, pp 103. DOE/METC-88/6092. NTIS/DE88010253. Springfield, Va: National Technical Information Service.

Gangwal, S.K., and R.P. Gupta, 1993. Enhanced Durability of Desulfurization Sorbents for Fluidized-Bed Applications. In Proceedings of the Coal-Fired Power Systems 93 - Advances in IGCC and PFBC Review Meeting, p. 146-157. DOE/METC-93/6131. NTIS/DE93000289. Springfield, Va.: National Technical Information Service.

Gangwal, S.K., R.P. Gupta, G.P. Khare, G.A. Delzer, and D.H. Kubicek. 1994. Fluidization Studies using Phillips Z-SORB Sorbent. In Proceedings of the CoalFired Power Systems 94 -Advances in IGCC and PFBC Review Meeting, p. 654. DOE/METC-94/1008. NTIS/DE94012252. Springfield, Va.: National Technical Information Service.

Gangwal, S.K., R.P. Gupta, W.M. Campbell, G.B. Henningsen . 1995. Zinc Titanate tests in Transport Reactor. In Proceedings of the Advanced Coal-Fired Power Systems '95 Review Meeting, Vol I , p 215. DOE/METC-95/1018. NTIS/DE95009732. Springfield, Va.: National Technical Information Service.

Gasper-Galvin, L.D., J.H. Swisher, and K Hammerbeck. 1994. Characterization and Fixed-Bed Testing of a Nickel-Based Hot Gas Desulfurization Sorbent. In Proceedings of the Coal-Fired Power Systems 94 -Advances in IGCC and PFBC Review Meeting, p. 308. DOE/METC-94/1008. NTIS/DE94012252. Springfield, Va.: National Technical Information Service.

Gasper-Galvin, L.D., and A.T. Atimtay. 1989. Novel Supported Hot Gas Desulfurization Sorbents: Zinc Oxide on Zeolite. In Proceedings of the Ninth Annual Gasification and Gas Stream Cleanup Systems Contractor's Review Meeting. ed. R.A. Johnson, and T.P. Dorchak. Vol 2, pp 563. DOE/METC-89/6107. NTIS/DE89011707. Springfield, Va.: National Technical Information Service. 
Gasper-Galvin, L.D., and A.T. Atimtay. 1991. Zeolite Supported Copper Sorbents for Hot Gas Desulfurization. Paper 82f presented at the 1991 AIChE Summer National Meeting, Pittsburgh, PA, August. 18-21, 1991.

Grindley, T. 1991. Lab-Scale Sorbent Development. In Proceedings of the Eleventh Annual Gasification and Gas Stream Cleanup Systems Contractor's Review Meeting. ed. V.K. Venkataraman, L.K. Rath, J.W. Martin, and R.C. Bedick. Vol 2, p. 516. DOE/METC-91/6123. NTIS/DE92001102. Springfield, Va.: National Technical Information Service.

Hepworth, M.T., and R. Ben-Slimane. 1994. Hot Gas Desulfurization with ManganeseBased Sorbents. In Proceedings of the Coal-Fired Power Systems 94 -Advances in IGCC and PFBC Review Meeting, p. 337. DOE/METC-94/1008.

NTIS/DE94012252. Springfield, Va.: National Technical Information Service.

Jalan, V., M. Desai, and F. Brown. 1989. Copper-Based Sorbents for Hot Gas Cleanup. In Proceedings of the Ninth Annual Gasification and Gas Stream Cleanup Systems Contractor's Review Meeting. ed. R.A. Johnson, and T.P. Dorchak. Vol 2, pp 541. DOE/METC-89/6107. NTIS/DE89011707. Springfield, Va.: National Technical Information Service.

Karpuk, M.E, R.J. Copeland, D. Feinber, D. Wickham, B. Windecker, and J. Yu. 1994. High Temperature Hydrogen Sulfide Removal with Stannic Oxide. In Proceedings of the Coal-Fired Power Systems 94 -Advances in IGCC and PFBC Review Meeting, p. 444. DOE/METC-94/1008. NTIS/DE94012252. Springfield, Va.: National Technical Information Service.

Lew S., M, K. Johtimurugesan, and Flytzani-Stephanopoulos. 1989. High-Temperature H2S Removal from Fuel Gases by Regenerable Zinc Oxide-Titanium Dioxide Sorbents. Ind. Eng. Chem. Res. 28, 535 (1989).

McDaniel, H.M, D.J. Mollot, and V.K. Venkataraman. 1995. editors. In Proceedings of the Advanced Coal-Fired Power Systems '95 Review Meeting, Vol I and II. DOE/METC-95/1018. NTIS/DE95009732. Springfield, Va.: National Technical Information Service.

Perry, H.R., and C.H. Chilton. 1973. Chemical Engineer's Handbook. 5th. Edition. McGraw-Hill, New York.

Rath, L.K., G.T. Lee, and P.H. Le. 1994. IGCC System Studies. In Proceedings of the Coal-Fired Power Systems $94-A d v a n c e s$ in IGCC and PFBC Review Meeting, p. 66. DOE/METC-94/1008. NTIS/DE94012252. Springfield, Va.: National Technical Information Service. 
Thambimuthu, K.V. 1993. Gas Cleanung for Advanced Coal-Based Power Generation. IEACR/53, March 1993. IEA Research, London.

Siriwardane, R.V., U.Grimm, J. Poston, and S. Monaco. 1994. Desulfurization Sorbent Development at the Morgantown Energy Technology Center. In Proceedings of the Coal-Fired Power Systems 94 -Advances in IGCC and PFBC Review Meeting, p. 662. DOE/METC-94/1008. NTIS/DE94012252. Springfield, Va.: National Technical Information Service.

Westmoreland, P.W., and D. P. Harrison. 1976. Evaluation of Candidate Solids for HighTemperature Desulfurization of Low-Btu Gases. Env. Sci. Tech., 10, 659 (1976).

Wheast, R.C., and M.J. Astle, 1978. CRD Handbook of Chemistry and Physics. CRD Press, Inc. West Palm Beach, Florida, 33409.

Westerterp, K.R., W.P.M van Swaaij, and A.A.C.M. Beenackers. 1984. Chemical Reactor Design and Operation. Wiley, New York.

Woods, M.C., K.E. Leese, S.K. Gangwal, D.P. Harrison, and K. Jothimurugesan. 1989. Reaction Kinetics and Simulation Models for Novel High-Temperature Desulfurization Sorbents. Final report. DOE/METC/24160-2671.

NTIS/DE89000950. Springfield, Va.: National Technical Information Service. 